Portland State University

PDXScholar

\title{
Actor and Partner Effects Among Marital Dyads in Retirement Adjustment and Well-being
}

Julie Guenette Howard

Portland State University

Follow this and additional works at: https://pdxscholar.library.pdx.edu/open_access_etds

Part of the Family, Life Course, and Society Commons, and the Urban Studies and Planning Commons Let us know how access to this document benefits you.

\section{Recommended Citation}

Howard, Julie Guenette, "Actor and Partner Effects Among Marital Dyads in Retirement Adjustment and Well-being" (2005). Dissertations and Theses. Paper 1661.

https://doi.org/10.15760/etd.1660

This Dissertation is brought to you for free and open access. It has been accepted for inclusion in Dissertations and Theses by an authorized administrator of PDXScholar. Please contact us if we can make this document more accessible: pdxscholar@pdx.edu. 


\section{DISSERTATION APPROVAL}

The abstract and dissertation of Julie Guenette Howard for the Doctor of Philosophy in Urban Studies were presented on April 26, 2005, and accepted by the dissertation committee and the doctoral program.

COMMITTEE APPROVALS:

$$
\text { Margaret } 3 \text {. Neal, Chair }
$$

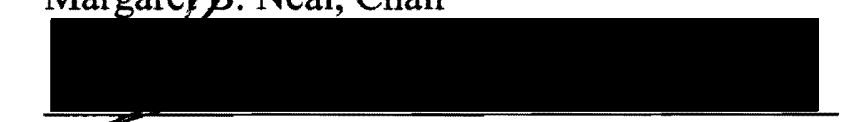

$$
\text { Jason T. Newson }
$$
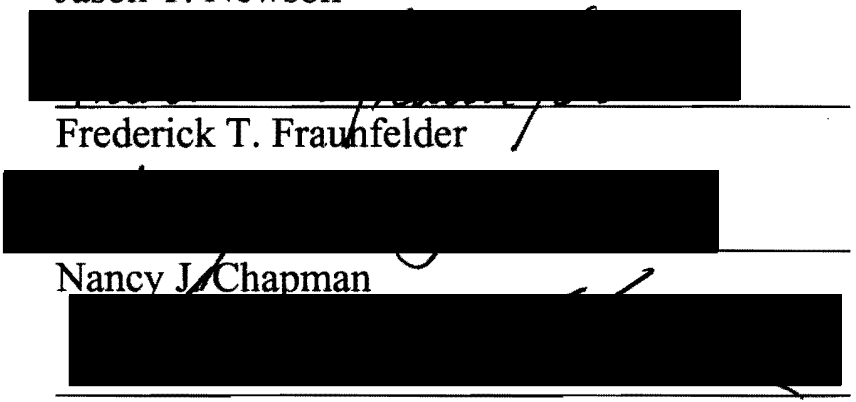

Leslie B. Hammer

Representative of the Office of Graduate Studies

DOCTORAL PROGRAM APPROVAL

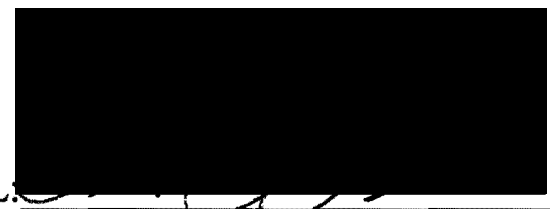

Loren Lutzenhiser

Urban Studies Ph.D. Program 


\begin{abstract}
An abstract for the dissertation of Julie Guenette Howard for the Doctor of Philosophy in Urban Studies presented April 26, 2005.
\end{abstract}

Title: Actor and Partner Effects Among Marital Dyads in Retirement Adjustment and Well-Being

Our understanding of and interest in how retirement impacts the lives of individuals have grown over the past 20 years. Studies to date have ranged from small, convenience samples composed primarily of men to large, national longitudinal samples of men and women from different professional and socioeconomic backgrounds. There is consensus in the literature that older adults generally function better with a partner; however, gaps remain. We know little about the impact of retirement beyond the individual, although research in other areas on couples has produced evidence of crossover and contagion effects relative to depression and other outcomes, including absenteeism, job stress and positive spillover effects. A major objective of this research was to offer a more holistic perspective of the factors which contribute to retirement adjustment among using dyadic data. A cross-sectional research design was used. The final sample included 183 couples. Structural equation modeling identified predictors of retirement adjustment and well-being in couples. Husbands' and wives' retirement adjustment were found to be highly intercorrelated, 
but, differences in predictors were found between husbands and wives and their adjustment to retirement. Men were more adversely affected by a forced retirement, and wives had lower levels of well-being than husbands. A forced retirement was not a predictor of retirement adjustment for wives. The relationship between a wife's forced retirement and a husband's well-being was mediated by husband's retirement adjustment. Wives' and husbands' well-being was predicted by health problems. Other positive predictors of retirement adjustment and well-being for wives included maintenance of living standards, low levels of boredom and high levels of social support and leisure activity. These variables also predicted adjustment for husbands. In addition, three other predictors of husbands' retirement adjustment were found, including: a fully retired work status, higher household income, and retirement plans that remained unaltered. These findings can inform the mental health and counseling practices of professionals serving older adults. It is hoped that this research serves as a basis from which future research may generate ideas and identify other instances of partner and actor effects in retirement adjustment and well-being in older couples. 
ACTOR AND PARTNER EFFECTS AMONG MARITAL DYADS

$\mathbb{I N}$

RETIREMENT ADJUSTMENT AND WELL-BEING

by

JULIE GUENETTE HOWARD

A dissertation submitted in partial fulfillment of the requirements for the degree of

DOCTOR OF PHILOSPOHY

in

URBAN STUDIES

Portland State University

(C)2005 
I dedicate this dissertation to my grandparents, Julia O. Guenette and Hennessey W. Leger, who embody courage and grace in the ninth decade. 
I express my deepest gratitude to my academic advisor and mentor, Dr. Margaret Neal, whose guidance, encouragement, professionalism, and warmth will be fondly remembered always, and to my husband, Richard Howard, for his tireless love, support and patience.

I thank Dr. Frederick Fraunfelder and Dr. James Gilbaugh for the generous contribution of data from their Retirement Lifestyles Survey, and I thank my other committee members, Dr. Jason Newsom, Dr. Leslie Hammer, and Dr. Nancy Chapman, for their support.

Finally, I thank my family, and my friends, with a special thanks to Kiley Ariail, Heather Hastings, and Dr. Jost Lottes, for their humor and advice, and for making the rough times smoother. 


\section{TABLE OF CONTENTS}

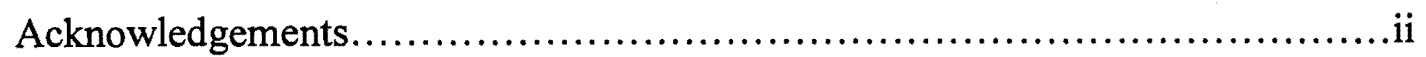

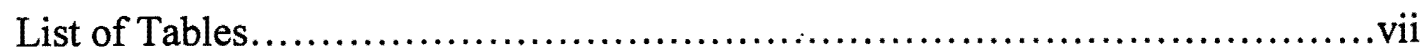

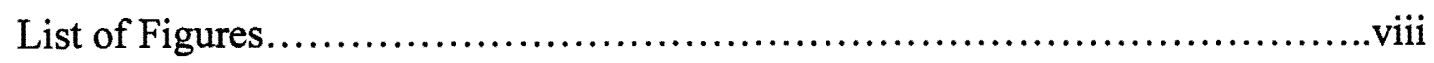

Introduction: Retirement as an American Institution...............................

Economic and Demographic Incentives.....................................

Social Status and Older Adults in Pre-industrial Societies.....................3

Social Status and Older Adults in Industrial America.........................5

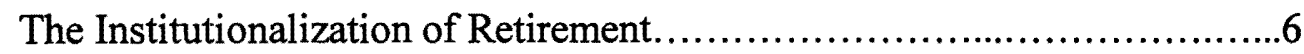

Mandatory Retirement, Pensions and Social Security ......................

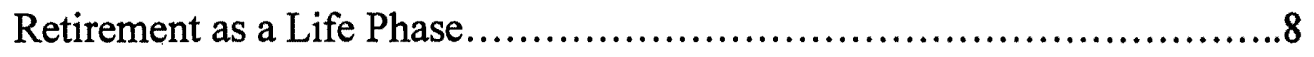

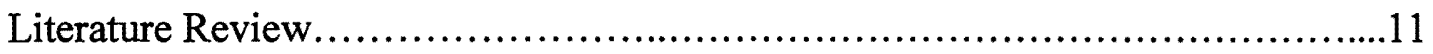

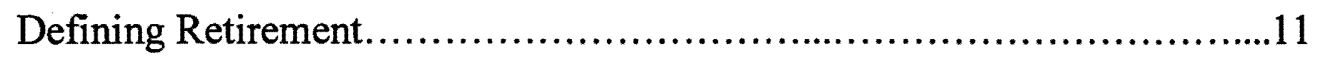

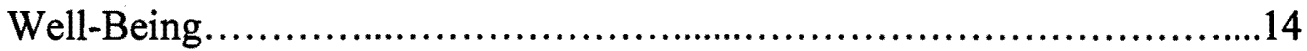

Definitions of Well-Being ...................................................

Well-Being and Measurement Issues....................................................16

Well-Being and Personal Control......................................18



Retirement Adjustment and Gender....................................................

Retirement Adjustment and Personal Control......................................27

Marriage and Retirement Adjustment..................................................28 
Crossover Effects in Family-Related Research.............................33

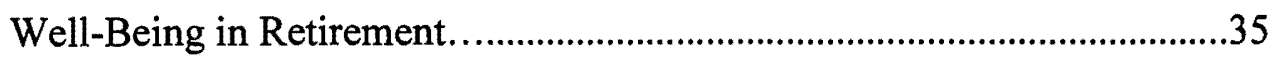

Well-Being, Adjustment to Retirement and Gender.......................36



Well-Being and Social Support in Older Adulthood................39

Well-Being, Social Support and Gender......................................40

Well-Being, Retirement Satisfaction and Health...................41

Well-Being, Retirement Satisfaction, Health and Gender..........42

Well-Being and Income in Retirement........................45

Well-Being, Income and Gender in Retirement...........................46

Well-Being and Occupational History in Retirement.....................49

Well-Being and Educational Attainment in Retirement..................50

Well-Being and Post-Retirement Work........................52

Well-Being and Voluntary vs. Involuntary Retirement............54

Summary of the Literature................................................58

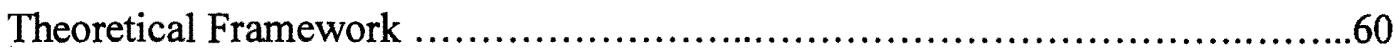

Family Systems ….....................................................................60

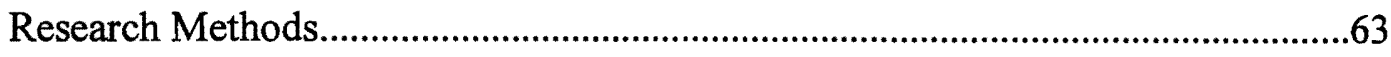

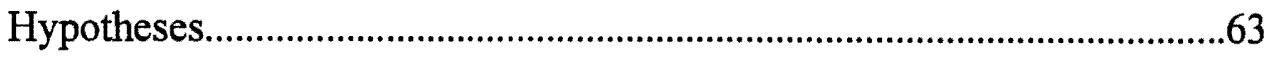

Actor-Effects Hypotheses ........................................ 64

Partner-Effects Hypothesis.........................................66

Final Actor-Effect Hypothesis...............................................67 


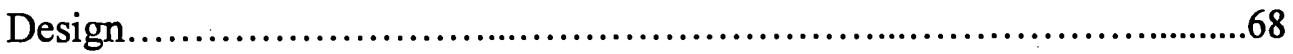

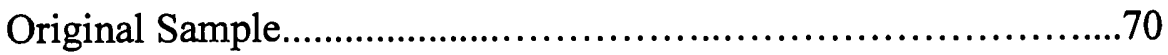

Study Sample Selection Criteria...........................................................71

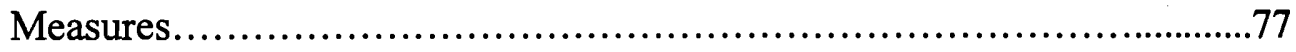

Dependent Variable ................................................................................77

Independent Variables.....................................................................

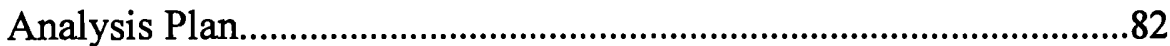

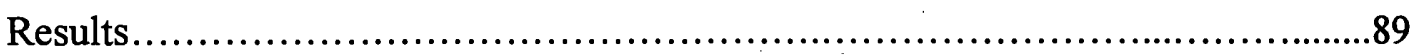

Measurement Model: Retirement Adjustment...........................90

Measurement Model: Well-Being..................................92

Research Hypotheses and Analyses.......................................93

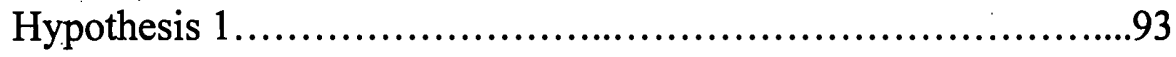

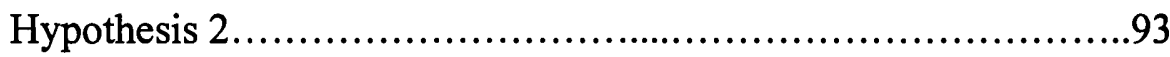

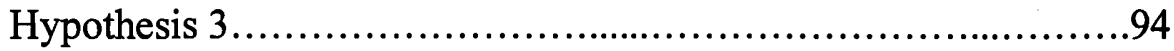

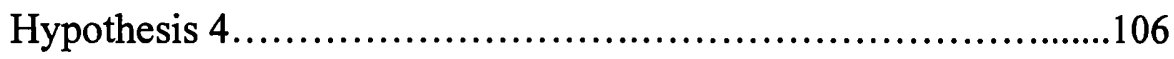

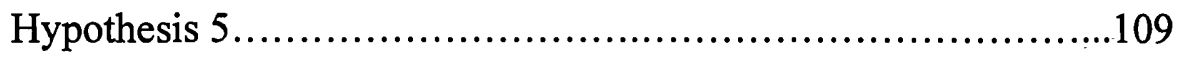



Actor-Effects Hypotheses....................................................................122

Partner-Effects Hypotheses................................................................129

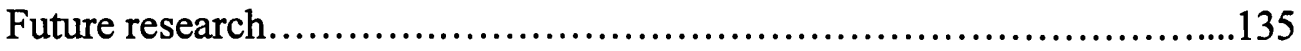

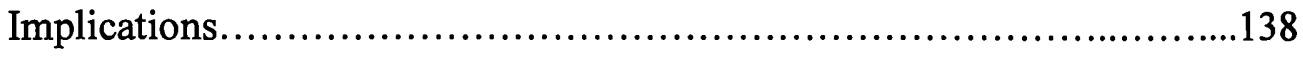




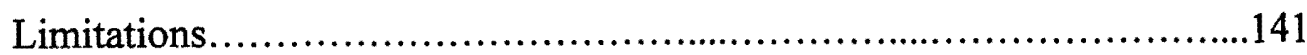

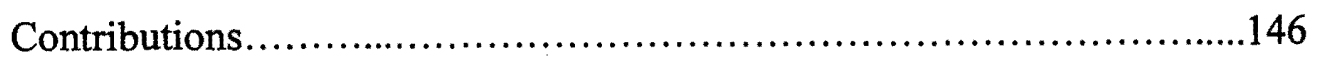

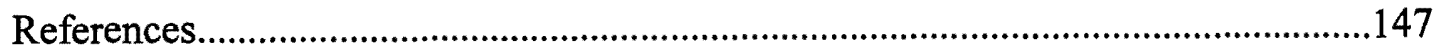




\section{LIST OF TABLES}

Table 1: Descriptive Information for Study Sample and Overview of Results of Paired comparisons between Husbands and Wives..................................................

Table 2: Reason for Forced Retirement Reported by Husbands and Wives................76

Table 3: Final Three-Item Confirmatory Factor Model Results for

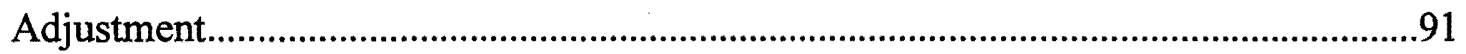

Table 4: Final Three-Item Confirmatory Factor Model Results for Well-Being..........93

Table 5: Combined Model Results for Well-Being Regressed on Retirement

Adjustment, Health Problems and Forced Retirement for Husbands and Wives......99

Table 7: Husbands' Retirement Adjustment Regressed on Husbands' own Socio-

demographic Indicators and Wives' Retirement Adjustment Variables..................102

Table 8: Wives' Retirement Adjustment Regressed on Wives' own Socio-

Demographic Indicators and Husbands' Retirement Adjustment Variables.

Table 9: Full Model of Hypothesized Predictors of Retirement Adjustment

and Well-Being

Table 10: Summary of Hypotheses. 


\section{LIST OF FIGURES}

Figure 1: Conceptual structural equation model representing well-being predicted by retirement circumstance and health.

Figure 2: Structural equation model representing possible actor effects and partner effects in retirement adjustment and well-being. .66

Figure 3: Conceptual structural equation model: predictors of retirement

adjustment and well-being. .68

Figure 4: Husband's well-being predicted by his forced retirement circumstance and

health.

Figure 5: Wife's well-being predicted by her forced retirement circumstance and health.

Figure 6: Crossover effects in spouses' retirement adjustment and wellbeing

Figure 7: Crossover effect of partner's forced retirement on one's own well-being mediated by one's own retirement adjustment

Figure 8: Predictors of husbands' retirement adjustment and well-being

Figure 9: Predictors of wives' retirement adjustment and well-being.

Figure 10: Full model of predictors of husband's retirement adjustment and well-being.

Figure 11: Full model of predictors of wives retirement adjustment and wellbeing. 


\section{Introduction: Retirement as an American Institution}

\section{Economic and Demographic Incentives}

Retirement is a paradox; it is a beginning and an ending, a young institution in the ancient history of human socialization implemented amid the intersection of many opposing social and economic factors. It was born of economic incentive and is a consequence of an advancing industrial economy, decreased infant mortality, and the demand for a higher level of workforce management unprecedented in feudal and agrarian economic systems.

From a $19^{\text {th }}$ century viewpoint in the United States, the concept of individual retirement from work, funded in part by a government-sponsored social provision, was a novel one, particularly because the rise of industrial capitalism cultivated a political climate that favored a "hands off" or laissez-faire government (Graebner, 1980). It was during the late $19^{\text {th }}$ century, however, that an important antecedent to the modern Social Security programs developed in the United States: a pension offered to hundreds of thousands of disabled veterans from the Civil War. Widows and orphans of veterans received pensions equal in amount to a soldier's disability pension (Dewitt, 2003). The Civil War benefit was distributed to disabled veterans and veterans' families in the years following the war. In 1890, the link with service-connected disability was broken; any Civil War veteran qualified for benefits, with or without a service-connected disability. In 1906, old age was made a sufficient qualification for receipt of benefits, and by 1910 , Civil War veterans and their survivors enjoyed a 
program of disability, survivors and old age benefits similar in some ways to the later Social Security program (Dewitt, 2003).

Despite this early example of a government-sponsored pension, state assumption of responsibility for the economic well-being of its citizens, particularly those capable of work, was antithetical to the burgeoning capitalist order. This marriage between a protective state and a capitalist economy was in essence a union of opposites; as Marx emphasized repeatedly in his critique of free market systems, capitalism attaches rights to the possession of property, and the welfare state attaches rights to individuals in their capacity as citizens (Tucker, 1979, citing Marx, 1848).

Even more remarkable is that a welfare program for older workers, Social Security, was established during the early twentieth century, a time in American history when the status of older adults was experiencing decline (Graebner, 1980). This decline was partially attributed to the shift from an agrarian to an industrial economic system. The new economic system created a demand for a federal welfare state to compensate workers who could no longer collect income from the industrial job market, for reasons pertaining to death, disability, poor health or old age.

The course of the natural history of work and family was significantly altered by this federal program. Social Security ushered in a new social institution, and with this new institution came a new stage of life for workers and their families -retirement. A social institution, as defined by Webster's II New Riverside University Dictionary (2002), is: “Groups of persons banded together for common purposes having rights, privileges, liabilities, goals, or objectives distinct and independent from 
those of individual members" (p. 426). According to the Sustainable Development Indicator (SDI) Group ${ }^{1}$, several categories of social institutions have been identified, including but not limited to: community, educational institutions, ethnic or cultural groups, extended families, families and households, government and legal institutions, health care, political and non government institutions, and market institutions. Elements of retirement are represented within all of these categories of social institutions. A few examples include: continuing education programs developed for adults aged 65 and older (educational institutions), the lobbying power of AARP (political institutions), and the connection between retired persons and health care through the federally sponsored Medicare program (health care institutions).

Retirement is a relatively new and complex social institution, and aspects of retirement remain unexplored, particularly the impact retirement has on another social institution: marriage. The objective of the research described here was to explore some of the psychosocial effects of this macroeconomic shift on older adults. This study focused on couples, their shared experience of retirement, and the factors which contribute to, or detract from, individuals' successful adjustment and well-being in retirement.

\section{The Social Status of Older Adults in Pre-industrial Societies}

In many agrarian societies, older people were considered a rich resource, collectors of history and wisdom (Stearns, 1982). Moreover, the elderly were often

\footnotetext{
${ }^{1}$ The SDI Group currently reports to the Council on Environmental Quality in the Executive Branch of the Federal government. A primary task of this group is to develop a framework to identify, organize, and integrate national sustainable development indicators. This framework will cover all aspects of the Earth system natural Earth system processes (e.g., hydrological, atmospheric, terrestrial, biological, or chemical); and (3) social, cultural, or political processes (Sustainable Development Indicators, 2004).
} 
the owners of family land, and this gave them the economic and legal basis for wielding power over kin and, hence, procuring status (Stearns, 1982). Older adults also held an important information control function in pre-industrial society (Kerzer \& Laslett, 1995). Largely illiterate, society depended on word of mouth; the elderly knew the most because their memories were longest, so they served as society's mentors (Kertzer \& Lazlett, 1995). Some historians, however, debate the higher status of elders in pre-industrial society, and remind us that many older adults were abandoned and sent to poor houses when they could no longer work (Minois, 1989). In some cases, geronticide was a cultural norm. The following example provided by Atchley (1975, p. 24, citing Donahue, Orbach and Pollock, 1960, p. 7), suggests retirement from productivity simply was not an option in some cultures: "If the Eskimo grandmother could no longer chew [hide for] boots of the family, she would be abandoned or walled up in an igloo to wait death."

At the same time, because it was a common belief in Europe that life in the new world was unhealthy, older people were prized for their longevity in Colonial America (Haber, 1988). They defended the honor of Colonial America by representing the vitality of the colonies, an advertisement for new world livability. Older adults were encouraged to participate in political debates, and they were leaders in business, agriculture and commerce (Haber, 1988). .

The status of the revered elder began to change around the time of the Civil War (Graebner 1980). In a rapidly changing society, knowledge -- rooted in science, supported by evidence and empirical tests -- replaced the folk wisdom handed down 
by older people. This change reduced the information-control function of older adults and slowly dismissed them from an important traditional role. Science, particularly early medical science, further diminished the status of older adults by defining old age as a chronic disease state; old age became associated with disease (Katz, 1996). A “person's advanced years began to represent the primary criterion for classifying him [sic] as unproductive and useless" (Graebner, 1980, p. 14).

\section{Social Status and Older Adults in Industrial America}

As the modern factory system continued to replace the agrarian system, less importance was placed on the experience that came with age, and older people had to worry about what they would do if forced to stop working (Graebner, 1980). Industrialization, with its capitalist economy and emphasis on use and exchange values, threatened the status of some older people, who, because of personal choice or health reasons, could no longer work. The social fabric that supported older people was rapidly unraveling. Industrialism resulted in greater job mobility, and the extended family began to disperse in pursuit of work (Atchley, 1975).

In a speech to Congress regarding the original Social Security legislation in 1934, President Franklin Roosevelt observed that "Social Security was attained in the early days through the interdependence of members of families on one another...the complexities of great communities and of organized industry make less real these simple means of security" (Haber, 1982, p. 76). By the late 19th century, the social position of America's older people had diminished noticeably, and by the early 20th 
century, old age was considered a social problem that needed to be addressed (Atchley, 1975).

\section{The Institutionalization of Retirement}

The social processes of modernization and industrialization are key explanatory factors regarding the advent of retirement. Graebner (1980) reported that one of the first public discussions of retirement in the United States occurred in 1905. Graebner cited a speech given by Dr. William Osler upon leaving his position as chief of staff at Johns Hopkins University. Osler discussed "the uselessness of men over 60 years of age, and the incalculable benefit it would be in commercial, political and professional life ...if men stopped work at this age" (p. 11). Although ageist, Osler's insights were important, in that he noted America's labor force was aging and rapidly mechanizing and that social procedures needed to be established to open jobs to younger workers.

Graebner's historical exploration of aging and early $20^{\text {th }}$ century culture revealed that the concept of the less productive older worker was commonplace, and with a new emphasis on productivity and efficiency, a worker's increasing age became a liability. This was particularly true with respect to the technological innovation that revolutionized the industrial production system: the assembly line, which was developed by automobile manufacturer, Henry Ford. Management preferred to hire younger workers for these jobs, which required speed, precision and physical endurance (Graebner, 1980). 


\section{Mandatory Retirement, Pensions and Social Security}

As the practice of hiring younger employees increased rapidly, unions found it necessary to accept the concept of mandatory retirement with pension support. The collective conscience of America demanded that federal government do something to relieve suffering among unemployed older adults. This public pressure led to "the most important historical development in the institutionalization of retirement in the United States," (Morrison, 1986, p.24), the signing of the Social Security Act in 1935.

The passage of the Social Security Act was preceded by many years of debate. The debate centered on the need to support older Americans who could no longer work versus the moral and social implications of rewarding those who did not produce. Retirement became an expected life stage, due largely to the financial security provided by these newly created public funds (Morrison, 1986).

Among Western nations, the United States was hardly a forerunner in instituting social welfare for older adults. The origins of the modern welfare state are usually associated with Bismarck's introduction of national pensions and other social benefits in Germany during the 1880's. Commenting on Bismarck's reforms, Myles (1991) wrote:

The founding fathers were explicit about the economic role of pensions: they should supplement the small wage still earned by the older worker or contribute to the family income of the disabled...the benefits of a male worker alone were not meant to allow for running an old couple's household (p. 17). 
As Butler (1975) pointed out, at least 11 other nations had a form of social welfare before the United States.

\section{Retirement as a Life Phase}

When we consider the great demographic shift that will shape our national future over the next fifty years, we are speaking not of a simple transition but of a genuine transformation. Just five years from now, in 2010, the first batch of Baby Boomers will reach the age of sixty-five. Today's life expectancy has been extended to an average of 72 years for men and 78 years for women (The World Bank, 2004). Since 1900, the percentage of Americans aged 65 and over has more than tripled from ( $4.1 \%$ in 1900 to $12.4 \%$ in 2000 ), and the number has increased eleven times (from 3.1 million to 35.0 million. By 2030 , there will be an estimated 70 million older persons, more than twice their number in 2000 . People aged 65 and older represented $12.4 \%$ of the population in the year 2000 and will be $20 \%$ of the population by 2030 (Administration on Aging, 2002). Much of the concern surrounding the aging of the Boomers centers on their collective impact and the allocation of public and private resources needed to accommodate this population.

Central to the present study is the recognition that this population of older adults is composed of individuals who struggle in the face of structural forces to make sense of their own role within a shifting society, often in conjunction with a spouse or life partner making a similar transition to retirement or a reduced number of hours worked. In 1998, 79 percent of men aged 65 to 74 were married, compared with 55 percent of women in the same age group. Among persons aged 85 and older, about 50 
percent of men were married, compared with only 13 percent of women (Federal Interagency Forum on Aging Related Statistics, 2000). For either gender, marriage particularly in the early phases of retirement, when the majority of men and women over age 65 are married - is an important variable in social research on retirement. The present study is guided in part by The Sociology of Retirement, written by Robert Atchley in 1975, a pioneering work which began to organize and conceptualize the meaning of retirement in a rapidly evolving post-industrial society. Retirement, as defined by Atchley, is many things: a process, a status, an event, a social role and a phase of life. As a status, retirement may be seen by many as a reward for a lifetime of participation in the work force. For others, retirement represents a loss of meaning and identity. As a process, it must account for work life circumstances, as well as life events, for example, a change in marital status, while incorporating macro influences such as economic and social conditions and policy.

These macro/structural influences have an important place in the lives of older adults. Andrew Blaikie (1999), in his post-modernist perspective of age consciousness and modernity, argued that separation of older people from the sphere of production led to increased classification of the life stages, i.e., young adulthood, middle age, older adulthood. These life stages increase stigma; older people are evaluated according to their market relation or perceived dependence (Blaikie, 1999). Blaikie argued that this process is reinforced by the consumer culture, which leads to even more age gradations for marketing purposes. 
As a phase of life, retirement requires adjustment and adaptation to new roles, new activities, and new concepts. For many, retirement is a rebirth and for some, an ending. This study examines the impact of retirement on the lives of married couples, specifically, the predictors of adjustment and well-being in retirement. The objective is to uncover factors that predict well-being in retirement for individuals within married couples. 


\section{Literature Review}

This review of the literature begins with a discussion about the definition of two concepts that are central to this research: retirement and well-being. The review will then focus on well-being, its relationship with retirement adjustment and its various predictors, followed by a review of the literature on retirement adjustment for individuals and couples. Finally, this chapter will include a discussion of crossover effects found in other family research and a summary of the review.

\section{Defining Retirement}

In Western cultures, the concept of retirement is related to leisure; it is a time for older adults to experience freedom from structured work for pay, a time for relaxation and avocations (Luborsky, 2003). How to define a person as retired is the first of many questions addressing the topic of retirement adjustment and well-being among couples. Attempts to arrive at one single definition of retirement have been futile. The following single-criteria definitions have been used to assign retirement status: separation from career, exit from the labor force, reduced effort, pension receipt and self-definition (Atchley, 1979). The difficulty with retirement status definitions that are based on a single criterion is that the criterion can be easily exempted by other single criterion definitions. As an example, consider an individual, who, when asked to state his or her work status, says, "I am retired," even though he or she currently attends professional conferences and edits articles for several journals. A retirement study which used the single criterion, "self-definition," would accept this person as a 
study participant; however, a retirement study which chose to define retirement status by the single criterion, "separation from career," would not accept this person as a participant. Researchers may inadvertently exempt eligible participants, or include ineligible ones, when using only one criterion to define retirement status.

Objections to the ambiguity of single-criterion definitions of retirement status led to consensus recommendations which were reported by Atchley (1979). The recommendations state that retirement status should be defined through crossclassifications of persons on three main criteria: pension receipt, reduced work or earnings, and self-definition (Atchley, 1979). This definition remains widely used in retirement research, although some researchers have chosen to use other criteria to define retirement. For example, George, Fillenbaum, and Palmore (1984) defined retirement as "respondents who were employed less than 35 hours a week and were receiving a public or a private pension" (p. 366). The use of hours worked per week is a less common criterion for defining retirement than the three main criteria from the consensus recommendations specified by Atchley (1979).

Recent work by Luborksy (2003), however, renders the three common criteria for defining retirement inadequate when applied beyond Western cultures. Luborksy investigated differences in retirement definitions among several non-Western cultures. He found that among older adults in the Fulani culture of West Africa, retirement begins with the marriage of the last child, after which parents pass on personal property and take on a dependent status. Among Andean peasants, retirement is defined by a shift to less arduous tasks. In Eastern cultures, retirement is often 
represented by a shift from economic to spiritual realms, in which older adults dedicate themselves to religious duties in the last stage of life. Luborsky (2003) argued that Western retirement is both an individually earned right to a period of leisure after a career of employment, and an age-grade social obligation. He offered the following definition of Western retirement:

The age-fixed and socially mandated final phase in a career of employment in which a person is excluded from full-time career jobs, is entitled to financial support without the stigma of dependency, and is personally responsible for managing his or her own life (p. 254)

Luborsky (2003) further argued that Western practices of retirement are unique and do not extend to non-Western nations, thereby limiting the scope of retirement research that has chosen to define retirement according to Western practices.

For couples, defining retirement is potentially more ambiguous, primarily because relatively few married couples are composed of individuals of the same chronological age, and because it is common for one spouse to retire before the other. Furthermore, some retirees choose to maintain an employed work status either full or part time beyond the age of 65. In 2002, 4.5 million (13.2\%) Americans aged 65 and over were in the labor force (working or actively seeking work), including 2.5 million men (17.9\%) and 1.9 million women (9.8\%). They constituted $3.1 \%$ of the U.S. labor force. About 3.6\% were unemployed. Labor force participation of men aged $65+$ has decreased steadily from 2 of 3 in 1900 to $15.8 \%$ in 1985 , and has stayed at $16 \%-18 \%$ 
since then. The participation rate for women $65+$ rose slightly from 1 of 12 in 1900 to $10.8 \%$ in 1956 , fell to $7.3 \%$ in 1985 , and has been around $8 \%-10 \%$ since 1988

(U.S. Bureau of Labor Statistics). For the purpose and scope of this research, the criteria for defining a couple as retired are the criteria specified by Atchley (1979) above.

\section{Well-Being}

\section{Definitions of Well-Being}

Defining "well-being" as a research concept has been challenging, as well. In a review of the psychological literature on well-being, Ryan and Deci (2001) defined well-being, in the broadest sense, as optimal psychological functioning and experience. These authors identified two paradigms of inquiry concerning well-being. The first paradigm, originally described by Kahneman, Deiner, and Schwartz (1999), was hedonism, and reflected the view that well-being is characterized by happiness or pleasure. Kahneman et al. (1999) defined well-being as "the study of what makes experiences and life pleasant and unpleasant" (p. 4).

The second paradigm was eudaimonism, the belief that well-being consists of fulfilling or realizing one's daimon, or true nature. Eudemonic theories state that not all desired outcomes result in well-being when achieved (Ryan and Deci, 2001). Waterman (1993) noted that according to the eudemonic approach, well-being is manifested in individuals whose actions are congruent with their most deeply held values. 
An important index of subjective well-being for individuals is the person's judgment about quality of life, and life satisfaction (Deiner, 1984). According to Ryan and Deci (2001), most hedonic psychological research has used assessment of subjective well-being (SWB) to evaluate the pleasure/pain continuum of the hedonic paradigm. The primary conceptualization for SWB used throughout the well-being literature in the past 20 years consists of three components: life satisfaction, the presence of positive mood, and the absence of negative mood (Ryan \& Deci, 2001).

Ryff and Singer (1998) argued that the primary conceptualization of SBW does not adequately define psychological well-being, and they generated an explicit operational definition of psychological well-being (PSW) that encompassed multiple components of well-being derived from psychological theory and eudemonic philosophical perspectives. Ryff (1995) described well-being as "the striving for perfection that represents the realization of one's true potential" (p. 17). The PSW model defined by Ryff and Singer included the following six components: selfacceptance, or positive attitudes toward oneself; positive relations with others, including the ability to achieve close unions with others; autonomy, including qualities of self-determination, independence, and the regulation of behavior from within; environmental mastery, which is the individual's ability to engage in, and manage, activities in one's surrounding world; purpose in life, including the beliefs that give one the feeling that there is purpose in, and meaning to life; and personal growth, which represents one's continual development and striving to realize one's potential to grow and expand as a person. 
Ryff (1995) applied these six categories to a national survey of young, middle aged, and older adults. Her findings revealed fluctuating patterns of these components of well-being based on age, with positive relationships with others increasing steadily from youth to old age, and purpose in life and personal growth decreasing with age. She found that environmental mastery and autonomy increased between young adulthood and midlife, and leveled off in midlife, and that good personal relationships were a more important predictor of well-being than personal control.

\section{Well-Being and Measurement Issues}

In addition to difficulties in defining well-being as a research concept, wellbeing has also been marked by problems of measurement. A primary issue has been inconsistency among conceptual levels and frameworks used to study well-being (Kahn \& Juster, 2002). Kahneman, Deiner and Schwartz (1999) addressed the issue of inconsistent conceptual levels. They proposed a single comprehensive framework for studying well-being. The five conceptual levels included:

1. external conditions (e.g., income, neighborhood, housing)

2. subjective well-being (e.g., self-reports of satisfaction and dissatisfaction)

3. persistent mood level (e.g., optimism/pessimism)

4. transient emotional states, immediate pleasures or pains (e.g., anger, joy)

5. biochemical, neural bases of behavior

For the purposes of the present research, the second conceptual level, subjective well-being, will be examined. 
In a review of the measures used in well-being research, Kahn and Juster (2002) found that most surveys of well-being use one or more of three measures: (1) satisfaction with life, (2) health and ability/disability, and (3) composite indexes of positive functioning. The authors criticized all three categories because, "They assume that well-being is a summation of a person's varied life experiences, and that it is relatively stable, unaffected by momentary events" (Kahn \& Juster, p. 634). In place of these commonly used measures of subjective well-being, the authors advocated a new approach with two emphases: (1) a substantive effort to study each of life's major roles and their contribution to well-being, and (2) a temporal approach which accounts for transient emotional states. Because these subjective measures occur within the context of larger objective measures, the authors also suggested that surveys of wellbeing should include questions about major life domains such as the quality of the neighborhood and the community in which people live, because these external conditions may influence SBW in ways that are not readily detected using SBW measures which do not account for these larger objective measures of well-being. In particular, research has identified three types of resources which contribute to retirees' subjective well-being: (1) economic resources, (2) social relationships, and (3) personal resources (Kim \& Moen, 1999; Mutran, Reitzes \& Fernandez, 1997). The first two types of resources are discussed in greater detail at a later point in this review of the literature, and a discussion of the third type, personal resources, will be begin next with the concept of personal control. 


\section{Well-Being and Personal Control}

Personal control appears in the literature in several related forms, including internal locus of control (Rotter, 1966), personal efficacy, (Bandura, 1977), personal autonomy (Seeman \& Anderson, 1983), and mastery (Pearlin et al., 1981). Earlier studies (Mancini, 1981; Reid, Haas, \& Hawkings, 1977; and Rodin \& Langer, 1977) and later studies (Lachman et al., 1994; Rowe \& Kahn, 1987) found that older persons who perceive themselves as having more personal control adjust better to the aging process. They also found personal control to be a major component of psychological well-being across the life span.

Ryff's (1995) finding that good personal relationships were a more important predictor of well-being than personal control is contradicted by results from a study by Smith, Kohn, Savage-Stevens, Finch, Ingate \& Lim (2000), who found that personal control was highly correlated with social support; specifically, higher levels of social support were correlated with higher levels of perceived control.

Personal control and gender. With respect to well-being, the findings concerning the relationships with personal control and gender are mixed. Abel and Hayslip (2001) found the relationship between self-rated health and desired control was unrelated to gender, but health expectancy, education expectancy, and education desirability differed by gender: more highly educated men in better health expected more control but valued it less, and women, who were less educated in this sample, expected less control and valued it more. 
Personal control appears to be an important indicator of overall well-being among retirees regardless of gender. As noted above, there is evidence that an internal locus of control predicts well-being in retirement. Based on these findings, high levels of personal control and social support appear to be key predictors of well-being in retirement. In addition, certain types of activities contribute to the effect that personal control has on well-being.

Personal control and leisure activity. The effect of personal control on retirement adjustment was influenced by the kinds of activities retirees typically engaged in, according to a study by Ross and Drentea (1998). The findings revealed that slightly more than 50 percent of retired persons declared housework and family was their primary activity, 21 percent reported leisure as their primary acitivity, 12 percent declared home maintenance and yard work, 8 percent claimed unpaid work for a family business, 4.5 percent reported school work, 4 percent reported volunteer work and .5 percent said they were looking for work.

Ross and Drentea (1998) found retirees' activities were more routine, provided fewer opportunities to acquire new knowledge, provided less positive social interaction with others, and were less likely to involve problem-solving. However, they also found that retirees' activities were equally enjoyable and more autonomous when compared to those of full-time workers. Moreover, they found that autonomous activities, fulfilling activities which are enjoyable and provide the opportunity to learn new things, and integrated activities were all positively associated with a sense of control and negatively associated with psychological distress. Retirees were found to 
have a significantly lower sense of control than full-time workers, in large part because the characteristics of their daily activities provided fewer integrated activities and fewer opportunities for problem solving and learning new things. Despite lower rates of personal control, however, the authors reported that the retirees in their study did not have significantly higher levels of psychological distress when compared to full-time workers.

\section{Retirement Adjustment}

Work provides the worker with money, status, power, identity, structure -tangible and intangible things often difficult to relinquish and even more difficult to replace outside of the work role. Adjustment to retirement can be challenging even for those who voluntarily retire. Atchley (1975) estimated that one-third of the population experiences problems with the retirement transition. Factors generally agreed upon by scholars (e.g., Dorfman, 1985; Levy, 1980; Matthews \& Brown, 1987, Riddick, 1982; Szinovacz, 1982, 1986-1987) to predict positive retirement adjustment are: having leisure roles and activities, adequate income, good subjective health, social relationships and friendship networks, positive attitudes toward retirement, retirement planning, meaningful use of time, opportunities for cultural and avocational events, and marital status (being married). The top five predictors are good subjective health, adequate finances, retirement planning, activities, and being married.

A review of the literature on adjustment to retirement by Braithewaite and Gibson (1987) revealed that those who have difficulty adjusting to retirement are in poor health, have inadequate incomes, and have negative attitudes toward retirement. 
The relationships of other factors, such as socioeconomic status, occupation, activity, career fulfillment, job satisfaction, and work commitments to retirement adjustment were less clear, but higher levels of education and a professional occupational status tend to be positively related to retirement adjustment. Adjustment tends to improve with time, but the rates vary according to retirement circumstances (Braithewaite \& Gibson, 1987).

One of the earliest studies to reveal differences in retirement adjustment styles among individuals was conducted by Neugarten, Havinghurst, and Tobin (1968). These authors identified eight patterns of aging in older adults based on the nature of coping strategies (such as active-passive or integrated-unintegrated); activity level in common roles (such as worker or neighbor); and pre-and post-retirement life satisfaction. Each of the eight patterns found were labeled based on the nature of the primary coping strategy used: Reorganizer, Focused, Successfully Disengaged, Holding-on, Constricted, Succorance-seeker, Apathetic, and Disorganized. Despite differences in coping style and activity level among individuals fitting the eight patterns, the authors found life satisfaction to be high or medium in most of the categories except those exhibiting the "Apathetic" or "Disorganized" patterns. Atchley (1975) was the first to develop a theoretical framework for adjustment to retirement. Previous gerontological theory categorized retirees as either busy (activity theory; Friedmann \& Havinghurst, 1954) or not busy (disengagement theory; Cummings \& Henry, 1961). Atchley postulated that adjustment to retirement was dependent on how many work-related goals an individual has, where work goals rank 
in their personal hierarchy of goals, and whether these goals are accomplished before retiring. Atchley argued that poor adjustment is the result of highly valued and unmet work goals that remain unsubstituted in retirement. Conversely, he theorized that when work-related goals are less important, the retiree needs to make fewer adjustments and substitutions to compensate for the loss of those goals.

It is important to note that Atchley developed this theory before mandatory retirement was abolished. Under mandatory retirement, the probability of a person highly motivated by work goals not meeting those goals before retirement was greater. It is also important to note that Atchley's estimate that one-third of the population would experience difficulty with retirement accounted for retirees forced to retire under mandatory retirement. Since the abolition of mandatory retirement, this estimate may be lower.

Walker, Kimmel and Price (1981) evaluated post-retirement work habits and activity and identified four styles of adjustment: "Reorganizers" were active, had looked forward to and planned for retirement, were highly satisfied with retirement and, to use Atchley's paradigm, had successfully substituted their work goals. The second adjustment style, "Holding On," was composed of highly active retirees whose preference would be to maintain a working life-style. This group often retired involuntarily. In contrast, "Rocking Chair" retirees had looked forward to retirement and were satisfied with reduced levels of activity. The final group, the "Dissatisfied," were lowest in satisfaction and highest in depression and frustration. Many had been 
forced to retire and now found it difficult to maintain a satisfactory level of activity. These individuals also reported the lowest levels of health, education and income. Hornstein and Wapner (1985) interviewed men and women from a variety of income and education levels before and after retirement. The sample varied with respect to demographic variables (such as occupation, educational level), and forced versus mandatory retirement. Their results were similar to the four styles found by Walker et al. (1981), i.e., "New Beginning," "Continuation," "Transition to Old Age," and "Imposed Disruption." Both of these studies, then, strengthen Atchley's (1975) theory of retirement adjustment, in which he argued that adjustment to retirement is dependent on how many work-related goals an individual has, where work goals rank in one's personal hierarchy of goals, and whether these goals are accomplished before retiring. If work-related goals are an important predictor of retirement adjustment, then gender may also be an important predictor due to the fact that women, particularly in this study cohort, may have work histories that are very different from those of men.

\section{Retirement Adjustment and Gender}

Who adjusts to retirement with more ease, women or men? The findings are inconsistent. As noted earlier, women workers in late midlife have less tenure in the work force, are less likely to have worked continuously (Han \& Moen, 1999;

Znaniecki \& Steinhart, 1971) and tend to experience retirement differently (Moen, 1996; Quick \& Moen, 1998; Smith \& Moen, 1998; Szinovacz, 1986-87; Szinovaz, Ekerdt \& Vinick, 1991; Vinick \& Ekerdt, 1991). Many women in the current cohort of retirees have work histories punctuated by years of absence from paid work due to 
time spent in child care other unpaid familial care responsibilities (Quick \& Moen, 1998).

The literature on female retirement has grown in the last 10 years, but as Slevin and Wingrove (1995) point out in their review of the literature, gaps exist. Especially notable is the absence of feminist theory, race as a focus, female life cycle issues and lack of overall understanding of a variety of effects upon work and retirement caused by women's different status and role set. Existing studies are largely atheoretical with small convenience and purposive samples.

Retirement adjustment among professional women is a particularly understudied topic in the literature on retirement adjustment. Positive retirement adjustment for professional women was found by Price (2003) to be influenced by the extent to which the following four factors were incorporated in the retirement adjustment process: (1) role expansion, or the substitution of professional roles with alternative roles such as volunteering; (2) maintaining a sense of self by pursuing activities that preserve feelings of productivity and usefulness; (3) establishing a structured retirement schedule; and (4) community involvement through volunteered and part-time work. Price suggested that adjustment to retirement, for professional women, may be enhanced by utilizing work-related skills, maintaining active lifestyles, and by nourishing individual self-concepts to counter the loss of former professional roles. Prentis (1980) and Price-Bonham and Johnson (1982) found professional women to be less interested in retirement than non-professional women. 
In an earlier study conducted by Price (2000), four common themes among participants' experiences were identified: the sacrificing of one's professional identity following retirement, the loss of social contacts, the loss of professional challenges, and encountering stereotypes during retirement. Findings from the study indicated that women with continuous work histories may enter retirement with apparent ease, yet then experience difficulty adjusting to the loss of their professional role. Quick and Moen (1999) found gender differences relative to employment and retirement, with men reporting greater retirement quality. Quick and Moen also found significant gender differences relative to employment experiences. Female participants had spent fewer years in the work force, had taken more year-long paid breaks from work, and had spent a greater proportion of their working years in part-time employment than men. Women who had spent less time in the work force and who had fewer continuous years in the work force also experienced reduced retirement quality. The results were reversed for men: the more time that men had spent in the workforce, the more likely they were to experience reduced retirement quality.

Another study by Quick \& Moen (1998) evaluated retirement quality based on gender differences in life pathways and employment experiences. That study found greater satisfaction among men, although the difference was small. For women, greater satisfaction was associated with good health, a continuous career, and a good retirement income. For men, key correlates included good health, an enjoyable preretirement job, low work-role salience, substantial planning and retiring for internally motivated reasons. Quick and Moen argued that the results underscore the importance 
of a life course focus on gendered pathways to and through life transitions, due to the differential employment experiences among men and women. The sample was composed of men $(n=244)$ and women $(n=214)$, aged $50-72$, who retired during the 1980's and 1990's. The experiences of the respondents were found to differ significantly by gender despite changes in gender role norms and expectations in the later half of the $20^{\text {th }}$ century.

Other studies suggest women adjust to retirement more easily than men, for example, two studies found women to have significantly more positive attitudes toward adjustment (Atchley, 1982; Jewson, 1982). Contrary to Atchley's (1982) and Jewson's (1982) findings, however, are several studies which indicate that women have more difficulty with the retirement transition. Szinovacz (1982) found that women missed the feeling of doing a good job and work-related social contacts more than men did, and they experienced higher levels of loneliness, less satisfaction and more financial strain in retirement. Women who were reluctant to retire did not adjust well to retirement regardless of their health status. Levy (1980) found that negative effects related to difficult retirement transitions last longer for women than men. No gender differences in adaptation to retirement were found by Gratton and Haug (1983), however, Seccombe and Lee (1986) found retired women reported lower levels of satisfaction than retired men, although the difference was small. But as Quick and Moen (1998) pointed out in their examination of the differential experiences of men and women in retirement, the generalizability of these data to today's population of retirees is questionable in light of women's increased workforce participation: more 
women who are retiring today have spent more time in the labor force than their early counterparts. If positive adjustment to retirement is predicted by a positive preretirement attitude (Glamser, 1976), and a positive pre-retirement attitude is predicted by a low attachment to work goals (Atchley, 1975), then longer labor force participation by women may logically result in increased attachment to work goals, thereby making retirement less desired and the adjustment to retirement more difficult.

\section{Retirement Adjustment and Personal Control}

Once a worker retires, personal control appears to influence the adjustment to retirement. Price and Bruchey (1998) found four distinct developmental stages in their retirement. The first stage involved psychological readiness to retire, awareness of time limitations, health considerations and financial considerations. The second stage was defined by loss of one's former professional identity. Events in this stage included loss of professional challenges and social contacts and confronting ageist and sexist stereotypes. The third stage was found to be a time to restructure one's daily life and to reestablish oneself individually. The characteristics of this stage were time management issues, increased community involvement, taking on new roles, and increased sense of self. The final stage took place after the initial adjustments and life reordering had been accomplished. This period was defined as lasting until death. Its properties included increased time in family relationships, friendship maintenance, and community activities.

In older adults, an internal locus of control (belief in one's ability to control outcomes) has been associated with more positive coping strategies in the face of 
challenging life events (Abel \& Hayslip, 1986), including the four phases of retirement adjustment defined by Price and Bruchey (1998). For example, an internal locus of control was found to be an important psychological moderator in adjusting to the intrinsic role change which accompanies retirement transition adjustment (Carter \& Cook, 1995). Similarly, a predisposition toward self-efficacy (the belief that one has the necessary skills and knowledge to effect control) was found to be an important predictor of retirement adjustment (Carter \& Cook, 1995; Taylor \& Shore, 1994). Two studies, however, found that locus of control had minimal effects on retirement adjustment (Hale, Hedgepeth \& Taylor, 1985-86, and Sherman, 1986). Workers who were more committed to their work perceived more control in their lives and displayed more favorable attitudes toward retirement (Abel \& Hayslip, 2001).

\section{Marriage and Retirement Adjustment}

Most early analyses of couples and retirement satisfaction regressed dependent variables on a set of predictor variables separately for men and women. The first study to analyze husbands and wives conjointly using hierarchical multiple regression was conducted by Stull in 1988. In each step of Stull's analysis, husbands' and wives' responses were measured separately until the final step, when the variables for both were included. Stull concluded that adding information about the spouse on several variables increased predictability relative to respondents' satisfaction with retirement.

As discussed in the above review of the literature on retirement adjustment, research has revealed some differences in retirement adjustment among men and women. Also previously discussed are apparent gender differences relative to 
subjective well-being in retirement. Both bodies of research point to questions concerning couples and retirement. If individual adjustment to retirement can be difficult, it is logical that within a couple, retirement adjustment difficulties may be compounded by the complexities of the marital relationship. Each individual must make his or her own personal adjustments, and each may need to make significant adjustments more than once based on changes in their spouse's work status. In the scenario where one spouse retires while the other continues to work, the retired spouse needs to adjust to hours spent alone. In a different scenario, where one spouse retires and joins an already retired spouse at home, the couple must adjust to extended spousal interaction. The equilibrium of the marriage undergoes fluctuations with each scenario.

Adjustment to retirement may be difficult when only one partner has worked outside the home, but when both spouses retire from work, the difficulties of adjustment are potentially doubled. Most research on couples and retirement analyzes the data by treating each spouse as a separate unit of analysis. A few early, crosssectional studies (Atchley \& Miller, 1983; Dressler, 1973) looked at reactions to retirement from the perspective of husbands and wives. Atchley and Miller (1983) studied predictors of well-being for husbands and wives in older couples but did not control for employment status. These studies found very few differences in adjustment by gender even after controlling for health and other variables.

A study of late midlife employment, gender roles and marital quality by Hofmeister and Moen (1999) found that when either spouse was the only one 
employed in midlife, husbands experienced less marital strain, but when both spouses were employed, marital strain was increased for both husbands and wives. Husband's egalitarian gender role ideology, in addition to having had a professional/managerial career, were also linked to higher strain. Egalitarian husbands reported higher marital quality in proportion with the length of time their wives were in the labor force. Wives' marital strain and positive marital quality were linked to their husbands' marital strain and feelings of positive marital quality. In other words, wives' marital happiness was predicted only by husbands' marital happiness. If husbands were happy, wives were happy. Wives' feelings of positive marital quality were not significantly predicted by the same variables that predicted husbands' marital quality, however (Hofmeister \& Moen, 1999).

Gilford (1984) found that retired couples between the ages of 63 and 69 reported more positive interaction than younger couples. Johnston (1990) found that role changes following retirement were significant stressors and that spouses became more aware of their partner's faults. Retirees who were satisfied with their marriages adjusted better to retirement, according to a study by Myers and Booth (1996).

Kulik (2001) found fewer marital complaints among retired couples than nonretired couples. Kulik found the impact of wives' retirement on the dyadic unit was as strong as that of husbands' retirement. Husbands became more involved in decisions about domestic affairs and participated more in household tasks after retirement. Husbands showed a greater tendency to consider themselves a main provider, saw themselves as more emotionally hardy than their wives, and saw themselves as making 
major decisions regarding household affairs. Women reported higher levels of marital quality and expressed fewer marital complaints and more enjoyment in retirement than did husbands.

A study by Haug, Belgrave, and Jones (1992) of 61 married couples found some interesting effects. A husband's chronic condition was found to impact his wife's retirement adjustment almost as much as his own. When conditions were reversed, a husband's retirement adjustment was not influenced by his wife's chronic condition. A possible explanation for this difference lies in gendered role expectations that women experience throughout their lives (Slevin \& Wingrove, 1995). Research shows, for instance, that women are significantly more likely to be caregivers to elderly parents and spouses (Stone, Cafferata, \& Sangl, 1987).

Among the couples in the study by Haug et al. (1992), their partner's as well as their own characteristics affected their adaptation to retirement when evaluated individually. One's own health and family income were important indicators of adaptation, but having a partner happy in his or her retirement seemed to outweigh health and money factors. In each couple, it was the spouse's adaptation that had the largest effect on the partner's own adjustment. The wife's prior job satisfaction, as well as her marital satisfaction, related to her husband's adaptation more than to her own. The husband's prior job satisfaction and marital satisfaction had no discernible impact on either partner.

A study by Ekerdt and Vinick (1991) used employment status as a predictor of marital satisfaction. The authors measured number of complaints relative to husbands' 
working or retired work status and found no variability. These findings conflict with evidence of marital discord prompted by retirement found in the literature (Ballweg, 1967; Cliff, 1993), in which husbands' presence complicated wives' routines, thereby requiring a period of marital adjustment. Ekerdt and Vinick's findings of minimal disruption are supported by findings of beneficial effects of retirement on marriage (Dressler, 1973; Keating \& Cole, 1980; Moen et al., 2001; Szinovacz, 1980, 2000), especially in dual-earner couples (Lee \& Shehan, 1989). One clear exception to these findings is a recent study by Moen, Kim and Hofmeister (2001), which found increased marital discord for both husbands and wives in the transition to retirement, with the greatest conflict found in couples with one spouse working and the other retired. This finding was supported by Szinovacz (2004), who reported that recently retired men were negatively affected by a spouse's continued employment. Once couples settled into retirement (defined as two years post-retirement), Moen and colleagues (2001) found marital quality improved. These findings seem to indicate that the initial role strain and adjustment to retirement is temporary. In other words, undergoing the retirement transition process itself may be more stressful than actually being retired, and this stress can be transferred, or transmitted to a spouse, creating the potential for heightened distress in both partners.

\section{Crossover Effects in Other Family-Related Research}

"Crossover" effects in the context of marital dyads is a term that refers to the influence that stress or strain experienced by one spouse has on the stress or strain experience by the other spouse (Bolger, Delonghis, Kessler \& Wethington, 1989; 
Hammer, Allen, \& Grigsby, 1997; Westman \& Vinokur, 1998). Westman and Vinokur (1998) identified three types of crossover effects: direct crossover via empathetic reactions, common stressors experienced by both members of a dyad, and/or indirect crossover via interpersonal conflict. Direct crossover effects via empathic reactions in retirement adjustment may occur when the retiree experiences distress at the time of retirement. The partner will absorb some of his or her spouse's distress as a result of feeling empathy for that spouse (Westman \& Vinokur, 1998).

Crossover can occur through a common stressor or major life event experienced by both members of a couple. Some examples of this include significant losses, such as the death of a family member, moving a household, or the retirement of both members of the dyad within the same time period (Westman \& Vinokur, 1998).

For example, indirect mediating crossover processes via interpersonal conflict may occur among couples adjusting to retirement when one spouse experiences difficulty and sadness due to losses sometimes associated with retirement, including loss of income, status and purpose. These feelings may produce heightened irritability in the affected spouse and conflict in the relationship. The conflict then becomes the means through which the effect of the transition crosses or transmits from one spouse to another (Westman \& Vinokur, 1998).

In the mid-1990's, a small body of research looked at depression and crossover effects in marital dyads (Bookwala \& Shulz, 1996; Tower \& Kasl, 1999; Whiffen \& Aube, 1996). In all three studies, the spouses' depressive symptoms were found to predict the partners' depressive symptoms. This phenomenon, otherwise known as 
affective contagion, or a contagion effect, is the process through which one person's mood is spread to others in close proximity (Hatfield, Cacioppo, \& Rapson, 1993, 1994; Sullins, 1991). Hatfield and colleagues (1994) proposed that people who share intimate relationships can "catch" their partner's emotions and moods.

Similarly, Westman and Vinokur (1998) found a direct crossover effect of depression, in which life events had a significant impact on the crossover process. For their study, non-supportive or social undermining behaviors on behalf of a spouse mediated the relationship between depression and crossover between spouses.

In a recent study of the effect of spousal mental and physical health on husbands' and wives' depressive symptoms, Seigel, Bradley, Gallo and Kasl (2004) examined spousal depressive symptoms and physical health on partners' depressive symptoms in a national sample of older married couples. The authors adjusted for respondents' mental and physical health and socio-demographic traits and found an association between spouses' depressive symptoms. Spouses with more depressive symptoms had partners with significantly higher depressive symptoms.

Another longitudinal study which explored depressive symptoms in married couples found that the symptoms appeared to correspond and fluctuate within the marital dyad: when one spouse began to feel better, the other spouse responded similarly (Tower \& Kasl, 1996).

Two more recent contributions found moderate correlations in husbands' and wives' depressive symptoms. Specifically, Townsend, Miller and Gau (2001) found that the symptom level in one spouse predicted 25 percent of the variance in the other 
spouse's symptom level. Beach, Katz and Brody (2003) established that marital satisfaction has an ameliorating effect on depressive symptoms. Cross-spouse effects were found in this study also, with earlier marital dissatisfaction in one spouse predicting later depressive symptoms in the other spouse and, consistent with earlier studies, a slightly larger relationship between marital distress and depression was found among wives. Beach et al. developed a structural model with an excellent fit that supported the hypothesis of a significant relationship between marital process and depression in long-term marriages.

In other crossover studies centered on distress and life events, Riley and Eckenrode (1986) found a crossover effect between husbands' life events and wives' distress. Women with lower personal resources were more distressed by the life events of their husbands. Similarly, Mitchell et al. (1983) found partners' negative events and strains were related to partners' depression. A longitudinal study by Barnett et al. (1995) examined the crossover effects of distress among couples and found that an increase in distress over time in one partner caused reciprocal changes in distress in the other partner. Eckenrode and Gore (1981) found womens' significant others' life events affected womens' own health status and health behavior.

\section{Well-Being in Retirement}

Employment can be an important role that is central to an individual's identity (Price, 2000). Retirement from full-time employment can be a major life transition requiring a period of adjustment due to the likelihood that roles, relationships and daily routines may change significantly with retirement, along with concurrent 
changes in income, and in some cases, health. These transitions may also bring about changes in the way people view themselves and their quality of life. As a result of these changes, individuals may experience an increase or decline in life satisfaction and their evaluation of the quality of their lives (subjective well-being).

Given these considerations, retirement adjustment is viewed here as an important process which contributes to, or detracts from, one's overall state of wellbeing. A logical proposition, therefore, is that well-being in retirement is dependent upon the quality of one's retirement adjustment. A fundamental hypothesis of this research is that the nature of one's retirement adjustment, i.e., positive or negative, will predict one's well-being in retirement and possibly a partner's well-being in retirement. Furthermore, because the sample was evenly divided between males and females, it is important to examine the role of gender as a principal organizing factor in the relationship between retirement adjustment and well-being. The following section of the literature review will be a discussion of well-being and the factors which contribute to well-being in retirement, including retirement adjustment.

\section{Well-Being, Adjustment to Retirement and Gender}

If a new directive of well-being research is, as Kahn and Juster (2001) proposed, to include the study of life's major roles and their contribution to wellbeing, then the study of well-being and gender is likely to benefit because many of life's major roles are organized by gender. Throughout the literature on well-being and retirement, women have been found to experience more depressive symptoms than men (Baruch \& Barnett, 1986; Beach, Katz, Kim, \& Brody, 2003; Bookwala \& 
Schulz, 1996; Whiffen \& Aube, 1999). Kim and Moen (2002) found that women enter retirement with higher levels of depressive symptoms than men and lower levels of morale, personal control, and perceived income adequacy. Gender differences in depression symptoms appear to decline with age, according to findings by Moen (1996).

A recent study by Szcinovacz (2004) found that newly retired men were negatively affected by their spouses' continued employment outside the home when compared with men whose wives had not been continuously employed in the workforce. A reason for this negative effect, according to the authors, may be that wives' continued employment in the workforce conflicts with traditional gender role ideologies and may undermine husbands' status in the marriage. Men who retired in marriages with a non-employed wife showed few depressive symptoms in the first months of retirement but reported more depressive symptoms after one year. These results indicated the presence of a honeymoon phase in early retirement followed by a more difficult adjustment period. In contrast, spouses' joint retirement had a beneficial effect on recently retired and longer-retired men, but only in couples who enjoyed joint activities. Recently retired wives reported fewer depressive symptoms if they retired jointly with a spouse or if the husband remained employed. Wives reported more depressive symptoms only if their husbands retired before the wives themselves.

Several studies indicate that being married and having a high-level of marriage satisfaction are predictors of well-being in retirement (Atchley, 1992; Calasanti, 1996; Reitzes, Mutran, \& Fernandez, 1996), but marriages with high levels of conflict 
contribute to reduced levels of well-being in retirement (Bosse, Levenson, Spiro, Aldwin, Mroczek, \& Vellas, 1992). These results suggest that marriage plays an important role in retirement well-being. In some cases where well-being is compromised by health problems, the spousal relationship may take on a new, caregiver/care recipient dynamic. This new dynamic can have significant effects on the well-being of both partners.

\section{Well-Being and Caregiving}

Moen (1996) considered the nature of post-retirement work roles in her examination of gender, retirement adjustment and well-being. Using the life course model, Moen considered gender to be a key factor in shaping the life course of older adults in retirement. She found that women are more likely to volunteer, to be caregivers and to have close ties. Women were also more likely to be burdened by these close ties and were more negatively affected by stress throughout adulthood. The finding that women bear the majority of caregiving burdens may explain why occupying multiple roles has more benefits for men than women (Barnett \& Baruch, 1985; Thoits, 1986). Men may benefit from occupying multiple roles more because those roles are less likely to include the demanding task of caregiving.

In an earlier study by Moen, Robison, and Fields (1994), caregiving was found to be positively associated with mastery in female caregivers in their 50's and early 60 's. In many cases, caregiving duties are performed in conjunction with full or parttime work (Ruhm, 1996). For women in their late 60's and 70's, however, caregiving was not positively associated with mastery. Moen et al. attributed this shift to 
caregiver concerns about their own health and future ability to provide care. These concerns may be moderated by the amount of social support available. Social support has been shown to buffer stress in older adults (Cutrona, Russell \& Rose, 1986).

\section{Well-Being and Social Support in Older Adulthood}

The concept of social support is plagued by issues regarding lack of consensus in its definition, operationalization, and measurement -- the same issues that surround the concept of well-being, as discussed earlier. Measures of social support can include structural features, such as size and composition of the network, frequency of interaction, quality and content of support, and perceptions of the adequacy of support (Siebert, Mutran, and Reitzes, 1999). These measures have not been standardized and, as a result, recommendations are frequently made for further specification (Dean, Matt $\&$ Wood, 1992).

Most scholars agree that social support is an important factor in well-being. Research frequently has found social support to be an important predictor of wellbeing (Berkman \& Syme, 1979; Carstensen, 1991; Forster \& Stoller, 1992; Minkler \& Langhauser, 1988). Several studies have found that positive social support has a protective and buffering effect relative to life stressors (Antonucci, 1991; Cutrona, Russell \& Rose, 1986; Krause, 1987). Good social relationships, in particular, the inclusion of at least one confidante in an individual's social network, have also been a key predictor of well-being (Lowenthal \& Haven, 1968). Friends appear to be a more important source of social support than family for older adults (Larson, Mannell, \& 
Zuzanek, 1986; Lee \& Sheehan; 1989, O’Connor, 1995). Variations in amounts and types of social support by gender have been found in the research as well.

\section{Well-Being, Social Support and Gender}

Social support differs by gender, according to findings from various studies. Women tend to have more extensive support networks, to provide and receive more support and to be more satisfied with their friendships (Field \& Minkler, 1988;

Siebert, Mutran, \& Reitzes, 1999, citing Acitelli \& Antonucci, 1994). Consistent with findings linking well-being with positive social support, women who have more frequent and a greater variety of social contact were found to have been more satisfied with their retirement than those with less social contact (Reeves \& Darville, 1994). Antonucci and Akiyama (1991) found men typically receive more support from spouses and less support from other family and friends. Richardson and Kilty (1991) found gender differences in mental health after retirement, with an increase in drinking problems and psychological anxiety for both men and women. Retired women in the study were found to suffer from anxiety more than men. Physical and mental health are key predictors of well-being in any life phase; however, because some retirees retire for health reasons, physical and mental health are particularly salient predictors of retirement adjustment and well-being.

\section{Well-Being, Retirement Satisfaction and Health}

Well-being is closely associated with health; it is difficult for one to exist without the other. For older adults, however, the literature reveals some contradictions relative to health, well-being and retirement satisfaction. Most early research on 
retirement found that being retired had no deleterious effects on either physical or psychological health; most retirees said they were satisfied with their retirement, and some even reported better health (Atchley, 1976; McGoldrick \& Cooper, 1988); poor physical health, however, is often a reason for retiring (Anderson \& Burkhauser, 1985; Chirikos \& Nestel, 1989; Palmore, Burchett, Filenbaum, George, \& Wallman, 1985). The latest study to be conducted on the direct effect of retirement on health was conducted in 1983 by retirement researcher David Ekerdt. Ekerdt's findings corroborated those of earlier studies, which found no direct link between retirement for health reasons and mortality or even health decline (Eisdorfer \& Wilkie, 1977; MacBride, 1976). The results from these studies suggest that some retirees retire in good health and, some retire in poor health, but retirement itself does not appear to influence health negatively.

As noted earlier, life satisfaction is considered an indicator of well-being. In a study of 99 frail older adults, four significant predictors of life satisfaction were found: perceived physical health, social support, emotional balance, and locus of control (Abu-bader, Rogers, \& Barusch, 2002). Perceived physical health was the most important predictor of life satisfaction, explaining $14 \%$ of the variance in life satisfaction in the multiple regression analysis. Over twice as much of the variance was explained by perceived physical health as compared with other predictors.

Frazier (2002) examined the ways in which perceived control over health may differ between older people $(\mathrm{N}=30 ; 50 \%$ female; average age $=68.6$ years $)$ living with a chronic illness (Parkinson's disease) in comparison to a group of relatively 
healthy older adults $(\mathrm{N}=30 ; 70 \%$ female; average age $=73.2$ years). Sense of control over health was examined to determine if the relationship between control and possible selves differed between groups. Possible selves were defined as the individual's expectations for the future and included what a person hopes to become, expects to become, and fears that he or she might become. Findings revealed that the relationships between possible selves and health locus of control were different between the groups, with healthy adults reporting a greater sense of internal locus of control over possible selves. Parkinson's disease patients were more likely to attribute control to powerful others in relation to their possible selves. These results suggest that personal control is correlated with health, and both are predictors of well-being. In addition, gender differences in health problems may result in different levels of retirement adjustment and well-being.

\section{Well-Being, Retirement Satisfaction, Health and Gender}

In a study of health conditions and perceived quality of life in retirement, Dorfman (1995) looked at two major sets of specific health conditions: (1) life threatening (e.g., heart disease, cancer, diabetes) and (2) non-life threatening (e.g., vision and hearing impairment, arthritis, incontinence) and their relationship with measures of satisfaction with retirement. The study did not investigate whether retirees retired because of the stated health conditions. Not surprisingly, retired participants with life-threatening health conditions were less likely to feel satisfied with retirement. A surprising finding was that having cancer showed no effect on retirement satisfaction. There are a number of possible explanations for this finding, according to 
Dorfman. One possibility is that some respondents were in complete remission or perhaps cured of their cancers at the time of the interviews. Another possibility is that some cancers that are amenable to control rather than cure; for example, lymphoma, may not interfere greatly with lifestyle.

Urinary incontinence showed no effect on retirement satisfaction, either. It may be that recent improvements in the treatment of urinary incontinence, including drugs, surgical treatment, and exercise and the availability of water-retaining undergarments, may mitigate the effects of urinary incontinence on lifestyles in later life, at least relative to more serious health conditions.

The study did find strong gender differences in the health problems which interfered with retirement satisfaction, however; among life-threatening conditions, only heart disease contributed to dissatisfaction with health for both sexes. It was the strongest predictor for men, closely followed by stroke. For women, who are typically healthier than men in older adulthood (Gold, Malmberg, McClearn, Pedersen, \& Berg, 2002), arthritis, a non-life threatening disease, was the strongest predictor of dissatisfaction with retirement (Dorfman, 1995).

Ozawa and Law (1991) examined health and retirement from a different angle: to what extent does health in later life depend on lifestyle factors such as education and income, levels of stress over the life course and access to medical care? The investigators found an inverse relationship between lifetime earnings, level of education, number of marital disruptions, and health problems in later life. In general, Ozawa and Law found that lower lifetime earnings were related to greater health 
impairments and functional limitations. The higher levels of health impairment and functional limitation among respondents' with lower income may be linked to their inability to pay for the health care services necessary to treat and manage their health conditions. Nonwhite workers tended to be significantly less healthy than white workers, and nonwhite workers who retired early tended to have more health problems. Therefore, nonwhite workers were more likely than white workers to face additional cuts in retirement benefits because of early retirement. Interestingly, the number of children raised had no significant effect on female respondents' health conditions but did have an effect on men's functional health limitations, with more children raised resulting in higher rates of functional limitation for men. The authors could not offer an explanation for this effect.

Instability in the retirement transition, characterized by moves in and out of the labor force prior to retirement, appears to have an adverse effect on the health of retirees (Marshall, Clarke \& Ballantyne, 2001). These findings are consistent with those of Ozawa and Law (1991); higher levels of income and being married were associated with fewer negative effects on health.

Matthews and Brown (1987) argued that the impact of retirement as a critical life event is less critical than previous research would indicate, particularly for women. They found that, as the number of life events increased, the more likely men were to report negative effects of retirement; the opposite was true for women. The authors found health to be the most significant predictor of retirement satisfaction for women, and both health and work saliency were important predictors for men. Life 
satisfaction was higher for older women who were currently employed than for either homemakers or retirees, who had nearly identical life satisfaction scores. The most significant predictors of life satisfaction for both homemakers and retirees were, in order of importance: (1) high levels of leisure activity participation, (2) high levels of income, and (3) low levels of health problems. For older working women, however, income and health problems had some effect on life satisfaction, but leisure activity did not. Another study by Ekerdt, Bossé and Locastro, (1983), showed that retired individuals sometimes report improvements in their (subjectively rated) health status following retirement; functional health may be enhanced after retirement due to reductions in stress, even if the improvement cannot be verified medically. A particularly strong predictor of well-being in retirement, to be discussed in the next section, is income. Higher levels of income are associated with higher levels of wellbeing.

\section{Well-Being and Income in Retirement}

Today's older population has a higher annual income, on average, than the previous generation in the U.S. In 1959, 35 percent of persons age 65 or older lived in families with incomes below the poverty line; in 1998, the percentage of the older population living in poverty had declined to 11 percent, according to the U.S. Census Bureau, Current Population Survey Reports (Olson, 1999). Among the elderly who are

living in poverty, poverty rates are higher for women (13 percent) than among men ( 7 percent) and among the non-married ( 17 percent) compared with the married ( 5 percent) (Olson, 1999). 
A review of the literature on income and well-being by Serow, Sly and Wrigley (1990) found consensus among scholars that having adequate income is an important predictor of well-being in retirement. Also, Haug, Gratton, and Jones (1992) found that individual health ratings and family income were important predictors of adaptation for each spouse in a study of health and retirement adaptation among women and their husbands. Generally, gender is not a factor in the relationship between income and well-being although a few exceptions were found in the literature, as described below.

\section{Well-Being, Income and Gender in Retirement}

A longitudinal study of gender differences in mental health before and after retirement by Richardson and Kilty (1995) found minimal effects for gender, although a certain subgroup, women who had worked at low status jobs, had a more difficult time in coping with retirement. Most observed changes in well-being seemed to derive not from gender, but from percentage of income retained after retirement, occupation status and age (Richardson \& Kilty, 1991). An analysis of pre-retired and retired women's attitudes toward retirement found both groups agreed that having activities and interests was the most essential factor for successful retirement, followed by adequate income and good health (Gigy, 1991).

Stone (1984) found the negative impacts and subjective reports of impaired well-being in retirement were partly explained by economic well-being, particularly perceived level of income adequacy and changes in this subjective assessment. Beck 
(1982) found income and health were important factors in personal happiness, and these factors were also important in respondents' subjective evaluation of retirement. An interesting anthropological study examined the lifestyles of 154 wealthy men and women living in an exclusive retirement community in the northeastern United States (Free, 1995). The author, an anthropologist who had previously studied lifestyles of affluent elderly in France, conducted fieldwork at the Hermitage, an elite retirement home in Connecticut for women and men aged 65 and older, financially solvent, and cognitively and physically competent enough not to require nursing care. The most impressive and ubiquitous characteristic of residents at the Hermitage was their positive sense of well-being. This sense of well-being was explored in relation to residents' use of personal sense of importance and their identity as a wealthy person to ensure administrative, social, domestic, and personal care. The study uncovered the ways in which these affluent residents use their social status and other resources (affluence, gender, sex, and power) to "cover the disparities of being culturally and biologically old," (Free, 1995, p. ii).

As previously noted, women are more likely than men to experience poverty in older adulthood. Retirement means a dramatic decrease in income for most women, particularly unmarried women, few of whom receive adequate pension benefits (Stanford \& Usita, 2002). Perkins (1992) explored the personal and social effects of retirement on women and suggested the underlying cultural dynamics of ageism and sexism have contributed to a "repulsion" of older women as well as the feminization of poverty (Perkins, 1992). The link between traditional female occupations and lower 
income levels contributes to the dynamics of ageism and sexism in female retirement, according to Perkins. However, the effects of occupation history, i.e., having held a professional or non-professional occupation, are an understudied topic.

One context in which to think about the links between income and well-being in older adulthood can be drawn from work by the classical French sociologist Emile Durkheim on anomie. Anomie, simply defined, is a state where norms (expectations for behaviors) are confused, unclear or not present (Orcutt, 1983). Anomie is the term Durkheim used to conceptualize his ideas about the estrangement of the individual from meaning derived from his or her civic engagement. Anomie results from the loss of social control which regulates an individual's behavior. When people's identity, self-concept, structures of meaning are challenged, their risk of experiencing anomie increases.

Anomie, taken to its conclusion, results in the act of suicide (Durkeim, 1933; Orcutt, 1983). In historical data on suicide rates in Europe, Durkheim (1933) found that sharp changes, either increases or decreases, in the economic prosperity of a society were associated with increasing rates of suicide. Suicide rates were lowest during times of economic stability. Durkheim identified three different types of suicide: Egoist suicide, exemplified by a sharp decline in health and medical institutionalization, i.e., the separation of a person from fellow man; Anomic suicide, or separation of the individual from society, as may be the case in rapid downward or upward economic mobility; and Altruistic suicide, in which the individual is subjected to too much social control. This type of suicide is exemplified by radical religious 
groups or individuals who sacrifice their lives for their beliefs (Thompson, 1985).

Durkheim believed that wealthy people were more susceptible to anomie because they live with the illusion that money makes them independent. Poor people have a greater immunity to anomie because they have limited resources and less to lose. In accordance with Durkheim's conceptualization of anomie, the maintenance of one's standard of living is important despite one's economic class. Wealthy retirees will maintain well-being as long as they maintain their economic status. Similarly, the ability to maintain one's standard of living may contribute to well-being in those who have fewer economic resources. Therefore, maintenance of standard of living may be an important predictor of retirement adjustment and overall well-being, regardless of the amount of financial wealth.

\section{Well-Being and Occupational History in Retirement}

A review of the literature uncovered few articles on the relationship between professional versus non-professional work histories and well-being in retirement. The lack of research in this area points to opportunities for research on how occupational history influences well-being in older adulthood.

Some assumptions may be made based on the links between income and wellbeing, as professional occupations typically command more income than nonprofessional occupations. Thus, given the aforementioned findings that higher levels of income are generally associated with higher levels of well-being, a professional work history would be expected to be associated with greater well-being than a nonprofessional work history. 
In an early dyadic study of couples and predictors of well-being, Stull (1988) found occupation to be a non-significant predictor of happiness before and during retirement for men; information about wives' professional history was not collected. Both spouses provided ratings of their happiness and health, as well as information about social contacts, income, the husband's occupation, and the wife's employment status. Significant predictors of happiness for husbands were the husband's health, household income, and the wife's happiness. Husbands' happiness was not related to their occupation or interaction with family. The only significant predictors of wives' happiness was their own health, and their husband's happiness.

Richardson and Kilty (1991) found occupational status was the most important factor influencing satisfaction with retirement. Respondents in the higher-status occupations had an easier time coping with the first year of retirement (Richardson \& Kilty, 1991). Because higher-level occupations typically demand higher levels of educational attainment, the effect of education on well-being in retirement was hypothesized to be another strong predictor in the relationship between retirement adjustment and well-being.

\section{Well-Being and Educational Attainment in Retirement}

According to a review by Feinstein (1993), post-secondary educational attainment is agreed upon by scholars to predict general well-being. However, few studies exist regarding the extent to which economic well-being after age 65 is associated with educational attainment. One study by Hammonds-Smith, Courtless, and Schwenk (1992) grouped respondents over age 65 into four categories of 
educational attainment. Almost 29 percent had 8 years or less of education, 19 percent had some high school, 27 percent had graduated from high school, and 25 percent had attended college and may have graduated. The authors found that those with lower educational attainment had less annual income than those with higher levels of education. Income level increased as educational level increased. The least educated group of older adults received 62 percent of their income from Social Security; the most educated group received 32 percent. Those with higher levels of education were more likely to be employed and received 27 percent of their income from earnings, compared with 19 percent among those with 8th grade or less education. The group with the lowest educational level spent more on health care than on transportation; the group with the highest educational level spent more on transportation than on food or health care.

A study by Crystal, Shea, and Krishnaswami (1992) examined determinants of economic well-being among young adult, middle-aged, and older men and found socioeconomic stratification is established early in the life course and continues into the later years. The results suggested that, through its effects on occupational status and other aspects of employment history, education has effects on economic wellbeing that are at least as strong after age 65 as before. Respondents with more education had access to higher-status jobs, were able to continue to work longer, and were more likely to be self-employed, all factors which tended to increase adjusted income. The overall result is a strong association between education and economic 
well-being that persists in the later years, and that those with higher levels of education and economic well-being may choose to work past retirement voluntarily.

\section{Well-Being and Post-Retirement Work}

Post-retirement employment is not uncommon, according to the findings from the Cornell Retirement and Well-Being Study (Moen, Erickson, Agarwal, Fields, \& Todd, 2000). The study found that 44 percent of retirees sampled reported working for pay at some point after retirement. Men from this study were more likely to work for pay than women ( $49 \%$ vs. $39 \%$ ), and more retirees from the younger cohort were likely to work post-retirement than those from older cohorts. Wide variability in the amount of hours worked was found among respondents engaged in post-retirement work, ranging from 1 to 98 hours per week, and from 2 to 52 weeks a year. Nine out of 10 respondents who continued to work after retirement (89\%) said they worked after retirement to keep active. Other common responses were: "had free time" (73\%), "to maintain social contacts" (68\%), "desire for additional income" (63\%), "not ready to retire" (58\%), and/or "to maintain their profession or professional contact" (56\%). About 2 in 5 respondents (41\%) said a reason for post-retirement work was for additional income.

These findings, particularly the finding that $68 \%$ of retirees work to maintain social contact, suggest that work is an important conduit for social integration and social support. Social integration appears to contribute to mental health, as discussed previously, as well as to functional health and longevity for both men and women (Berkman \& Breslow, 1983). 
The findings on the relationship between life satisfaction and employment among older adults are inconsistent. Two studies found post-retirement age employment to be positively related to life satisfaction (i.e., Aquino, Cutrona, \& Altmaier, 1996; Kim \& Feldman, 2000). One study found that paid employment was not positively associated with life satisfaction for people aged 60-96 (George, Okun, \& Landerman, 1985). A study which sampled employed and retired men and women between the ages of 50 and 74 (Warr, Butcher, Robertson \& Callinan, 2004) found higher levels of well-being in individuals below the age of 65 who had retired, and lower levels of well-being in individuals below the age of 65 who were still employed. After the age of 65, however, employed individuals reported higher levels of wellbeing. Herzog, House and Morgan (1991), however, found that life satisfaction was unrelated to paid employment in older adults. Respondents working the hours they desired in the study by Herzog and colleagues tended to have higher levels of health and well-being. Older persons working in psychologically stressful jobs had more depressive symptoms and unhappiness than those in jobs with relatively little stress or many rewards.

Choi (2001) analyzed the effects of post-retirement employment on older women's life satisfaction by comparing those who continued to work or who (re)entered the labor market with those who did not engage in paid work after receiving their first Social Security benefits. The findings showed that post-retirement employment in itself does not contribute to older women's life satisfaction, but financial resources, and especially the older women's concerns about their own 
financial situation, are potent determinants of their life satisfaction. Choi (2001) found that returning to work did not increase life satisfaction for women. These findings suggest that for some women, returning to work may help improve life satisfaction, but the improvement is due to increased financial security and not work itself. Another potential benefit of post-retirement work is that work offers an opportunity for role fulfillment, and individuals appear to fare better when they have multiple roles (Thoits, 1983). It is possible that post-retirement employment adds to well-being by providing a role; however, not all roles contribute to well-being in retirement. The ability to choose whether one retires or continues to work regardless of age appears to be a more important predictor of well-being.

\section{Well-Being and Voluntary vs. Involuntary Retirement}

American workers accumulate a significant proportion of the wealth that will finance their retirements in the decade preceding retirement (Mitchell \& Moore, 1998), and unemployment during this period appears to have a significant negative effect, at least for women. Specifically, Marshall et al. (2001) found the effects of unemployment periods on level of stress were significant for women but not for men. This may be associated with the finding that in general, women accumulate fewer resources for retirement than men, and therefore, unemployment before retirement may be more disruptive for women (Choi, 2001). For example, Szinovacz's (19861987) sample of women from mid-level to lower-level occupations were negatively influenced by involuntary retirement due to the general economic hardship that 
followed early job loss, and in particular, the interruption of financial planning for retirement.

As described below, a strong predictor of well-being in retirement is the circumstance underlying the retirement event, that is, whether retirement is voluntary or involuntary. This is an important distinction regarding the retirement event which appears to have a strong relationship to overall well-being.

Retirement circumstance, for example, appears to influence retirement satisfaction regardless of age of retirement. Herzog, House, and Morgan (1991) found that retirement had negative effects only when persons were forced to retire against their personal preferences. This finding supports previous ones that involuntary early retirement is associated with lower levels of retirement satisfaction than voluntary retirement (Isaksson \& Johansson, 2000; Kim \& Moen, 1999; Kimmel, Price \& Walker, 1979; Knesak, 1991).

A study by Palmore, Fillenbaum, and George (1984) examined the problems of early retirement (before age 65) as compared with retirement after age 65 . The authors found early retirement to be associated with less satisfaction than late retirement among their all-male sample, but they attributed these findings to an overrepresentation of health problems among early retirees. A study by Beck (1982) of adjustment to retirement and satisfaction with retirement among men found that the loss of the work role did not have a significant negative effect on personal happiness. However, men who retired early, whether voluntarily or involuntary, were significantly less likely to be happy with their lives than men still in the labor force. 
A recent study by Szinovacz and Davey (2004) suggested that depressive symptoms increase when retirement is abrupt and perceived as too early or forced. Women retirees who stopped working and who were either forced into retirement or who thought their retirement occurred too early reported significantly more depressive symptoms with increased limitations of spouses' activities of daily living (ADLs). The same effect was not found for men. The opposite effect was found for retirees who retired on time; depressive symptoms decreased with increasing limitations in spouses' ADLs. These results emphasize the importance of retirement circumstance on postretirement well-being. They suggest that retirement circumstances and marital contexts, such as spouse's disability, influence postretirement well-being, and these effects differ by gender (Szinovacz \& Davey, 2004).

Other studies (McGoldrick \& Cooper, 1988; Williamson, Rinehart, \& Blank, 1992) have shown generally higher levels of satisfaction among younger, voluntary retirees. In a study of individuals' assessment of satisfaction with, and perceptions of the retirement experience, Floyd, Haynes, Doll, Winemiller, and Lemsky (1992) found that those retirees who experienced pressure from an employer to retire reported the highest levels of negative affect at the onset of retirement. Floyd et al. (1992) reported that this group rated having freedom and control less positively and experienced fewer positive long-term changes from pre to post-retirement. The voluntary retirees in this study reported comparatively higher rates of satisfaction with retirement. These works underscore the importance of choice in employment status in older adulthood. 
Education and voluntary/involuntary retirement. Some older adults, particularly those who possess higher levels of educational attainment, voluntarily continue to work well past retirement age. A study by Hardy (1984) found that higher educational levels were associated with a decreased likelihood of retirement among white-collar workers. Possession of a college degree reduced the likelihood of retirement among professional and technical workers, while possession of a high school diploma reduced the likelihood of retirement among sales and clerical workers (Hardy, 1984).

Gender, pre-retirement attitudes and voluntary vs. involuntary retirement. Positive pre-retirement attitudes were found to be important for an overall positive retirement experience. Erdner and Guy's study (1990) found that female teachers with stronger work identities had significantly more negative attitudes toward retirement than those with weaker work identities; this difference remained significant when controls were introduced for years of teaching experience, expected age of retirement, and attitude toward work. Due to the higher education of women now in the workforce, Ernder and Guy concluded that modern career-oriented women will face problems similar to those faced by men in transition to retirement. They will still have needs for prestige, achievement, and recognition that must be met (Erdner \& Guy, 1990).

Floyd et al. (1992) discovered that the women in their study of 402 retirees not only anticipated less satisfaction in retirement, but also experienced more initial stress at the time of retirement. Isakson and Johansson (2000) found that women were more 
likely to choose voluntary early retirement than men and were more satisfied with the outcome than men. However, forced retirement is more negative for women, according to findings by Riddick (1986). Women with continuous professional work histories may enter retirement with apparent ease, yet experience difficulty adjusting to the loss of their professional role. Further research investigating the transition from professional status to retirement status among women is needed (Price, 2000).

\section{Summary of the Literature}

This review of the literature has demonstrated that some retirees experience more difficulty with the transition to retirement than others. Specifically, three crossgender categories of retirees appear to have the most difficulty with the retirement transition: (1) retirees with strong work identities who have not found ways to substitute work-related goals; (2) retirees who are forced to retire early; and (3) retirees with health problems.

With regard to gender and retirement adjustment difficulties, this review demonstrated that men whose wives continue working after they themselves retire adjust more poorly than men whose wives are already retired or have been housewives. Housewives sometimes experience difficulty adjusting to their husbands' retirement because of his interference in their daily routines. Women with stronger work identities had more difficulty with retirement adjustment.

Overall, the literature revealed that women experience more depressive symptoms in retirement, but no clear pattern was found regarding which gender has

more difficulty with retirement adjustment. In general, retirees with health problems 
had more difficulty with retirement adjustment, although perceived control over health problems seems to mediate this relationship in some cases. Other factors which appear to predict a positive retirement adjustment include an active post-retirement lifestyle, higher levels of personal control, marital satisfaction, social support, health, income and a voluntary retirement. Post-retirement employment also seems to contribute to adjustment and well-being in retirement.

These factors appear to predict individual adjustment to retirement which, in turn, predicts spouse's adjustment to retirement. Evidence of crossover effects among couples exists in the literature with regard to depression, distress, negative events and strains. These findings highlight the possibility of positive or negative synergy in crossover effects and retirement adjustment. Our understanding of how retirement impacts the lives of individuals has grown over the past 20 years. We know that men and women experience retirement both differently and similarly, and that the retirement transition can be a time of enhanced well-being or a time of psychological distress. Gaps in research concerning couples' adjustment to retirement remain, however; we know little about retirement and its effect on the subjective well-being of husbands and wives. The primary objective of the present study was to advance knowledge of issues facing couples as they adjust to retirement with synchronous interactions and influences, otherwise known as crossover, contagion, or partnereffects. 


\section{Theoretical Framework}

\section{Family Systems Theory}

The concept of the couple as an interdependent unit is central to this study. Family Systems Theory, which views the family as more than just the sum of its parts, was used to guide the research.

Contemporary systems theories about families are derived from General Systems Theory, which is both a transdisciplinary field of study and a theoretical framework in which various micro level approaches are known as "systems theories." Systems theorists attempt to explain the behavior of complex, organized systems of all sorts, from thermostats to families. Systems thinking is a way of looking at the world in which objects are interrelated with one another (Aronson, 1998).

Family Systems Theory is an orientation that developed out of general systems

- theory to examine how between-family, within-family, and within-individual differences emerge from family interactions in adulthood. Family systems theory is centered on the idea that families are units with values, beliefs and rules that shape, and are shaped by, individual members over time (Duhl, 1983; Hoffman, 1981). According to Morgaine, $2000, \uparrow 2$, the following are components of Family Systems Theory. Families have:

- interrelated elements and structure. The elements of a system are the members of the family. Each element has characteristics; there are relationships between the elements; the relationships function in an interdependent manner 
- interact in patterns. There are predictable patterns of interaction that emerge in a family system.

- have boundaries and can be viewed on a continuum from open to closed. No family system is completely closed or completely open.

- function by the Composition Law: the Whole is More than the Sum of Its Parts. Every family system, even though it is made up of individual elements, results in an organic whole.

- use messages and rules to shape members. Messages and rules are relationships agreements which prescribe and limit a family members' behavior over time.

- have subsystems. Every family systems contains a number of small groups usually made up of 2-3 people. The relationships between these people are known as subsystems, coalitions, or alliances.

Family systems theory considers the external and internal events that take place within a family to have circular causality. A singular action by a family member will have an effect on the other family members, and their responses will be reciprocal to that initial actor and the family's overall response (Nichols \& Everett, 1986). This concept is compared allegorically to a mobile in a quote by family therapy pioneer, Virginia Satir, in her book, Peoplemaking (1972):

In a mobile all the pieces, no matter what size or shape, can be grouped together in balance by shortening or lengthening the strings attached, or rearranging the distance between the pieces. So it is with a family. None of the 
family members is identical to any other; they are all different and at different levels of growth. As in a mobile, you can't arrange one without thinking of the other...[T]he strings are...rules and communication patterns. (Satir, 1972, pp. 119-120).

Although family systems theory has traditionally been used in studies of families with young children, it offers a useful theoretical framework for examining the research and hypothesis for the present study. The family life cycle model is premised mostly on childrearing transitions (e.g., marriage, childhood, empty nest) yet continues to exert influence over day-to-day behaviors and continues to guide development (Kreppner \& Learner, 1989). Fingerman and Berman (2000) argue that the family as a social context has not been adequately studied in gerontological literature and that a family systems approach to studying older adults may improve our understanding of adult development and functioning. 


\section{Research Methods}

\section{Hypotheses}

Two general types of hypotheses are tested in the present study: actor-effects hypotheses and partner-effects hypotheses. Actor effects refer to the individual and the effects of his or her own independent variables on his or her own dependent variables. Partner effects refer to the effect of an individual's own independent variables on a partner's dependent variables. The idea that these effects can cross over from an actor to a partner is central to this research.

As mentioned previously, retirement from full-time employment can be a major life transition requiring a period of adjustment due to the likelihood that roles, relationships and daily routines may change significantly with retirement, along with concurrent changes in income, and in some cases, health. These transitions may also bring about changes in the way people evaluate their subjective well-being. As a result of these changes, individuals may experience an increase or decline in life satisfaction or well-being. Given these considerations, retirement adjustment is a specific context in which levels of well-being may vary, and depending on the outcome of that specific context of well-being, retirees may experience high or low levels of overall wellbeing. Therefore, in the development of the following research hypotheses, retirement adjustment was viewed as an important context-specific process which contributes to, or detracts from, one's overall state of well-being. A central conceptualization behind all five hypothesis is that well-being in retirement is dependent upon one's adjustment to retirement. Specifically, the level of one's retirement adjustment, i.e., positive or 
negative, will predict one's own well-being in retirement and possibly a partner's well-being in retirement.

This study used couple-level, dyadic data to examine actor and partner effects in the relationship between retirement adjustment and well-being in retirement as predicted by health status, income, education, retirement circumstance (forced, not forced), income, gender, occupation, and current work status (fully retired or were fully retired and returned to work part or full-time). The research used regression analysis and structural equation modeling to examine both partner and actor effects, between and within dyads.

\section{Actor-Effects Hypotheses}

H1: Husbands and wives differ in respect to their levels of retirement adjustment and well-being. The literature is inconsistent with regard to gender and levels of adjustment. Some studies indicate that men experience higher levels of adjustment to retirement and have higher levels of well-being in retirement. Other studies indicate that women experience higher levels of retirement adjustment and higher levels of well-being in retirement.

H2: One's own health status and retirement circumstance (forced/not forced) are predictors of one's own well-being and are partially mediated by one's own retirement adjustment. Previous research has shown that health status is correlated with well-being, that is, good physical health is associated with higher levels of subjective well-being. Research has found lower levels of adjustment and well-being in retirement among those who are forced to retire. Forced retirement and health 
problems are predicted to lead to poor retirement adjustment, which in turns leads to lower levels of well-being. Therefore, it is hypothesized that the relationship between the two independent variables, health problems and forced retirement, and the dependent variable, well-being, is mediated by adjustment, as shown in Figure 1.

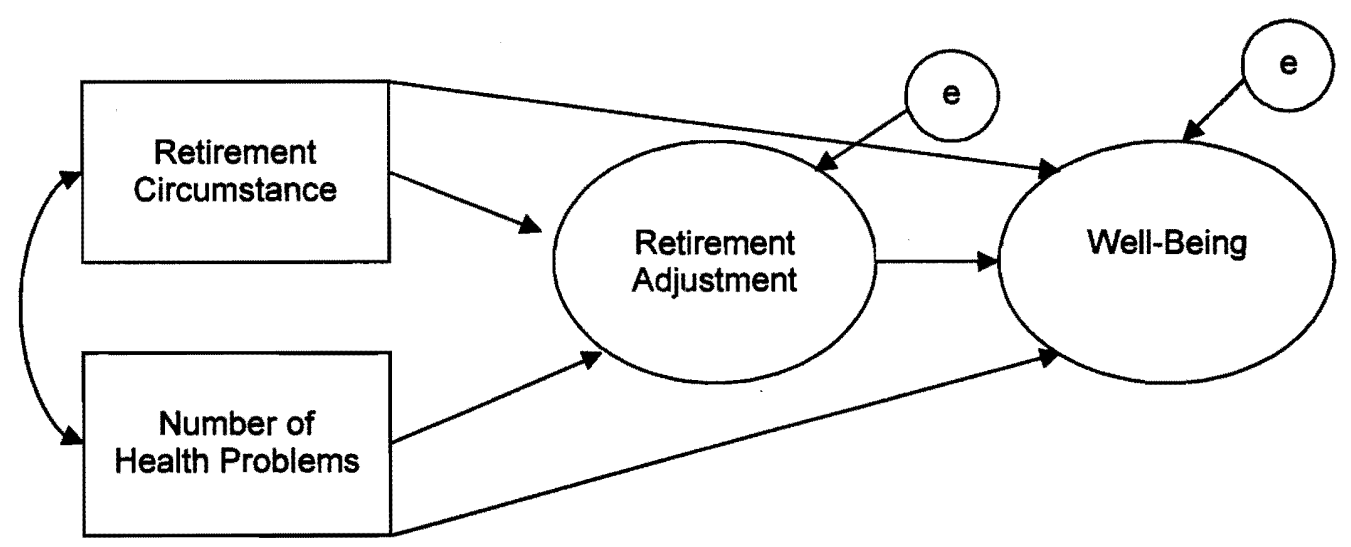

Figure 1. Conceptual structural equation model representing well-being as predicted by retirement circumstance and health.

Note: The boxes in this diagram represent the independent variables. The circles are latent constructs. Arrows represent relationships between variables.

\section{Partner Effects Hypotheses}

H3: An individual's retirement adjustment and well-being is influenced by his/her partner's retirement adjustment. The level of retirement adjustment of one spouse to retirement will be influenced by the other spouse's retirement adjustment. Prior research has established the non-independence of couple-level data (Kenny, 1996), with evidence of high correlation in responses within a couple, otherwise known as the partner effect (Kenny, 1996) or contagion effect (Bookwala \& Schulz, 1995). Simply 
stated, in dyadic data, the actor's response will be influenced by the partner (Kenny, 1996). Thus, it is predicted that the retirement adjustment of one spouse will significantly influence the partner's as shown in Figure 2.

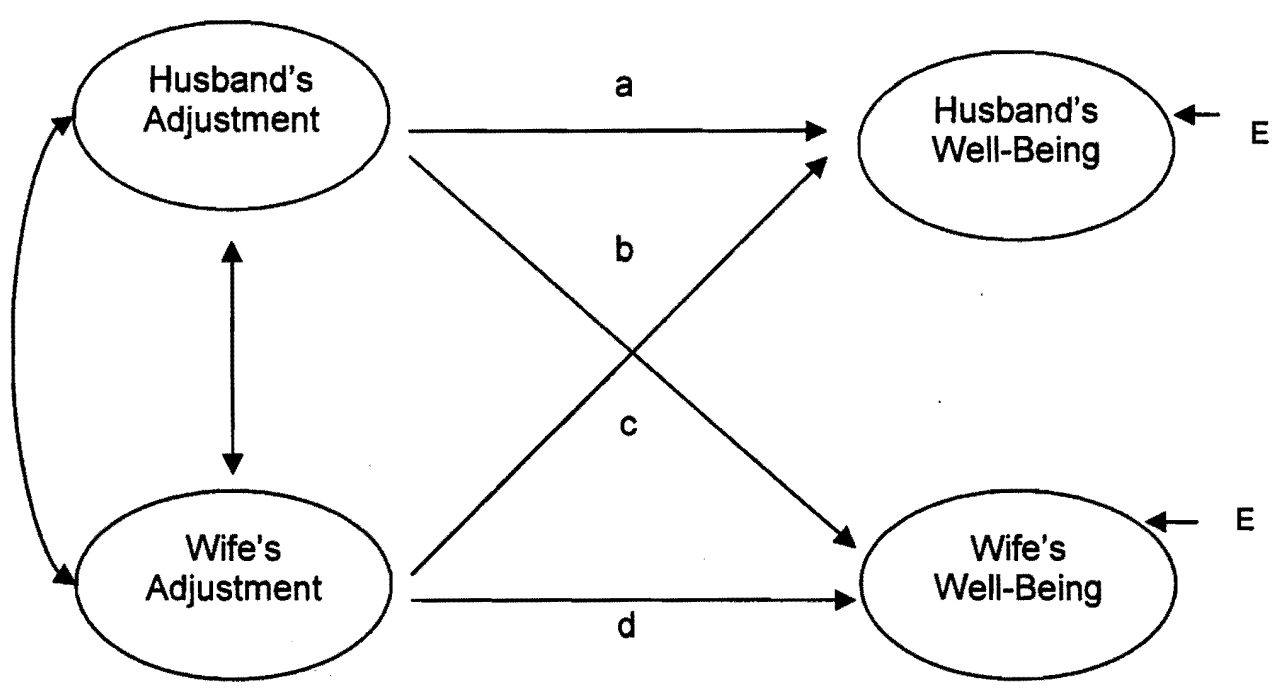

Figure 2. Structural equation model representing possible actor effects and partner effects in retirement adjustment and well-being.

H4: An individual's well-being is influenced by his/her partner's retirement circumstance. The spouse of an individual who was forced to retire will have lower levels of retirement adjustment due to the hypothesized partner effect (as shown in Figure 1). Low levels of individual retirement adjustment will predict low levels of individual retirement adjustment in partners. Conversely, high levels of individual retirement adjustment in one partner will predict high levels of individual retirement adjustment in the other. 


\section{Final Actor-Effect Hypothesis}

H5: Predictors of retirement adjustment and well-being for individuals will include health, education, income, a fully retired work status, and a non-forced retirement circumstance.

Higher levels of health, education and income, along with a fully retired work status and a voluntary retirement circumstance, will predict higher levels of retirement adjustment and well-being, as depicted in Figure 3. The literature found high levels of health, education and income to be positively related to retirement adjustment. A voluntary retirement circumstance was also found to positively predict retirement adjustment and well-being. Results were mixed on whether a fully retired work status or a part or full-time work status predicted retirement adjustment. The same relationships are predicted for both husbands and wives in this hypothesis. 


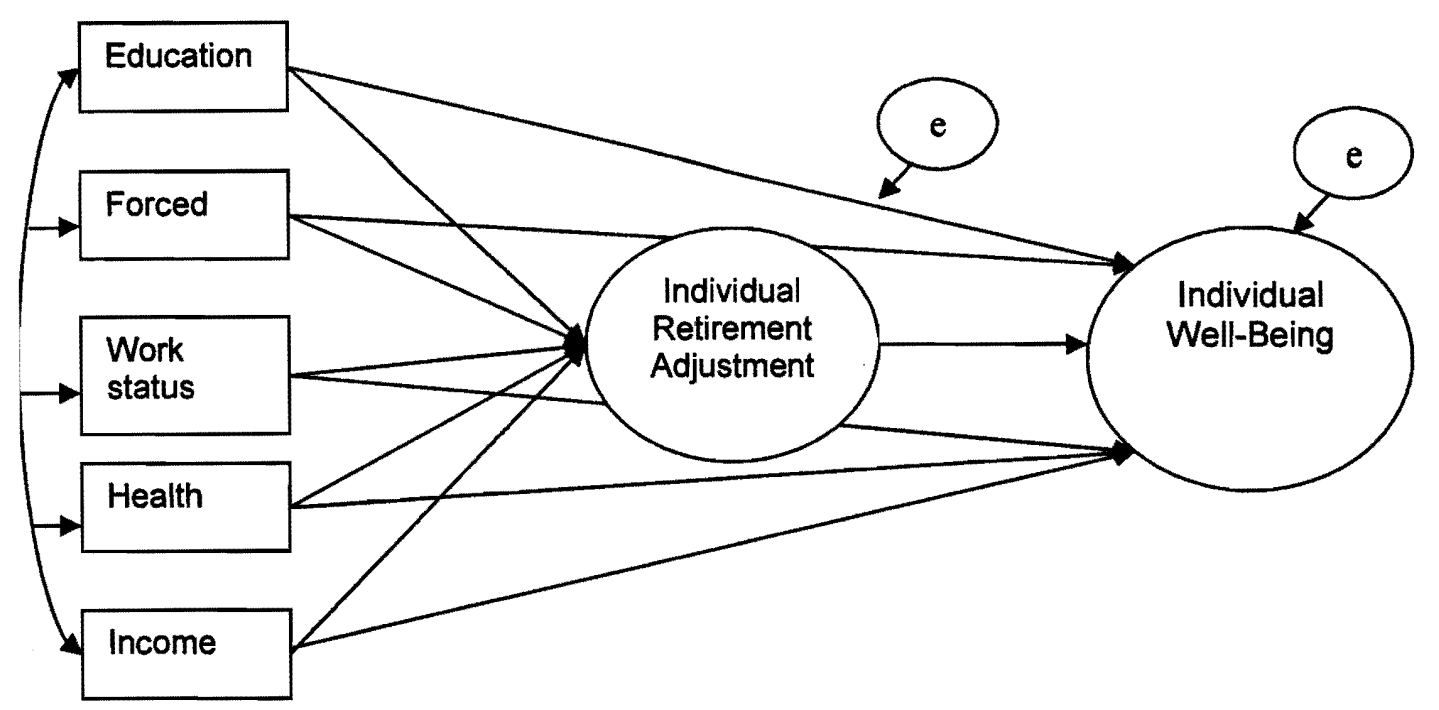

Figure 3. Conceptual structural equation model: predictors of retirement adjustment and wellbeing.

Note. The latent variable retirement adjustment is hypothesized to mediate the effect between the independent variables and the dependent variable, well-being.

\section{Design}

The basic design for this project was a within-subjects factorial design approach using secondary survey data. Hypotheses were analyzed using regression analysis and structural equation modeling. The survey collected data from 796 people, of whom 580 were members of married couples ( $n=290$ couples). Respondents were asked to choose from seven employment status options, including: (1) Retired, but returned to work part-time, (2) Retired, but returned to work full-time, (3) Still working for income - never retired, (4) Semi-retired -reducing my workload but not 
fully retired, or (5) Fully-retired - not working for any income, (6) Homemaker - no or minimal or outside employment, or (7) I don't fit into any of these categories.

For the purposes of this research, only couples in which both partners described themselves as either (1) Retired, but returned to work part-time, (2) Retired, but returned to work full-time, (4) Semi-retired - reducing my workload but not fully retired, or (5) Fully-retired - not working for any income, were selected for the analyses. Among 290 married couples, 183 couples met the retirement criterion and thus were selected for the present study. Couples who were not selected for the study sample were couples in which one or both members of the couple responded (3) Still working for income - never retired, (6) Homemaker - no or minimal or outside employment, or (7) I don't fit into any of these categories. Among the 290 married couples, 107 couples did not meet these criteria.

The data used to test the research hypotheses were from the Retirement Lifestyle Research Survey, conducted by Drs. Frederick Fraunfelder and James Gilbaugh in 2000. Responses were tested on two levels. Actor-level research hypotheses (Hypotheses 1,2 and 5) were tested using responses from individuals within a couple, and partner-level hypothesis (Hypotheses 3 and 4) were analyzed by utilizing responses from both members of each couple. A within-subjects data set, locating each husband's and wife's data on a single record, was constructed for the latter analyses. The partner responses were combined using syntax in the Statistical Package for the Social Sciences (SPSS) software. Given that couples' scores are 
assumed to be correlated (Kenny, 1996) structural equation modeling was used to partial out actor effects within couples (Kashy and Kenny, 1996).

\section{Original Sample}

The participants for the original study were randomly selected from among patients and spouses in a referral ophthalmology medical practice and a referral urology medical practice in the Portland, Oregon metropolitan area. Twelve hundred surveys were mailed to patients and their spouses with a letter from the investigators. A total of 796 patients and spouses (66\%) responded. The survey instrument was created by Drs. Fraunfelder and Gilbaugh. The survey collected self-reported data. Items were selected by the investigators based on their personal and professional interests in the nature of retirement and through an informal review of the literature to identify understudied topics regarding retirement. The purpose of the data collection effort was to identify the predictors of retirement success, and to develop a popular press book on the topic. The entire sample consisted of 395 males and 396 females and 5 individuals who did not indicate their gender. Surveys sent to the same household were given identical ID numbers followed by "a" or "b". Of the 796 returned surveys, 634 shared an ID number with one other respondent. Among those who shared an ID number with another respondent, 580 were married couples. The remaining surveys with shared ID numbers $(n=54)$ belonged to respondents who were not members of married couples.

The majority of participants were either fully (42.3\%) or partially retired (22.6\%). The remaining participants had not retired (16.2\%), reported their occupation 
as full-time homemakers $(17.9 \%)$, or chose a response indicating they did not fit these categories (.6\%). Three responses were missing (.4\%). Participants ranged in age from 34 to 97 , with a mean age of 71 , (standard deviation 11.97). The annual household income of most respondents was well above average, with a mean annual income of $\$ 100,000$ to $\$ 150,000$.

\section{Study Sample Selection Criteria}

For the purposes of the present study, all respondents needed to be members of a couple and to have retired at least partially at one time. First, only respondents who answered "married" $(n=290)$ or "unmarried w/ partner" $(n=0)$ in the item inquiring about marital status were selected. Second, only married couples who were fully retired or semi-retired or who had once been fully retired but then returned to work full or part-time selected for the final sample $(n=183)$ couples.

The survey, distributed in the spring of 2001, contained 67 closed-ended questions and one open-ended question. Of the 67 closed-ended items, 17 were dichotomous variables, 13 were interval variables, 32 were ordinal variables and 5 were nominal variables. Among the questions included were self-reported items concerning demographic characteristics such as age, gender, marital status, formal education, past and present occupation. The majority of the questions centered on respondents' attitudes and opinions toward retirement, their relative satisfaction with or adjustment to retirement, and their well-being. All had Likert-scale response options. Information was also collected concerning respondents' beliefs regarding the importance of several material, spiritual and physical aspects of retirement. Finally, 
some items inquiring about reproductive health and functioning were included. All variables for the present study were measured at the ordinal or interval level (the retirement adjustment, well-being, health status, and total household income variables) or through dichotomous measurement (gender, retirement circumstance, current work status and primary occupation designation).

The second criterion for inclusion of couples in the data analysis was employment status. For the purposes of this research, only individuals who had fully or partially retired were selected for analysis. Only those married couples in which both partners claimed to be fully retired, semi-retired or once retired but now working were considered candidates for the analyses $(n=183)$.

Descriptive information was prepared for husbands and wives, and paired comparisons of husbands' and wives' characteristics were conducted. The results are shown in Table 1. Husbands were significantly older than wives in this sample, $t(173)$ $=10.17, \mathrm{p}<.001$. Husbands reported significantly higher levels of education than wives, $\mathrm{t}(181)=9.14, \mathrm{p}<.001$, and were more likely to hold professional occupations, $t(180)=-10.35, p<.001$. Wives were more likely to have a fully retired work status, $\mathrm{t}(182)=3.88, \mathrm{p}<.001, \mathrm{p}<.001$. Wives reported significantly higher levels of spirituality than husbands, $\mathrm{t}(177)=-4.11, \mathrm{p}<.001$, and had significantly lower numbers of health problems than husbands, $\mathrm{t}(174)=2.21, \mathrm{p}<.05$. Wives reported less satisfaction with financial planning for retirement, $t(171)=2.11, \mathrm{p}<.05$, and husbands reported higher levels of stress handling ability, $t(174)=3.03, p<.01$. 
Nineteen husbands and 10 wives reported that they were forced into semiretirement or retirement (see Table 2). Among those respondents, seven husbands (21.8\%) and three wives (18.8\%) reported that they were forced to retire due to age, 12 husbands (37.5\%) and seven wives (43.5\%) reported that they were forced to retire due to sickness or disability, four husbands (12.5\%) and one wife reported a forced retirement $(6.3 \%)$ because their job had been eliminated. One husband $(6.3 \%)$ and one wife (3.2\%) retired to be a caregiver, and eight husbands (25\%) and four wives (24.8\%) retired for other reasons. The item in the survey allowed respondents to respond "yes" or "no" to one or more of these five reasons for a forced retirement, therefore, some respondents reported more than one reason for a forced retirement. 
Table 1. Descriptive Information for Study Sample (Means) and Overview of Results of Paired Comparisons between Husbands and Wives

\begin{tabular}{|c|c|c|c|c|c|c|c|}
\hline & \multicolumn{2}{|c|}{ Means } & \multicolumn{2}{|c|}{$S D$} & \multicolumn{2}{|c|}{$n$} & \multirow[t]{2}{*}{ Sig. } \\
\hline & Husbands & Wives & Husbands & Wives & Husbands & Wives & \\
\hline Age & 72.88 & 70.02 & 7.79 & 8.11 & 175 & 175 & *** \\
\hline Education ( 1 = did not complete high school, 6 = graduate degree) & 5.04 & 4.03 & 1.29 & 1.25 & 183 & 182 & *** \\
\hline Occupation $(1=$ professional, $0=$ non-professional $)$ & 1.83 & 1.10 & .94 & .31 & 181 & 181 & *** \\
\hline $\begin{array}{l}\text { Work status }(1=\text { semi-retired or retired but returned to work. } \\
2=\text { fully retired })\end{array}$ & 1.69 & 1.84 & .464 & .366 & 183 & 183 & $* * *$ \\
\hline $\begin{array}{l}\text { At the present time: "My religious belief or spirituality influences my } \\
\text { life." ( } 1=\text { not at all, } 2=\text { very large extent })\end{array}$ & 3.45 & $3 . .49$ & .42 & .69 & 181 & 178 & \\
\hline $\begin{array}{l}\text { At the present time: "I am adaptable or flexible when events or } \\
\text { circumstances change." ( } 1=\text { not at all, } 5=\text { very large extent })\end{array}$ & 3.72 & 3.83 & .88 & .84 & 178 & 179 & \\
\hline $\begin{array}{l}\text { How satisfied are you with: "The social support you get from family." } \\
(1=\text { very dissatisfied, } 5=\text { very satisfied })\end{array}$ & 4.25 & 4.29 & .78 & .87 & 181 & 182 & \\
\hline $\begin{array}{l}\text { Rate yourself: "I am often bored." } \\
(1=\text { strongly disagree, } 5=\text { strongly agree) (reversed for analyses) }\end{array}$ & 2.11 & 1.97 & .97 & .99 & 183 & 179 & \\
\hline $\begin{array}{l}\text { At present time: "The amount of variety in my leisure activities is." } \\
(1=\text { Almost none, } 5=\text { great amount })\end{array}$ & 3.46 & 3.45 & .80 & .84 & 179 & 182 & \\
\hline $\begin{array}{l}\text { "You are maintaining your standard of living in retirement." } \\
\text { (1=yes, definitely, } 5=\text { definitely not) (reversed for analyses) }\end{array}$ & 4.26 & 4.19 & .98 & .96 & 182 & 175 & \\
\hline “Were you forced into semi-retirement or retirement?" (1=yes, $0=n 0)$ & .11 & .07 & .32 & .25 & 170 & 148 & \\
\hline
\end{tabular}




\begin{tabular}{|c|c|c|c|c|c|c|c|}
\hline & \multicolumn{2}{|c|}{ Means } & \multicolumn{2}{|c|}{$S D$} & \multicolumn{2}{|c|}{$n$} & \multirow[t]{2}{*}{ Sig. } \\
\hline & Husbands & Wives & Husbands & Wives & Husbands & Wives & \\
\hline $\begin{array}{l}\text { How important are the following in retirement? "Spirituality." } \\
(1=\text { not at all, } 5=\text { very large extent) }\end{array}$ & 3.15 & 3.54 & 1.19 & 1.25 & 182 & 179 & **** \\
\hline $\begin{array}{l}\text { "You have experienced changes in your life since semi-retirement or } \\
\text { retirement that forced you to significantly alter your retirement plans } \\
\text { or activities." (no }=2, \text { yes }=1 \text { ) (reversed) }\end{array}$ & 1.82 & 1.80 & .38 & .40 & 175 & 161 & \\
\hline $\begin{array}{l}\text { "Please indicate whether or not each of the following (health) } \\
\text { conditions interfere with your quality of life." (range from 0-12) }\end{array}$ & 2.76 & 2.49 & 1.57 & 1.55 & 176 & 175 & $*$ \\
\hline $\begin{array}{l}\text { Latent variable retirement adjustment items: } \\
\text { How satisfied are you with: “How well you planned financially for } \\
\text { retirement?" (1=very dissatisfied, 5=very satisfied) }\end{array}$ & 4.22 & 4.05 & .89 & 1.05 & 176 & 172 & $*$ \\
\hline $\begin{array}{l}\text { How satisfied are you with: "How well you planned for the } \\
\text { non-financial aspects of retirement?" } \\
\text { (1=very dissatisfied, } 5=\text { =very satisfied) }\end{array}$ & 4.01 & 3.99 & .77 & .88 & 144 & 140 & \\
\hline $\begin{array}{l}\text { "Would you call your semi-retirement or retirement "successful" at } \\
\text { this point?" (1=definitely not, 4=definitely yes) (reversed) } \\
\text { Latent Variable Well-Being items: }\end{array}$ & 3.59 & 3.55 & .63 & .63 & 168 & 154 & \\
\hline $\begin{array}{l}\text { Rare yourself: "I often feel depressed" } \\
(1=\text { strongly disagree, } 5=\text { strongly agree }) \text { reversed for analyses }\end{array}$ & 4.13 & 4.13 & .69 & .77 & 183 & 176 & \\
\hline $\begin{array}{l}\text { Please rate yourself in terms of the following at the present time: } \\
\text { "Overall sense of well-being." }(1=\text { very poor, } 5=\text { excellent })\end{array}$ & 4.30 & 4.26 & .67 & .67 & 169 & 169 & \\
\hline $\begin{array}{l}\text { Please rate yourself in terms of the following at the present time: } \\
\text { "Ability to handle stress." }(1=\text { very poor, } 5=\text { excellent })\end{array}$ & 4.04 & 3.80 & .77 & .81 & 178 & 180 & $* *$ \\
\hline
\end{tabular}


Table 2. Reasons for Forced Retirement Reported by Husbands and Wives $(n=48)$

\begin{tabular}{lcccc}
\hline & \multicolumn{2}{c}{$\begin{array}{c}\text { Forced Retirement } \\
\text { Husbands }\end{array}$} & \multicolumn{2}{c}{ Forced Retirement } \\
& $n$ & $\%$ & $n$ & $\%$ \\
\hline $\begin{array}{l}\text { If [you were "forced" into } \\
\text { semi-retirement or } \\
\text { retirement], was this due to: }\end{array}$ & & & & \\
Age & 7 & $21.8 \%$ & 3 & $18.8 \%$ \\
Sickness/disability & 12 & $37.5 \%$ & 7 & $43.8 \%$ \\
Job eliminated & 4 & $12.5 \%$ & 1 & $6.3 \%$ \\
To be a caregiver & 1 & $3.2 \%$ & 1 & $6.3 \%$ \\
Other & 8 & $25.0 \%$ & 4 & $24.8 \%$ \\
Total & 32 & $100 \%$ & 16 & $100 \%$ \\
\hline
\end{tabular}




\section{Measures}

Previously established measures were not used in the development of this survey; however, a test of inter-item consistency (Cronbach's alpha) of the two latent variables to be used in the SEM analysis (see Figure 2), confirmed reliability and validity for both. The conceptualization for the latent variable retirement adjustment was based on a component of the Dyadic Adjustment Scale (DAS) (Spanier, 1976) which utilizes measures of satisfaction to determine levels of adjustment in couples.

\section{Dependent Variable}

The primary conceptualization for the dependent latent variable well-being and the rationale for selecting the items for the construct were the three components of the subjective well-being index (SWB): life satisfaction, the presence of positive mood, and the absence of negative mood (Ryan \& Deci, 2001). These SWB measures are consistent with the hedonism paradigm of well-being (Ryan \& Deci, 2001) which reflects the view that well-being is characterized by happiness or pleasure. Well-Being was a latent construct developed from three ordinal-level questions. The first two items asked respondents to "Rate yourself in terms of the following at the present time: (a) your overall sense of well-being, and (b) your ability to handle stress," $(1=$ very poor, 2 = poor, 3 = fair, 4 =good, $5=$ excellent). Finally, a single item measuring depression was included: $I$ often feel depressed, $(1=$ strongly disagree, 2 = disagree, 3 $=$ neutral, $4=$ agree, $5=$ strongly agree). This item was reverse-coded for analytical purposes. A test of internal reliability confirmed the internal consistency of the means of the items. The subsequent validity of well-being as a latent construct for use in the 
structural equation model (SEM) portion of the analysis was thus tested and established, as described later.

\section{Independent Variables}

Retirement adjustment was a latent variable at the ordinal level identified through a series of three questions regarding respondents' satisfaction with retirement. The first two items asked respondents to rate their (a) "satisfaction with financial planning," and (b) "satisfaction with non-financial planning," with a scaled response option ranging from (1) very dissatisfied to (5) very satisfied. The third item inquired about retirement success: "Would you call your semi-retirement or retirement "successful" at this point? (1) = definitely not, (2) = yes to some degree, (3) = yes, for the most part, and (4) = definitely yes." This question was reverse coded for analytical purposes.

A test of internal reliability confirmed the internal consistency of the items, and the validity of retirement adjustment as a latent construct for use in the structural equation model (SEM) portion of the analysis. Retirement adjustment was the latent mediator variable in the structural equation model portion of the analysis.

Retirement circumstance was a dichotomous variable identified by a two-part question which asked respondents to indicate first whether they were forced into semiretirement or retirement and if yes, they were given a choice of five reasons for the forced retirement, including: age, sickness/disability, job eliminated, to be a caregiver, or other. Respondents who answered "yes" were classified in a forced group, coded as 
1. Respondents who responded "no" were classified in a non-forced group, coded as 0. Retirement circumstance was an observed measure in the structural equation model.

Current work status was a dichotomous variable, recoded from a seven response option survey question inquiring about current employment status. The recoded variable was assigned the code of $1=$ semi-retired or retired but returned to work full or part-time, $2=$ fully retired. As noted earlier, only respondents who were semi or fully retired or who were retired but then returned to work full or part-time comprised the sample for the present study. Both members of the couple had to meet one of these criteria.

Primary occupation was a dichotomous variable created from an open-ended survey item which inquired about the respondent's former or current primary occupation. Responses were classified based on whether the primary occupation was professional, coded as 1 , or non-professional, coded as 0 .

Gender was a dichotomous variable included for comparative purposes. Husbands' responses were coded 0 , and wives responses were coded 1 .

Number of Health Problems was a variable identified on the survey with a checklist of 13 serious health conditions. Respondents were asked to "please indicate whether or not each of the following conditions interferes with your quality of life: arthritis, diabetes, hypertension, strokes, tinnitus, visual impairment cancer, heart disease, depression, mental illness, orthopedic, hearing impairment or other $(0=$ no, 1 $=$ yes). The number of health conditions reported then was counted with possible 
scores ranging from $0-12$. Low scores indicate few health problems from these conditions; high scores indicate many health problems.

Total household income was a categorical interval variable to be controlled for because of the hypothesized significant associations with the dependent latent variable, well-being. Income was measured as a seven-category variable: $1=$ income under $\$ 50,000,2=\$ 50,000-\$ 74,999,3=\$ 75,000-\$ 99,000,4=\$ 100,000-$ $\$ 149,000,5=\$ 150,000-\$ 199,999,6=200,000-\$ 249,999$, and, $7=$ income greater than or equal to $\$ 250,000$.

Maintenance of Living Standard was a categorical variable with the following stem: "You are maintaining your desired standard of living in retirement" $(1=$ Yes, definitely, $2=$ Probably, $3=$ Not sure, $4=$ Probably not, $5=$ Definitely not). This item was reverse coded for analyses so that higher scores would reflect maintenance of living standard.

Education was measured as a six-category ordinal variable: $1=$ Did not complete high school, $2=$ Completed high school, $3=$ Some college, $4=$ College degree, $5=$ Some postgraduate work, $6=$ Graduate/Professional Degree.

Leisure variety was an ordinal variable. Measured by the item "The amount of leisure variety I have is..." $(1=$ Almost none, $2=$ Small amount, $3=$ Moderate amount, $4=$ Large amount, $5=$ Great amount).

Religious influence was a categorical variable. Respondents were asked to indicate the extent to which "My religious belief or spirituality influences my life," (1 
$=$ Not at all, $2=$ Some extent, $3=$ Moderate extent, $4=$ Large extent, $5=$ Very large extent).

Importance of Spirituality was measured by asking respondents to indicate how important spirituality/religious belief were for them in retirement, $(1=$ Not very important, 2 = Somewhat important, $3=$ Important, 4 = Very Important, $5=$ Extremely Important).

Boredom was measured by asking respondents were asked to indicate the extent to which they agreed or disagreed with this statement: "I am often bored" $(1=$ Strongly disagree, $2=$ Disagree, $3=$ Neutral, $4=$ Agree, $5=$ Strongly agree). This item was reverse coded for analyses.

Flexibility was measured by asking respondents to indicate the extent to which they agreed with the statement below: "I am adaptable and flexible when events or circumstances change" $(1=$ Not at all, $2=$ Some extent, $3=$ Moderate extent, $4=$ Large extent, $5=$ Very large extent).

Setbacks was a dichotomous variable. Respondents were asked to respond "yes" or "no" to the following statement: "You (and your partner if applicable) have experienced changes in your life (e.g., financial, health, family issues) since semiretirement or retirement that forced you to significantly alter your retirement plans and activities..." "No" responses were coded 2 and "yes" responses were coded 1.

Social support was a çategorical variable. Respondents were asked to indicate how satisfied they were with: "The social support you get from family. Response 
options were: (1) very dissatisfied, (2) dissatisfied, (3) neutral, (4) satisfied, and (5) very satisfied.

\section{Analysis plan}

Overview. Basic descriptive statistics were computed separately for husbands and wives for all study variables. Differences between husbands' and wives' were tested with paired t-tests. The primary predictive analyses were performed using multiple regression analyses and structural equation modeling. Mediation analyses used structural equation modeling. To analyze the data, the Statistical Package for the Social Sciences (SPSS), Version 10.0 and Mplus, Version 3.1, structural equation modeling software were used.

\section{Measurement models}

Structural Equation Modeling (SEM) developed from path analysis and confirmatory factor analysis and was helpful in revealing the causal and correlational links between theoretical variables (Kenny, 1998). SEM was used to test the models because of its application to issues involving (a) linear relationships, (b) the presumed causal ordering of variables, and (c) the need to determine the direct and indirect effects of predictor variables on criterion variables. SEM allows researchers to test several regression equations in one model. Latent or unobserved variables are an important feature of SEM. Factor loadings from confirmatory factor analysis determine if a series of items presumed to measure the latent construct can be combined to form one latent variable (for example, measures of well-being in several key areas were indicators of one variable measuring overall well-being). 
Reliability testing. As noted previously, the first step of the analysis was to assess the internal reliability of the hypothesized latent constructs, retirement adjustment and well-being. Items from the survey pertaining to satisfaction with retirement were chosen to test the reliability of the hypothesized latent variable retirement adjustment. Items pertaining to subjective well-being were chosen to test the reliability of the hypothesized latent variable well-being. This task was accomplished using Cronbach's alpha, the most commonly used metric to assess internal reliability. Alphas are generally considered to be acceptable if over .80 (Tabachnik \& Fidell, 1997).

Tests of internal reliability using Cronbach's alpha on the three items hypothesized to measure retirement adjustment, 3 items yielded a standardized Cronbach's alpha coefficient of $.857(n=118)$ for husbands, and $.824(n=111)$ for wives. These items were then subjected to a confirmatory factor analysis. Similarly, a test of internal reliability was conducted on the three items measuring well-being. These 3 items yielded an acceptable standardized Cronbach's alpha coefficient of .812 $(n=123)$ for husbands, and $.799(n=108)$ for wives and then subjected to a confirmatory factor analysis. The data set contained some missing data on some items; therefore the valid $n$ for each item is indicated in the table. Missing deletion was applied to the entire data set yielding a valid $n$ of 183 for the confirmatory factor analysis.

Confirmatory factor analyses of latent variables. In the second step of the analysis, four measurement models, two for husbands, and two for wives, were 
developed from the results of the Cronbach's alpha reliability tests. The items measuring (a) adjustment and (b) well-being for husbands and wives were hypothesized to form latent variables to be used in other analyses. Specifically, confirmatory factor analyses were conducted in order to assess the factor structure of each hypothetical latent variable as follows: husbands' retirement adjustment; wives' retirement adjustment; husbands' well-being; and wives' well-being. The confirmatory factor analyses were conducted using Mplus, Version 3.1 (Muthen \& Muthen, 2001), with maximum likelihood estimation.

Procedures. The following statistical procedures were performed to address the research hypothesis below.

\section{H1: Husbands and wives differ in respect to their levels of retirement adjustment} and well-being. The initial step in examining differences in retirement adjustment was to run paired t-tests to compare spouses' scores on the three indicators of retirement adjustment. Next a paired t-test was run to compare the husbands' and wives' scores on the three indicators of well-being.

H2: One's own health status and retirement circumstance (forced/not forced) are predictors of one's own well-being and are partially mediated by one's own retirement adjustment. A forced retirement circumstance was hypothesized to negatively influence one's own retirement adjustment, and in turn, negatively influence one's own well-being for husbands and for wives. In addition, number of 
health problems was hypothesized to negatively influence one's own retirement adjustment, and in turn, negatively influence one's own well-being. A structural equation model was developed to test the effects of retirement circumstance (forced, not forced) and number of health problems on retirement adjustment and well-being. Retirement adjustment was hypothesized to mediate the relationship between the independent variables retirement circumstance and number of health problems, and the dependent variable, well-being.

\section{H3: An individual's retirement adjustment and well-being is influenced by his/her} partner's retirement adjustment. Multiple regression analyses were used to determine the influence of one spouse's adjustment on the other spouse's adjustment. In the first step of the regression analyses, the socio-demographic variables of age, income and education were entered, followed by the adjustment indicators in the second step. This approach provided information about the contribution of the spouse's adjustment on the partner's adjustment, independent of the sociodemographic variables. The regression analyses were conducted to evaluate the proportion of variance shared between spouse's adjustment variables, e.g., satisfaction with financial planning, that was explained by his or her spouse's same adjustment items. This analysis would help determine the extent to which spouses' scores on adjustment items were intercorrelated.

Next, a structural equation model tested husbands' and wives' retirement adjustment and well-being latent variables. Hypothetical paths included the path from 
wife's retirement adjustment to husband's well-being and the path from husband's retirement adjustment to wife's well-being. In addition, the path from husband's own retirement adjustment to his own well-being and the path from wife's own retirement adjustment to her own well-being were tested. An important consideration in a measurement model is the amount of variance shared between items within a construct. Research has established the non-independence of couple-level data (Kenny, 1996), with evidence of high correlation in responses within a couple; therefore, the correlated errors from husbands and wives retirement adjustment items and well-being items were included in the model to reduce bias. Scores from two members of a dyad are nearly always related (Newsom, 2002), and this association can be modeled by estimating the correlated measurement errors. Correlated errors are the association between two items beyond the association with a latent variable. These errors were an important consideration in this measurement model, due to the probability that husbands' and wives' scores would be highly correlated due to the crossover effects, or interdependence, in responses. For example, correlated measurement error between husbands and wives responses on a depression item may be explained by an unmeasured item such as the recent death of a family member. Correlated errors can reduce bias in predictive relationships and determine the true score variance for each individual within a dyad.

\section{H4: An individual's well-being is influenced by his/her partner's retirement} circumstance. Mediation analyses with structural equation modeling were used to 
determine the effect of one partner's retirement circumstance on his or her spouse's retirement adjustment and the spouse's well-being in retirement. In the case of partial mediation, the path from $\mathrm{X}$ to $\mathrm{Y}$ is reduced in absolute size but is still different from zero when the mediator $(\mathrm{M})$ is controlled. In the case of full mediation, the relationship between $\mathrm{X}$ and $\mathrm{Y}$ ceases to exist when the $\mathrm{M}$ is controlled (Judd and Kenny, 1981). In this study, retirement adjustment (M) was hypothesized to partially mediate the relationship between retirement circumstance $(\mathrm{X})$ and well-being $(\mathrm{Y})$ (i.e., the relationship between an individual's retirement circumstance and well-being was thought to be influenced by the partner's retirement adjustment). The spouse of a partner reporting an involuntary retirement circumstance was hypothesized to have lower levels of retirement adjustment and well-being. Due to the fact that responses concerning retirement adjustment and those concerning well-being were correlated, the errors from husbands' and wives' retirement adjustment and husbands' and wives' well-being items were correlated to reduce bias.

H5: Predictors of retirement adjustment and well-being include health, education, income, a fully retired work status, and a voluntary retirement circumstance. The predictors for retirement adjustment and well-being were selected based on the review of the literature. All five variables were found to influence either retirement adjustment or well-being. Structural equation modeling was used to analyze the hypothesized causal relationships between these variables and the possible mediating effects of retirement adjustment. Hypothesized predictors of retirement adjustment 
and well-being were low levels of health problems, a voluntary retirement circumstance, a full retirement work status, and higher levels of education and income. 
Results

Actor and Partner Effects Among Marital Dyads in Retirement Adjustment and

Well-Being

Structural models. Kraemer and Jacklin (1979) originally proposed a data analysis strategy for dyadic data, but analyses were restricted to dichotomous causal variables. Kenny's Social Relationship Model (SRM) (1996) is an extension of the Kraemer-Jacklin method and can be used with continuous causal variables. By applying a variation of this model to the analyses of these data, it was possible, for example, to determine the effect of retirement adjustment on well-being across partners. This model posits that a wife's retirement adjustment is a function of both her and her husband's retirement adjustment, and a husband's retirement adjustment is a function of his and his wife's adjustment. Because each person's adjustment is influenced by characteristics of the partner's adjustment, their adjustment levels will be correlated. When latent variables are used in the theoretical model of a structural equation model, the measurement model must confirm the reliability of the latent constructs.

Initial analyses of the retirement adjustment and well-being measures suggested adequate reliability. Reliability was tested for these analyses through confirmatory factor analyses. Internal reliability of these measures was further examined using confirmatory factor analyses. Parameters implied by the model are fit to predict the correlations or covariances between the observed covariances among variables. Fit indices reflect the discrepancy or match between the covariances among 
variables implied by the model and those observed. The following fit indices were chosen to evaluate model fit for the structural equation analyses as recommended by Bollen (1990) and $\mathrm{Hu}$ and Bentler (1999):

- A non-significant Chi-square statistic

- Standardized root mean square residual, standardized RMR (SRMR). The smaller the standardized RMR, the better the model fit. SRMR is the average difference between the predicted and observed variances and covariances in the model, based on standardized residuals. SRMR is 0 when model fit is perfect; an SRMR between .08 and 0 indicates a good fit.

- Comparative Fit Index (CFI). The CFI compares the tested model to a null model having no paths that link the variables, therefore making the variables independent of each other. Scores can range from 0 to 1.0 ; scores less than .95 are considered to be unacceptable.

Tucker-Lewis Index (TLI): The TLI is a test of relative fit between a null model and the tested models. Scores can range from 0 to 1.0 ; scores less than .95 are considered to be unacceptable.

\section{Measurement Models: Retirement Adjustment}

A latent construct is typically an abstract concept such as "retirement adjustment" or "well-being." In SEM, latent constructs are modeled as common factors underlying the associated multiple measures. The factor loadings are the 
correlation coefficients between the variables and factors and were used to evaluate the acceptability of the items.

The three-item latent variable model for retirement adjustment was tested for husbands and for wives with items from the Cronbach's alpha test of internal reliability. The three items and the loadings for the initial models for husbands' retirement adjustment and for wives' retirement adjustment are shown in Table 3 .

Table 3. Final Three-Item Confirmatory Factor Model Results for Adjustment

\begin{tabular}{llcccc}
\hline Item & Factor & \multicolumn{2}{c}{ Path } & \multicolumn{2}{c}{$N$} \\
\cline { 2 - 6 } & & Husbands & Wives & Husbands & Wives \\
\hline $\begin{array}{l}\text { "Satisfaction with } \\
\text { financial planning" }\end{array}$ & $\begin{array}{l}\text { Retirement } \\
\text { adjustment }\end{array}$ & .748 & .582 & 176 & 172 \\
$\begin{array}{l}\text { "Satisfaction with } \\
\text { non-financial } \\
\text { planning" }\end{array}$ & $\begin{array}{l}\text { Retirement } \\
\text { adjustment }\end{array}$ & .645 & .826 & 144 & 140 \\
$\begin{array}{l}\text { "Retirement } \\
\text { success rating" }\end{array}$ & $\begin{array}{l}\text { Retirement } \\
\text { adjustment }\end{array}$ & .713 & .642 & 168 & 154 \\
\hline
\end{tabular}

The fit of the initial models for both husbands' and wives' retirement adjustment was evaluated as good; however, both models were just-identified, meaning that the number of free parameters exactly equaled the number of known values. A just-identified model is a model with zero degrees of freedom; therefore, it cannot be evaluated for fit using the chi-square test. Chi-square tests the difference between the tested model and a just-identified version of it, so the closer the tested model is to being just-identified, the more likely a good fit will be found. However, 
because the chi-square test cannot be used to evaluate the fit, other indicators are evaluated, such as whether the items each have strong standardized loadings. Strong standardized loadings for each item in the model suggested strong intercorrelations for the latent variable husbands' retirement adjustment, as presented in Table 3 . This is an indication of good model fit. Similarly, strong standardized loadings for each item suggested good model fit for the wives' retirement adjustment latent variable, as presented in Table 3. Thus, both models were found to fit the data well. The resulting measures of retirement adjustment for husbands and wives were used as latent variables in subsequent analyses.

\section{Measurement Models: Well-Being}

The three items hypothesized to form the latent variable well-being were entered into a separate confirmatory factor models to assess the latent construct's validity separately for husbands and wives. The confirmatory factor models yielded a satisfactory fit for husbands' well-being, and a satisfactory fit for wives' well-being. The results are listed in Table 4. 
Table 4. Final Three-Item Confirmatory Factor Model Results for Well-Being

\begin{tabular}{llllll}
\hline Item & Factor & \multicolumn{2}{c}{ Path } & \multicolumn{2}{c}{$n$} \\
\cline { 3 - 6 } & & Husbands & Wives & Husbands & Wives \\
\hline $\begin{array}{l}\text { Often depressed } \\
\text { (reversed) }\end{array}$ & $\begin{array}{l}\text { Well- } \\
\text { Being }\end{array}$ & $.468^{* * *}$ & $.520^{* * *}$ & 183 & 176 \\
$\begin{array}{l}\text { Sense of well- } \\
\text { being }\end{array}$ & $\begin{array}{l}\text { Well- } \\
\text { Being }\end{array}$ & $.910^{* * *}$ & $.895^{* * *}$ & 179 & 179 \\
$\begin{array}{l}\text { Stress handling } \\
\text { ability }\end{array}$ & $\begin{array}{l}\text { Well- } \\
\text { Being }\end{array}$ & $.492^{* * *}$ & $.381^{* * *}$ & 178 & 180 \\
\hline Note: ${ }^{* * *} \mathrm{p}<.001$ & & & & \\
\hline
\end{tabular}

\section{Research Hypotheses and Analyses}

\section{Hypothesis 1}

No directional hypothesis was chosen for the first analyses, which examined the relationship between gender and levels of retirement adjustment and well-being. This was due to inconsistency in the findings reported in the literature regarding gender and adjustment to retirement.

Paired samples t-tests for spouse retirement adjustment and well-being items.

A paired sample t-test for each of the items composing this latent variable found a significant difference between husbands' and wives' satisfaction with financial planning for retirement, $\mathrm{t}(171)=2.11, \mathrm{p}<.05$. The mean for women was lower $(4.05)$ than that for men (4.22), suggesting wives are generally less satisfied with couples' financial planning. The results of the paired sample t-test for the remaining retirement 
adjustment variables, "Satisfaction with non-financial planning for retirement", and "Rate your retirement success", however, were non-significant. Husbands' and wives' levels of adjustment did not vary significantly on these remaining two items.

Next, a paired sample t-test for each of the items composing the latent variable well-being found a significant difference between husbands' and wives' stress handling ability, $\mathrm{t}(177)=3.02, \mathrm{p}<.01$. Wives reported significantly lower levels of stress handling ability, the mean for wives on this item was lower (3.80) than that for men (4.04). The results of the paired sample t-test for the remaining well-being variables, "Own sense of well-being", and "I'm often depressed," (reversed for analyses) were non-significant. Husbands' and wives' levels of well-being did not vary significantly on these remaining two items.

\section{Hypothesis 2}

A forced retirement circumstance was hypothesized to negatively influence one's own retirement adjustment, and in turn, negatively influence one's own wellbeing for husbands and for wives. In addition, number of health problems was hypothesized to negatively influence one's own retirement adjustment, and in turn, negatively influence one's own well-being. These results were significant for husbands, but not for wives ${ }^{2}$.

\footnotetext{
${ }^{2}$ Additional analyses to determine if poor health status predicted forced retirement were conducted; specifically, forced retirement was regressed on number of health problems for both husbands and wives, with non-significant results. Thus, health status did not predict whether retirement was forced or not for husbands or wives.
} 
Health status and retirement circumstance model: husbands. The structural model that tested the fit of the latent variable husband's well-being regressed on the latent variable husband's retirement adjustment, and husband's retirement adjustment regressed on husband's health status (number of health problems) and forced retirement (see Figure 4) yielded a good fit. The three main indicators of fit, a nonsignificant chi-square test $(\chi 2(27, \mathrm{n}=183)=25.977, \mathrm{p}<.100)$, the CFI $(.967)$, and the TLI (.950), suggested an acceptable model fit. The SRMR of .054 also indicated an acceptable model fit.

The results of the structural equation models for the dependent variable wellbeing regressed on retirement adjustment, retirement circumstance (forced, not forced) and number of health problems found several significant relationships (see Figure 4), including a significant indirect effect or mediation effect. As previously mentioned, in the case of partial mediation, the path from $\mathrm{X}$ to $\mathrm{Y}$ is reduced in absolute size but is still different from zero when the mediator $(\mathrm{M})$ is controlled. In the case of full mediation, the relationship between $X$ and $Y$ ceases to exist when the $M$ is controlled (Judd and Kenny, 1981).

A significant direct path between number of health problems and retirement adjustment $(-.285, \mathrm{p}<.001)$, and a significant but reduced direct path from health problems to well-being $(-.346, \mathrm{p}<.001)$, is consistent with partial mediation. Number of health problems was found to have a direct effect on well-being for husbands as shown in Figure 4. Thus, for husbands, the effect of number of health problems on well-being is consistent with partial mediation by retirement adjustment with an 
indirect effect of $[-.113, \mathrm{p}<.05]$. The hypothesis that the effect of husband's number of health problems on his well-being is consistent with partial mediation by his retirement adjustment is supported for husbands in this analysis.

There is a significant direct path between forced retirement circumstance and retirement adjustment for husbands in this model $(-.262, \mathrm{p}<.05)$ and a non-significant direct path from forced retirement circumstance to well-being $(-.165, \mathrm{p}<.05)$. Thus, a husband's forced retirement is a significant predictor of his retirement adjustment, but is not a significant predictor of his well-being. An indirect effect between husbands' forced retirement and his well-being was not found in this model. As shown in Figure 4, the findings reveal a significant positive direct effect for husbands between wellbeing and retirement adjustment $(.603, \mathrm{p}<.001)$. 


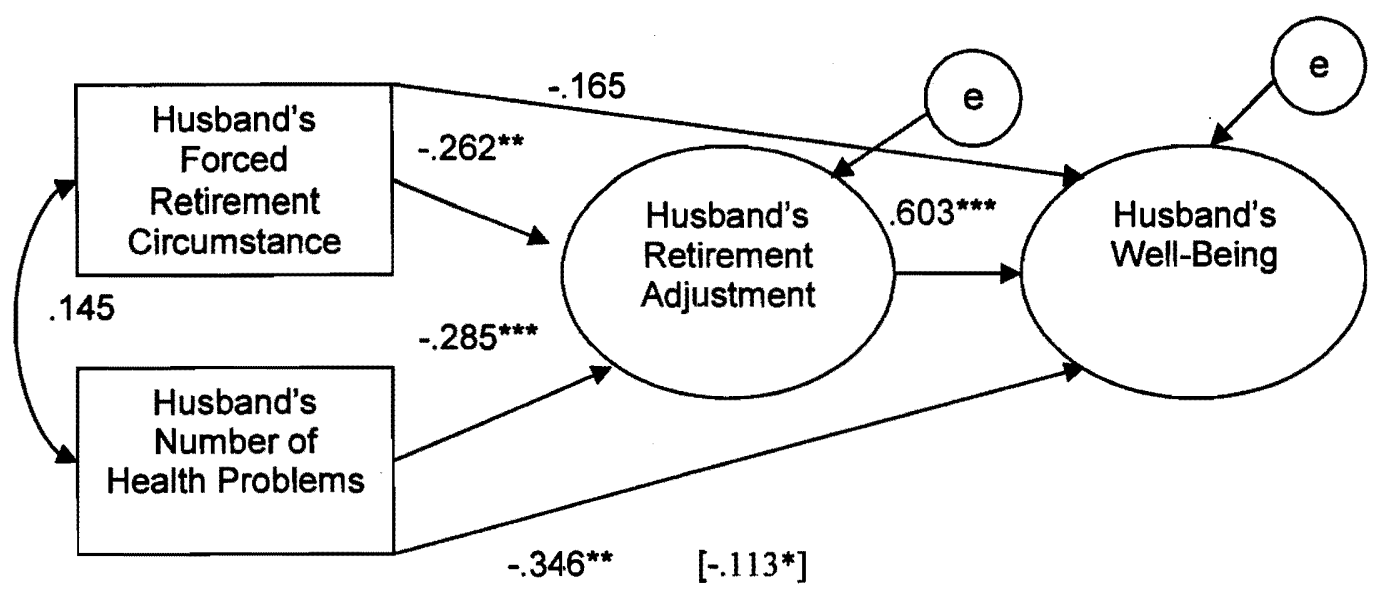

Figure 4. Husband's well-being predicted by his forced retirement circumstance and health.

$\mathrm{p}<.05, * * \mathrm{p}<.01, * * * \mathrm{p}<.001$

Note: the bracketed value is the indirect effect coefficient

Health status and retirement circumstance model: wives. As shown in Figure 5 , for wives, a significant direct effect was found between retirement adjustment and well-being $(.585, \mathrm{p}<.001)$. The relationships between health problems and retirement adjustment, and retirement circumstance and retirement adjustment, however, were non-significant for wives. Number of health problems did have a direct effect on a wife's well-being $(-.357, \mathrm{p}<.001)$. Contrary to the results for husbands, the effects of a wife's forced retirement and health problems on well-being were not mediated by retirement adjustment. The significant chi-square test $(\chi 2(18, \mathrm{n}=183)=49.729, \mathrm{p}<$ $.001)$, the CFI (.840), and the TLI (.760), and the SRMR of (.074) all suggest an unacceptable model fit for wives' well-being as predicted by wives' retirement 
adjustment, forced retirement circumstance, and number of health problems. Thus, the hypothesis that the effect of a forced retirement and number of health problems on well-being was mediated by retirement adjustment was not supported for wives in this analysis. The combined coefficients are presented in Table 5.

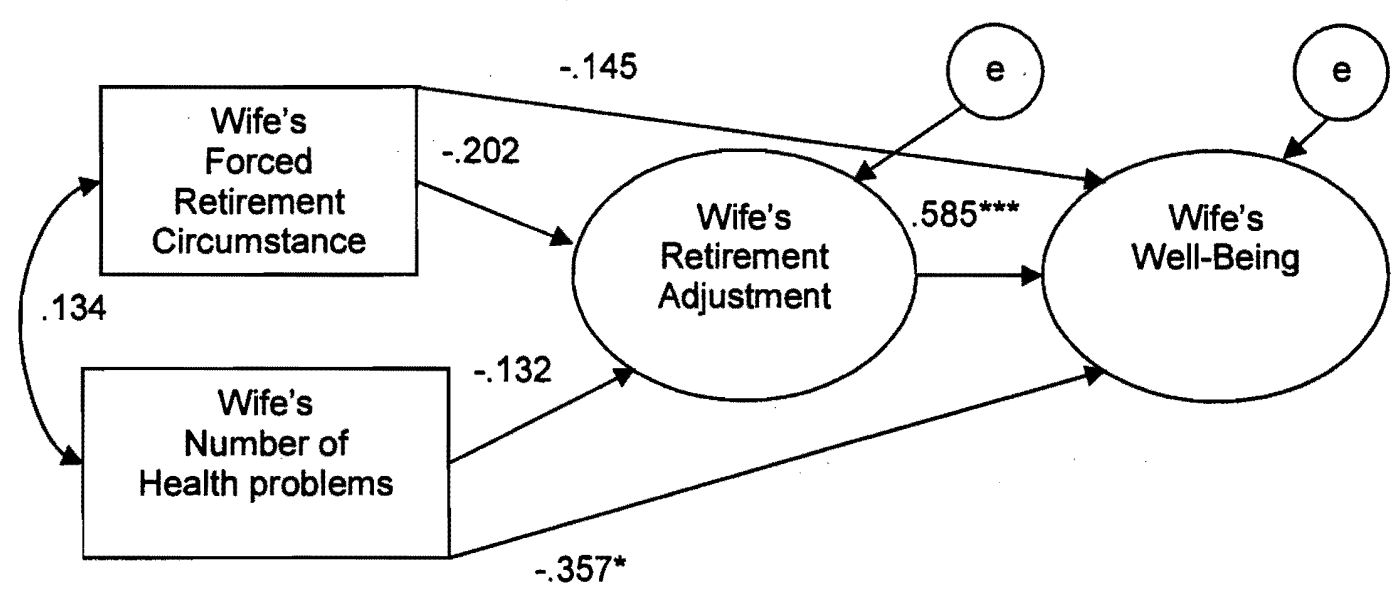

Figure 5. Wife's well-being predicted by her retirement circumstance and health.

$* \mathrm{p}<.05, * * \mathrm{p}<.01, * * * \mathrm{p}<.001$. 
Table 5. Combined Model Results for Well-Being Regressed on Retirement Adjustment, Health Problems and Forced Retirement for Husbands and Wives $(n=183)$

\begin{tabular}{llcl}
\hline Item & Factor & \multicolumn{2}{c}{ Path } \\
\cline { 2 - 4 } & & Husbands & Wives \\
\hline Health problems & $\begin{array}{l}\text { Retirement } \\
\text { adjustment }\end{array}$ & $-.285^{* * *}$ & -.132 \\
$\begin{array}{l}\text { Retirement } \\
\text { circumstance }\end{array}$ & $\begin{array}{l}\text { Retirement } \\
\text { adjustment }\end{array}$ & $-.262^{* *}$ & -.202 \\
$\begin{array}{l}\text { Retirement } \\
\text { adjustment }\end{array}$ & Well-Being & $.603^{*}$ & $.585^{*}$ \\
$\begin{array}{l}\text { Retirement } \\
\text { circumstance }\end{array}$ & Well-Being & -.165 & -.145 \\
$\begin{array}{l}\text { Health problems } \\
\text { Well-Being }\end{array}$ & $-.346^{* *}$ & $-.347^{*}$ \\
\hline$* \mathrm{p}<.05,{ }^{* *} \mathrm{p}<.01,{ }^{* * *} \mathrm{p}<.001$. & &
\end{tabular}

\section{Hypothesis 3}

Crossover effects among spouses and retirement adjustment. In the third analysis, one's own rate of retirement adjustment was hypothesized to influence his/her partner's retirement adjustment. Research has established the nonindependence of couple-level data (Kenny, 1996; Newsom, 2002), with evidence of high correlation in responses within a couple, otherwise known as the partner effect (Kenny, 1996; Newsom, 2002) or contagion effect (Bookwala and Schultz, 1995). 
Simply stated, in dyadic data, the spouse's response will be influenced by the partner (Kenny, 1996; Newsom, 2002).

\section{Multiple Regression Tests for Partner Effects}

Investigation into possible partner-effects began with a series of multiple linear regression analyses which revealed significant relationships between an individual's three demographic variables (age, income and education), his or her partner's retirement adjustment variables and the individual's own retirement adjustment variables. The regression analyses were conducted to evaluate the proportion of variance shared between spouses' adjustment variables, e.g., satisfaction with financial planning, that was explained by his or her spouse's same adjustment item. This analysis would help determine the extent to which spouse's scores on adjustment items were intercorrelated. High intercorrelations between these items could reduce the ability to determine a crossover effect between husbands' retirement adjustment and wives' well-being, and vice versa. Conversely, low intercorrelations between items could improve the ability to determine a crossover effect between partners' retirement adjustment and spouses' well-being.

The results for this analyses found a high level of intercorrelation between spouses' adjustment items. High levels of intercorrelations on retirement adjustment items were found even after controlling for a partner's own demographic characteristics. This effect indicates that spouses' share similar experiences related to the three retirement adjustment items. The high level of intercorrelation, however, reduced the ability to find crossover effects in the subsequent crossover model. This 
effect will be addressed in the next discussion related to the crossover model for spouses' retirement adjustment and well-being.

The first set of analyses, those for husbands, are shown in Table 7. The regression coefficients are presented for husbands' retirement adjustment variables regressed on husbands' own socio-demographic variables and their wives' retirement adjustment variables. The hypothesis that a husband's retirement adjustment is a function of his wife's retirement adjustment was supported in this analysis. The results indicated that a wife's retirement adjustment variables explained a significant proportion of the variance in a husband's retirement adjustment variables. A wife's satisfaction with financial planning explained a significant proportion of the variance in a husband's satisfaction with financial planning, $R^{2=} .36, F(3,167)=23.41, p<.001$. Similarly, a wife's satisfaction with non-financial planning explained a significant proportion of the variance in a husband's satisfaction with non-financial planning, $R^{2}$ $=20, F(3,134)=8.3, p<.001$. Finally, a wife's retirement success explained a significant proportion of the variance in a husband's retirement success $R^{2}=.13$, $F(3,144)=5.5, p<.001$.

Other significant predictors of a husband's retirement adjustment included income for each of the three retirement adjustment items, i.e., satisfaction with financial planning, satisfaction with non-financial planning, and retirement success. Age was a significant predictor of husband's financial planning satisfaction, and education was a predictor of husband's retirement success. The hypothesis that 
husbands' retirement adjustment was predicted by wives' retirement adjustment was fully supported in this set of analyses.

Table 7. Husbands' Retirement Adjustment Variables Regressed on Husbands' Own Socio-Demographic Indicators and Wives' Retirement Adjustment Variables

\begin{tabular}{|c|c|c|c|}
\hline & $\begin{array}{c}\text { Financial planning } \\
\text { satisfaction (husband's) }\end{array}$ & $\begin{array}{l}\text { Non-financial planning } \\
\text { satisfaction (husband's) }\end{array}$ & $\begin{array}{l}\text { Retirement success } \\
\text { (husband's) }^{c}\end{array}$ \\
\hline Age (husband's) & $.186^{* *}$ & .028 & .084 \\
\hline Income (husband's) & $.236 * * *$ & $.265^{* * *}$ & $.229 * * *$ \\
\hline Education (husband's) & .124 & -.055 & $.172^{*}$ \\
\hline $\begin{array}{l}\text { Financial planning } \\
\text { satisfaction (wife's) }\end{array}$ & $.440 * * *$ & - & - \\
\hline $\begin{array}{l}\text { Non-financial } \\
\text { planning satisfaction } \\
\text { (wife's) }\end{array}$ & - & $.325^{* * *}$ & 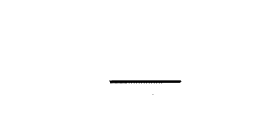 \\
\hline $\begin{array}{l}\text { Retirement success } \\
\text { (wife's) }\end{array}$ & - & - & $.187^{* *}$ \\
\hline
\end{tabular}

Table 8 presents the regression coefficients for wives' retirement adjustment variables regressed on wives' own socio-demographic variables and husbands' adjustment variables. The results indicate that a husband's retirement adjustment variables explained a significant proportion of the variance in a wifes retirement adjustment variables. Specifically, a husband's satisfaction with financial planning explained a significant proportion of the variance in a wife's satisfaction financial 
planning, $R^{2}=.38, F(3,149)=22.43, p<.001$. Husband's satisfaction with nonfinancial planning also explained a significant proportion of the variance in a wife's satisfaction with non-financial planning, $R^{2}=.24, F(3,120)=9.3, p<.001$. Finally, a husband's retirement success explained a significant portion of the variance in a wife's retirement success, $R^{2}=.16, F(3,120)=6.20, p<.01$.

The hypothesis that a wife's retirement adjustment was a function of a husband's retirement adjustment was supported in this regression analysis across all three of the husband's retirement adjustment predictor variables, that is, satisfaction with financial planning, satisfaction with non-financial planning, and your rating of retirement success. Other significant predictors of a wife's retirement adjustment included income for the three retirement adjustment items, i.e., satisfaction with financial planning, satisfaction with non-financial planning, and retirement success rating. Education and age were also significant predictors of a wife's financial planning satisfaction, but not of the other two retirement adjustment variables. 
Table 8. Wives' Retirement Adjustment Variables Regressed on Wives' Own SocioDemographic Indicators and Husbands' Retirement Adjustment Variables

\begin{tabular}{|c|c|c|c|}
\hline & $\begin{array}{l}\text { Financial planning } \\
\text { satisfaction (wife's) }\end{array}$ & $\begin{array}{l}\text { Non-financial planning } \\
\text { satisfaction (wife's) }\end{array}$ & $\begin{array}{l}\text { Retirement success } \\
\text { (wife's) }^{c}\end{array}$ \\
\hline Age (wife's) & $.143^{*}$ & .193 & .131 \\
\hline Income (wife's) & $.223^{* * *}$ & $.187^{*}$ & $.203^{*}$ \\
\hline Education (wife's) & $.171^{* *}$ & .018 & .145 \\
\hline $\begin{array}{l}\text { Financial planning } \\
\text { Satisfaction (husband's) }\end{array}$ & $.420^{* * *}$ & - & - \\
\hline $\begin{array}{l}\text { Non-financial planning } \\
\text { satisfaction (husband's) }\end{array}$ & 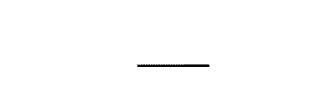 & $.369 * * *$ & - \\
\hline $\begin{array}{l}\text { Retirement success } \\
\text { (husband's) }\end{array}$ & - & - & $.227 * *$ \\
\hline
\end{tabular}

Crossover model for spouses' retirement adjustment and well-being. The initial step was to calculate the mean of the items in the latent variable retirement adjustment for wives and for husbands. Next, a structural equation model tested husbands' and wives' retirement adjustment and well-being latent variables, as shown in Figure 6. Hypothetical paths included the path from wives' retirement adjustment to husbands' well-being and the path from husbands' retirement adjustment to wives' well-being. In addition, the path from husbands' own retirement adjustment to his own well-being, and the path from wives' own retirement adjustment to her own well-being were tested. Due to the fact that responses concerning retirement adjustment and those 
concerning well-being were correlated, the errors from husbands' and wives' retirement adjustment and husbands' and wives' well-being items were correlated to reduce bias. The model produced a good fit, with a non-significant chi-square test $(\chi 2$ $(42, \mathrm{n}=183)=62.456, \mathrm{p}<021$.$) , and acceptable level on the CFI (.957), the TLI$ (.932), and the SRMR (.057). The coefficients for each path are presented in Figure 6.

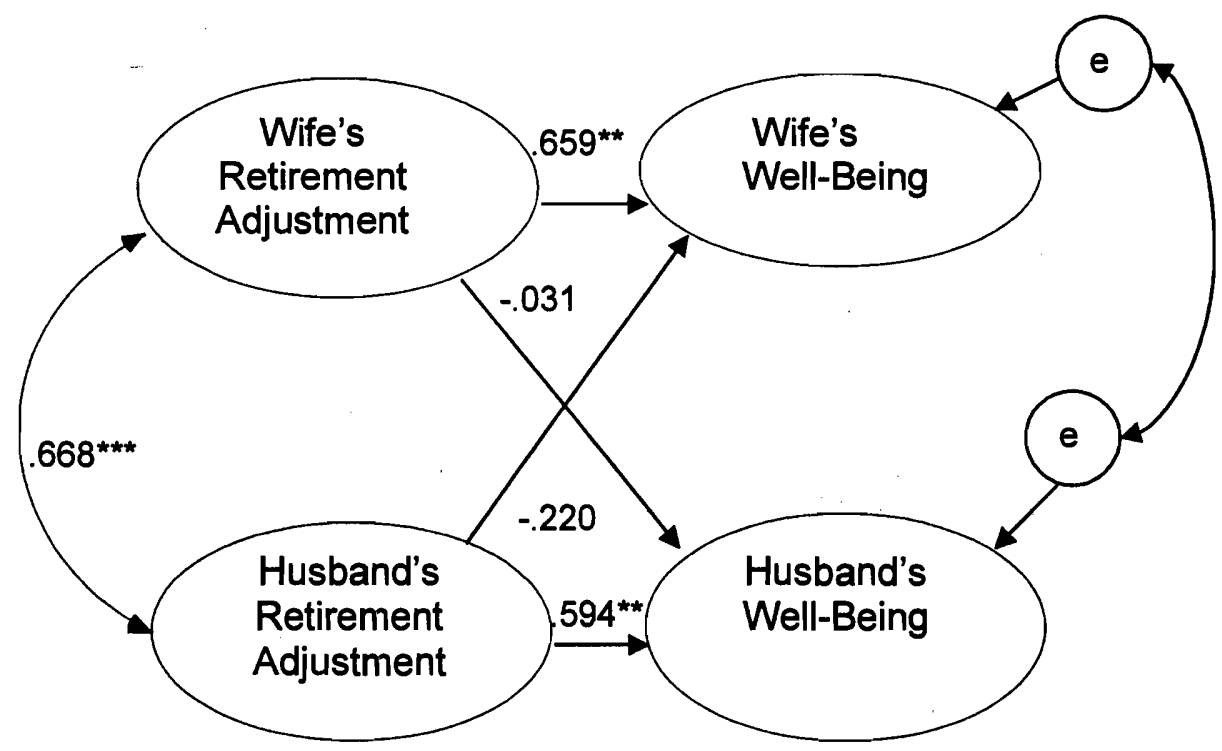

Figure 6. Crossover effects in spouses' retirement adjustment and well-being.

${ }^{*} \mathrm{p}<.05,{ }^{* *} \mathrm{p}<.01,{ }^{* * *} \mathrm{p}<.001$

As shown in Figure 6, however, significant crossover effects between husbands' and wives' retirement adjustment and well-being were not found in this sample. As mentioned in the previous section discussing the results of the multiple regression analyses, a possible reason for this is the strong intercorrelations between husbands' and wives' adjustment items. High correlations between spouses' items 
reduces the amount of variance left to predict other relationships. In this case, the ability to predict the effect of one partner's adjustment on his or her spouse's wellbeing is reduced by the high intercorrelations between their retirement adjustment items. This effect was corrected for in the present SEM analyses by correlating the error terms between the items between spouses' retirement adjustment and well-being variables, however; the results remained non-significant. Although non-significant, the results indicate a strong positive direction in the relationship between husbands' retirement adjustment and wives' well-being, and it is possible that with greater power from a larger sample, this effect would become statistically significant.

The correlation between wives' well-being and husbands' well-being was nonsignificant in this model. The correlation between husbands' retirement adjustment and wifes' retirement adjustment, however, was strong $(\mathrm{r}=.668, \mathrm{p}<.000)$, and when a path regressing a wife's retirement adjustment on a husband's retirement adjustment was tested, the relationship was significant $(.744, \mathrm{p}<.001)$.

\section{Hypothesis 4}

A structural model was used to test the fourth hypothesis that one's partner's retirement circumstance predicts one's own retirement adjustment, which in turn predicts well-being. One's own retirement adjustment is hypothesized to partially mediate the relationship between partner's retirement circumstance and one's own well-being. As discussed previously, partial mediation occurs when the path from X (partner's retirement circumstance) to Y (one's own well-being) is reduced in absolute size but is still different from zero when the mediator (M) (one's own retirement 
adjustment) was controlled. In the case of full mediation, the relationship between $\mathrm{X}$ and $Y$ ceases to exist when the $M$ is controlled. Research has established the nonindependence of couple-level data (Kenny, 1996; Newsom, 2002) with evidence of high correlation in responses within a couple. Therefore, the correlated errors (as shown in Figure 7) from husbands' and wives' retirement adjustment items and wellbeing were included in the model to reduce bias.

A hypothetical partner effect between one's own retirement adjustment and one's own well-being and a partner's forced retirement circumstance was tested in this model. The hypothesis was tested at the partner level; the spouse of an individual who was forced to retire was expected to have lower levels of adjustment due to a hypothesized partner effect (Kenny, 1996) or contagion effect (Bookwala and Schulz, 1995). Low levels of individual adjustment were hypothesized to predict low levels of individual adjustment in partners. Conversely, high levels of individual adjustment in one partner were hypothesized to predict high levels of individual adjustment in the other.

To determine if retirement adjustment was a mediator in the relationship between retirement circumstance and well-being, the model indirect effects were tested. The relationship between $\mathrm{X}$ (partner's retirement circumstance) and $\mathrm{Y}$ (one's own well-being) is indirect if $\mathrm{X}$ causes $\mathrm{M}$ (one's own retirement adjustment) which in turn causes Y., but the direct relationship between X (partner's retirement circumstance) and $\mathrm{Y}$ (one's own well-being) was not tested in this model. The overall model fit was poor; however, the indirect effect between a wife's forced retirement 
circumstance and a husband's well-being was significant, $[\mathrm{r}=-.247, \mathrm{p}<.05]$ as shown in Figure 7. This finding supports the hypothesis that a wife's forced retirement status negatively influences a husband's well-being.

In contrast, the indirect effect between a husband's forced retirement and a wife's well-being was non-significant, which suggests that wives are not as negatively influenced by a husbands' forced retirement. Partial support was found for the hypothesized crossover effect between a partner's retirement circumstance and one's own well-being. The hypothesis that one's own retirement adjustment would significantly influence his or her partner's retirement adjustment and well-being was partially supported in this analysis. 


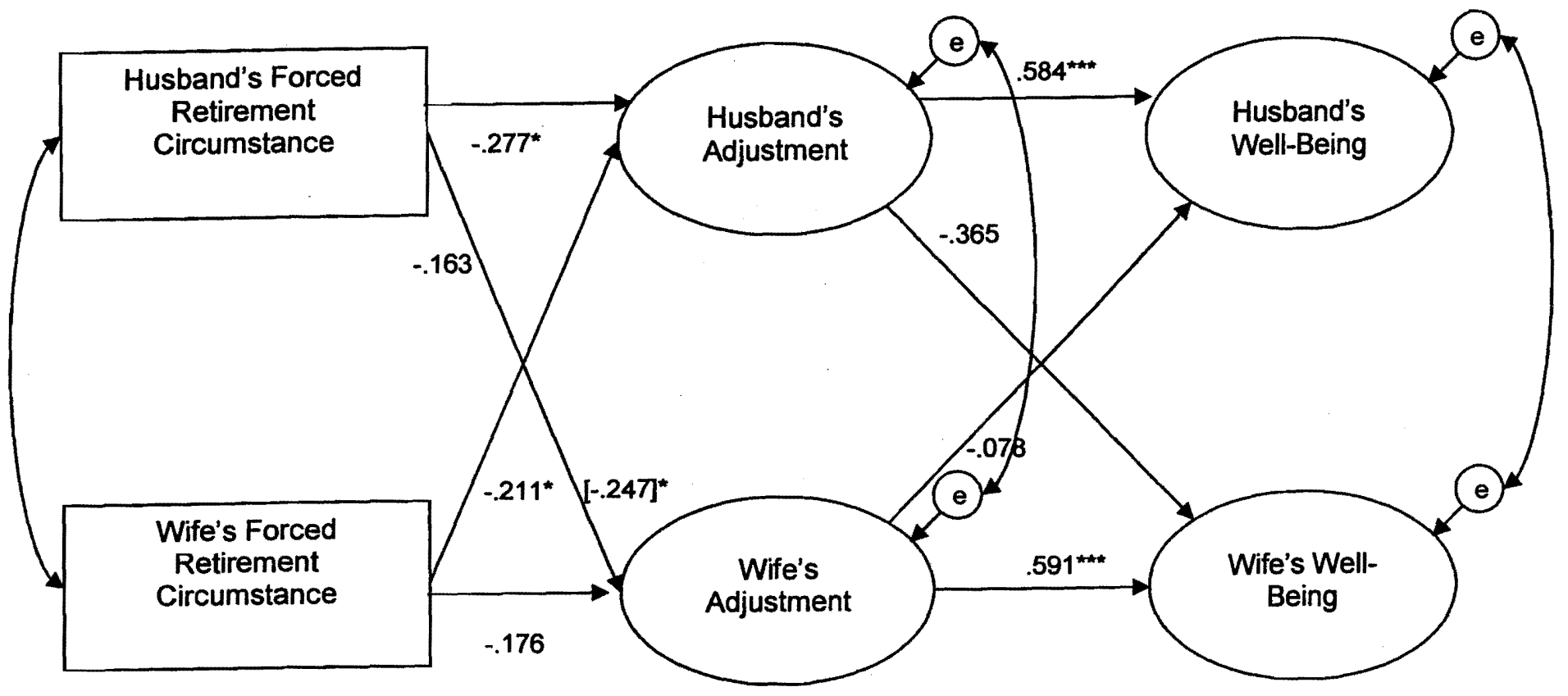

Figure 7. Crossover effects of partner's forced retirement on one's own well-being mediated by one's own retirement adjustment.

Note: Significant crossover between wives' forced retirement and husbands' retirement adjustment. The bracketed value represents the indirect effect coefficient. 


\section{Hypothesis 5}

In the final analyses, it was hypothesized that predictors of retirement adjustment and well-being for both husbands and wives would include low numbers of health problems, a voluntary retirement circumstance, a fully retired work status, education and income. The predictors for retirement adjustment and well-being were selected based on findings from a review of the literature. All five variables were found in the literature to influence either retirement adjustment or well-being. Structural equation modeling was used to analyze the hypothesized causal relationships between these variables and the possible mediating effects of retirement adjustment. The measurement model was specified with separate confirmatory factor analyses for husbands and wives. Couples with the highest levels of retirement adjustment and well-being in retirement were hypothesized to be fully retired, to have a low number of health problems, higher levels of education, higher household incomes and a voluntary retirement circumstance. First, a structural equation model was tested separately for husbands and for wives regressing well-being on retirement adjustment and retirement adjustment on the five hypothesized predictors of retirement adjustment. In the second step, direct paths from the observed variables to well-being were added.

Retirement adjustment mediation model: husbands. In the initial model, as described above, which tested only for direct effects of the observed variables on retirement adjustment without direct paths from the observed variables to well-being, education was a significant a predictor of a husband's retirement adjustment $(.192, \mathrm{p}<$ 
05), not shown. This relationship lost significance, however, when a direct path from education to well-being was added to the model, $(.124, \mathrm{p}=\mathrm{ns})$, as shown in Figure 8 . The significant direct effect between education and well-being, and the non-significant direct effect between education and husband's retirement adjustment, indicates that an indirect effect in the relationship between education and well-being was not found.

For husbands, total household income was also a significant predictor of a husband's retirement adjustment $(.375, \mathrm{p}<.001)$. The direct path from income to wellbeing was reduced yet remained significant $(.258, \mathrm{p}<.05)$ for husbands when a path to retirement adjustment was added in the second model. Because both paths remained significant in the second model, the relationship between a husband's income and a husband's well-being is consistent with partial mediation by retirement adjustment $[.126, \mathrm{p}<.05]$. Number of health problems did not significantly affect retirement adjustment for husbands; however, number of health problems had a significant direct negative effect on a husband's well-being $(-.256, \mathrm{p}<.05)$.

Another significant negative predictor of a husband's retirement adjustment was a forced retirement status $(-.197, \mathrm{p}<.05)$ ("Yes" responses to this item, "were you forced to retire," were coded 1, "no" responses were coded 0 ). This item remained significant when the direct path to well-being was added to the model, however, the direct path from a husband's forced retirement to well-being was non-significant $(-.85$, $\mathrm{p}=\mathrm{ns}$ ) and thus an indirect effect between a husband's forced retirement and his wellbeing was not consistent with mediation by his retirement adjustment. "Fully Retired Work Status," $(.265, \mathrm{p}<.001)$, was also a significant predictor of a husband's 
retirement adjustment (a "semi-retired or retired but returned to work full or parttime," was coded 1, and a "fully retired" current work status was coded 2). Three predictors of husbands' retirement adjustment were found including a negative relationship with forced retirement and positive relationship with a fully retired work status and income. In addition, education and number of health problems were found to have a significant direct effect on well-being.

The relationship between a husband's income and his well-being is consistent with partial mediation by his retirement adjustment because when well-being was added to the model, this relationship was reduced but remained significant. Thus, the hypothesis that the five predictors of retirement adjustment were education, a voluntary retirement, a fully retired work status, number of health problems and income, was partially supported by this analysis. 


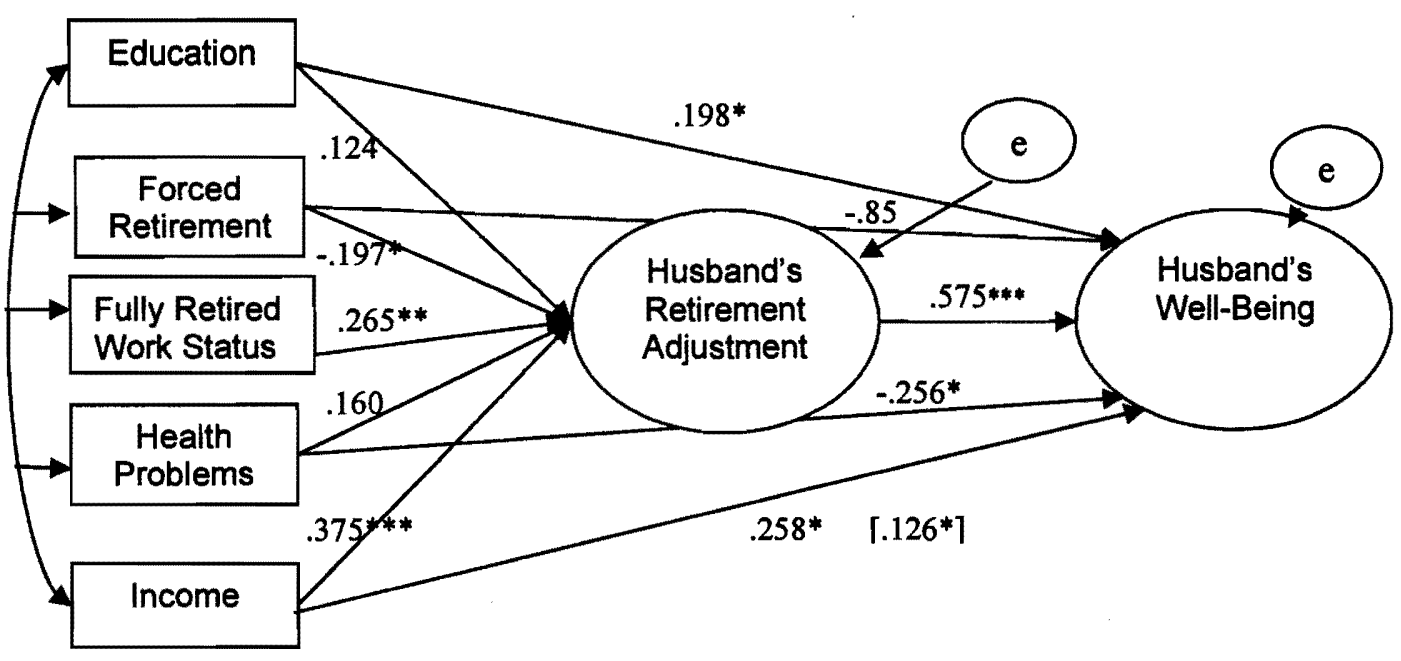

Figure 8. Predictors of husbands' retirement adjustment and well-being

${ }^{*} \mathrm{p}<.05,{ }^{* *} \mathrm{p}<.01,{ }^{* * *} \mathrm{p}<.001$.

Note: the bracketed value is the indirect effect coefficient.

Predictors of retirement adjustment: wives. In the first model, in which direct paths to well-being were not included, the two significant predictors of retirement adjustment were "How much formal education have you had?" $(.213, \mathrm{p}<.001)$, and, "Your total annual household income last year," $(.348, \mathrm{p}<.001)$ (not shown). In the second model, a direct effect test of education on well-being for wives (as shown in Figure 9) was also significant $(.179, \mathrm{p}<.05)$, this indicates the relationship between education and wives' well-being is consistent with partial mediation by wives' retirement adjustment $\left[.121^{*}, \mathrm{p}<.05\right]$. 
A direct effect test between income and well-being in the second model was significant $(.223, \mathrm{p}<.05)$. Income remained a significant predictor of retirement adjustment for wives $(.348, \mathrm{p}<.001)$ in the second model. This indicates the relationship between income and well-being is consistent with partial mediation by wives' retirement adjustment [.234, $\mathrm{p}<.05]$, as shown in Figure 9. A forced retirement did not have a significant effect on a wife's retirement adjustment, but a forced retirement did have a significant direct negative effect on a wife's well-being $(-.101, \mathrm{p}<.05)$. Similarly, number of health problems did not have a significant relationship with a wife's retirement adjustment but number of health problems did have a significant direct negative effect on a wife's well-being $(-.281, \mathrm{p}<.01)$. Retirement adjustment was a significant predictor of well-being for wives $(.608, \mathrm{p}$ $<.001)$. The hypothesis that the five predictors of retirement adjustment were education, a voluntary retirement, a fully retired work status, low number of health problems and high levels of household income, was partially supported by this analysis.

Two predictors of wives' retirement adjustment were found, including a positive relationship with education and income. In addition for wives, education, income, a forced retirement and number of health problems were found to have a direct effect on well-being. The relationships between a wife's income and her wellbeing, and between a wife's education and her well-being, were found to be partially mediated by her retirement adjustment. The hypothesis that five predictors of 
retirement adjustment were education, a forced retirement, a fully retired work status, health problems and income, therefore, was partially supported by this analysis.

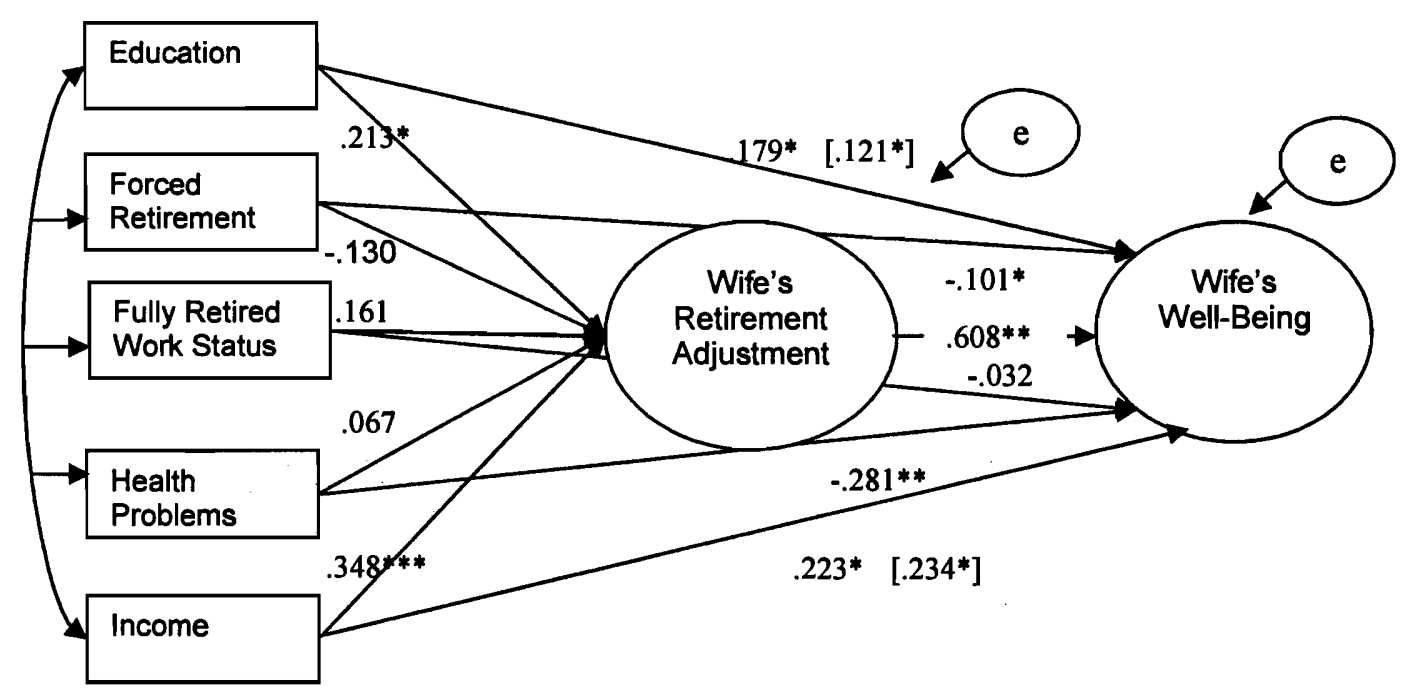

Figure 9. Predictors of wives' retirement adjustment and well-being

${ }^{*} \mathrm{p}<.05,{ }^{* *} \mathrm{p}<.01,{ }^{* * *} \mathrm{p}<.001$

Note: the bracketed values are the indirect effect coefficients.

To evaluate the possibility of other predictors of retirement adjustment and well-being in retirement for husbands and wives, a full model including a range of possible predictors was tested for each, as presented in Table 9. The fit for these models was poor for both husbands and wives.

Full model of retirement adjustment predictors for husbands. The fit of this model was poor with a significant chi-square test $(\chi 2(77, \mathrm{n}=183)=153, \mathrm{p}<.001)$, a 
CFI .813, a TLI of .760, and a SRMR of .056. Despite a poor model fit, significant paths were found between several observed items and the latent variable retirement adjustment. Boredom, had a negative relationship with a husband's retirement adjustment $(-.172, \mathrm{p}<.05)$. Social support, $(.261, \mathrm{p}<.001)$, had a positive relationship with a husband's retirement adjustment; maintenance of living standard in retirement, $(.333, \mathrm{p}<.001)$, had a positive relationship with a husband's retirement adjustment and leisure activity $(.180, \mathrm{p}<.05)$, had a positive relationship with a husband's retirement adjustment. These four relationships were also significant for wives as discussed in the following section.

Four additional items were significant predictors of retirement adjustment for husbands but were non-significant for wives: a forced retirement had a negative relationship with a husband's adjustment, $(-.145, \mathrm{p}<.05)$. A fully retired work status was a positive predictor of a husband's retirement adjustment, $(.220, \mathrm{p}<.01)$. Other positive predictors of a husband's retirement adjustment were household income, $(.251, \mathrm{p}<.01)$; and lack of setbacks or changes since retirement that forced the respondent to alter plans, $(.253, \mathrm{p}<.001)$. As shown earlier, husbands' well-being regressed on husbands' retirement adjustment was highly significant $(.675, \mathrm{p}<.001)$. The results for this model are shown in Figure 10.

The following predictors of retirement adjustment were non-significant for husbands: education, religious beliefs, spirituality, flexibility, occupation, and number of health problems. See pages 77-79 for information about how these items were coded. 




Figure 10. Full model of predictors of husbands' retirement adjustment.

${ }^{*} \mathrm{p}<.05,{ }^{* *} \mathrm{p}<.01,{ }^{* * *} \mathrm{p}<.001$ 
Table 9: Full Model of Hypothesized Predictors of Retirement Adjustment ( $n=183)$

\begin{tabular}{|c|c|c|}
\hline \multirow[t]{2}{*}{ Item } & \multicolumn{2}{|c|}{ Loadings } \\
\hline & Husbands & Wives \\
\hline Education & .055 & .108 \\
\hline $\begin{array}{l}\text { Religious beliefs or spiritual } \\
\text { influences }\end{array}$ & .035 & -.047 \\
\hline $\begin{array}{l}\text { Bored }(1=\text { strongly disagree, } 5= \\
\text { strongly agree })\end{array}$ & $-.172^{*}$ & $-.264^{* *}$ \\
\hline Importance of spirituality & .038 & .187 \\
\hline Adaptability or flexibility & -.059 & .101 \\
\hline Social Support & $.261^{* * *}$ & $.204^{*}$ \\
\hline $\begin{array}{l}\text { Ability to maintain desired standard } \\
\text { of living }\end{array}$ & $.333^{* * *}$ & $.223 * *$ \\
\hline $\begin{array}{l}\text { Forced into semi-retirement or } \\
\text { retirement }(1=\text { yes, } 2=\text { no })\end{array}$ & $-.145^{*}$ & -.119 \\
\hline $\begin{array}{l}\text { Current work status }(1=\text { semi or fully } \\
\text { retired but returned to work, } 2=\text { fully } \\
\text { retired) }\end{array}$ & $.220^{* *}$ & .032 \\
\hline $\begin{array}{l}\text { Primary occupation }(0=\text { professional, } \\
1=\text { non-professional) }\end{array}$ & -.105 & .003 \\
\hline Leisure activity & $.180^{*}$ & $.338^{* * *}$ \\
\hline Number of health problems & -.051 & -.030 \\
\hline Total annual household income & $.251^{* *}$ & .181 \\
\hline $\begin{array}{l}\text { Changes in your life since retirement } \\
\text { that forced alteration of plans }(1= \\
\text { yes, } 2=\text { no) }\end{array}$ & $.253^{* * *}$ & .124 \\
\hline
\end{tabular}


Full model of retirement adjustment predictors for wives. The same full model of possible predictors of retirement adjustment was tested for wives. The model fit was poor with a chi-square test that was significant $(\chi 2(77, \mathrm{n}=183)=196, \mathrm{p}<001$.$) ,$ CFI of .685, and TLI of .595, and a SRMR of .057. As mentioned previously, the wives shared four significant relationships between predictor variables and retirement adjustment with husbands. Significant paths were found between the following observed items and the latent variable retirement adjustment (see pages $75-76$ for information regarding the coding of these variables): "I am often bored," (-.264, $p$ $<.01)$; "The social support you get from family?" $(.204, \mathrm{p}<.01)$; "You are maintaining your desired standard of living in retirement," $(.223, \mathrm{p}<.01)$; and "leisure activity," $(.338, \mathrm{p}<.001)$, as shown in Figure 11. These results provide more information about predictors of retirement adjustment and well-being in retirement for wives, particularly regarding the importance of intellectual stimulation and variety in leisure activities. Specifically, these results indicate that a high level of boredom predicts poor retirement adjustment for a wife, but a greater level of leisure activity is associated with greater retirement adjustment for wives. Furthermore, these results indicate that higher levels of satisfaction with social support from family positively predicted a wife's retirement adjustment, as did maintaining one's desired standard of living in retirement.

As found in previous analyses, the path between a wife's retirement adjustment and wife's well-being was highly significant, $(.768, \mathrm{p}<.001)$. The 
coefficients for each path for wives and for husbands are presented in Table 9. Although a forced retirement status predicted poor adjustment for husbands, it did not do so for wives. Similarly, a fully retired work status was a positive predictor of retirement adjustment for men but not for wives, and higher levels of income were associated with higher levels of adjustment for husbands but not wives. A number of other non-significant predictors of retirement adjustment for wives: level of education, importance of religious beliefs, importance of spirituality, flexibility/adaptability, a forced retirement, a fully retired work status, professional vs. non-professional occupation, number of health problems, household income, and lack of setbacks. Please refer to pages 77-79 for information about how these variables were coded. 


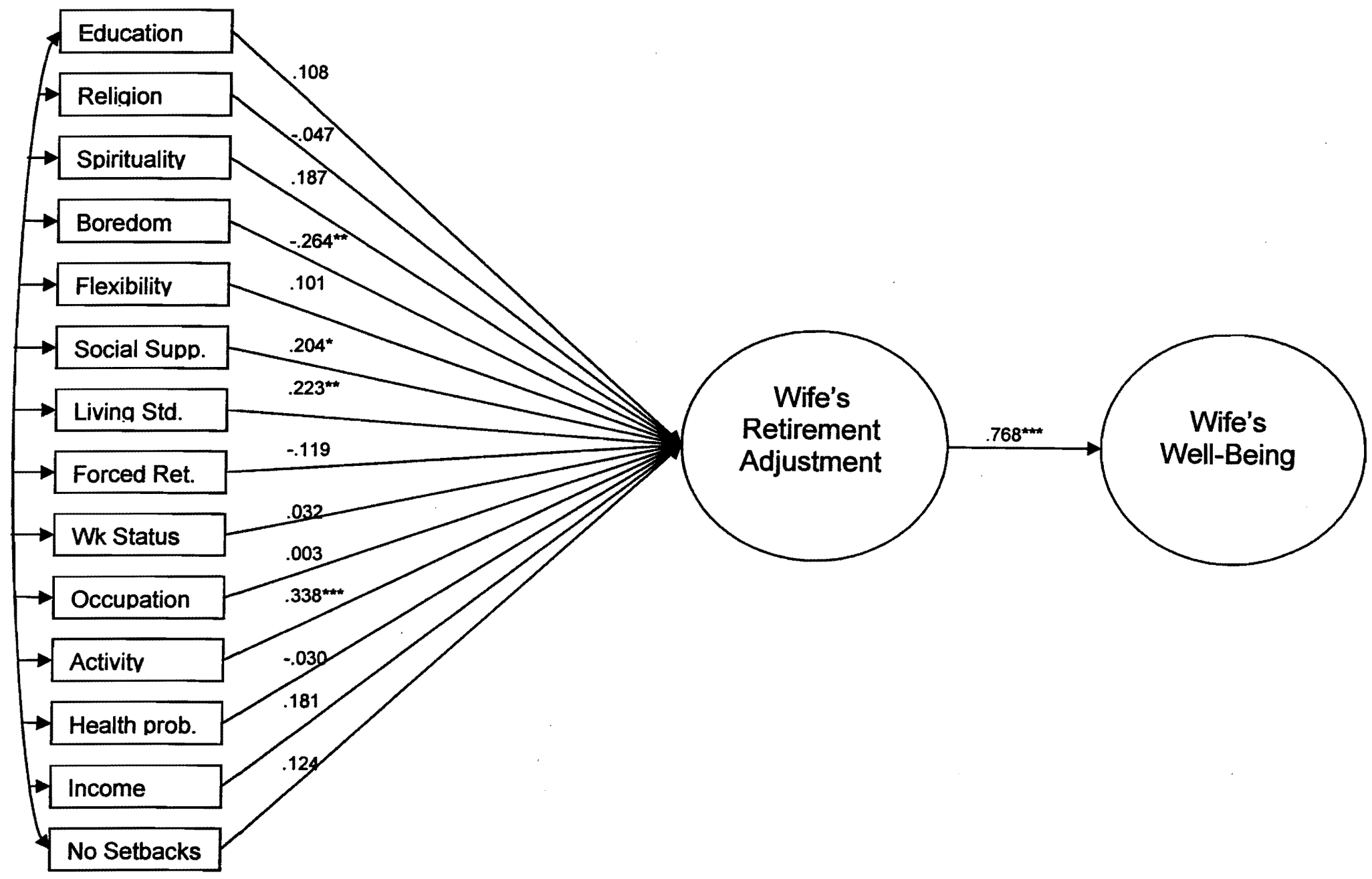

Figure 11. Full model of predictors of wives' retirement adjustment.

${ }^{*} \mathrm{p}<.05,{ }^{* *} \mathrm{p}<.01,{ }^{* * *} \mathrm{p}<.001$. 


\section{Summary and Discussion}

Most research focused on adjustment and well-being in retirement has concentrated on individual adjustment and well-being. This individualistic approach captures a singular portion of the retirement experience; for those who retire with a spouse, the retirement experience is merged with their partner's retirement experience. Gerontologists have identified a need to account for a spouse's or partner's experience when studying retirement adjustment ( Kulik and Bareli, 1997; Phillipson, 1994; Vinick and Ekerdt, 1991). This study examined the crossover effects between husbands and wives as they adjust to retirement, with an emphasis on how this mutual influence affects individual retirement adjustment and subjective well-being. A major objective of this research was to offer a more holistic perspective of the factors which contribute to retirement adjustment and well-being among couples.

\section{Actor-Effects Hypotheses: $\mathrm{H1}, \mathrm{H} 2$ and $\mathrm{H} 5$}

The first hypothesis proposed in this study, for which a direction was not selected due to inconsistent findings in the literature regarding gender and levels of adjustment to retirement, did not reveal a pattern of lower or higher levels of adjustment based on gender except for one item, satisfaction with financial planning. The results of the t-test for this item indicated that wives experience lower levels of satisfaction with a couples' financial planning for retirement. The scale-level test of the aggregated retirement adjustment items, however, did not find significant differences between husbands' and wives' levels of retirement adjustment. These 
Table 10: Summary of Hypotheses

\begin{tabular}{|c|c|c|c|}
\hline & Supported & Partially Supported & Not Supported \\
\hline $\begin{array}{l}\text { Hypothesis } 1: \text { Husbands and wives } \\
\text { differ in respect to their levels of } \\
\text { retirement adjustment and well-being } \\
\text { Hypothesis } 2: \text { One's own health status } \\
\text { and retirement circumstance } \\
\text { (forced/not forced) are predictors of } \\
\text { one's own well-being and are partially } \\
\text { mediated by one's own retirement } \\
\text { adjustment } \\
\text { Hypothesis } 3: \text { An individual's } \\
\text { retirement adjustment and well-being } \\
\text { is influenced by his/her partner's } \\
\text { retirement adjustment }\end{array}$ & & $\begin{array}{l}\text { Wives experienced significantly lower levels of well-being and } \\
\text { significantly lower levels of satisfaction with couples' financial } \\
\text { planning. } \\
\text { Number of health problems negatively predicted retirement adjustment } \\
\text { and well-being for husbands. The relationship between a husband's } \\
\text { number of health problems and his well-being was consistent with } \\
\text { partial mediation by his retirement adjustment. A forced retirement } \\
\text { circumstance negatively predicted a husband's retirement adjustment. } \\
\text { Number of health problems predicted well-being for wives. } \\
\text { A husband's retirement adjustment items predicted a wife's retirement } \\
\text { adjustment items, and vice versa in the regression analyses, but not in } \\
\text { the structural equation model }\end{array}$ & \\
\hline $\begin{array}{l}\text { Hypothesis } 4: \text { An individual's well- } \\
\text { being is influenced by his/her } \\
\text { partner's retirement circumstance }\end{array}$ & & $\begin{array}{l}\text { The negative effect of a wife's forced retirement on a husband's well- } \\
\text { being was mediated his retirement adjustment. A wife's retirement } \\
\text { adjustment predicted her well-being and a husband's retirement } \\
\text { adjustment predicted his well-being. }\end{array}$ & \\
\hline $\begin{array}{l}\text { Hypothesis 5: Predictors of retirement } \\
\text { adjustment and well-being for } \\
\text { individuals will include health, } \\
\text { education, income, a retired work } \\
\text { status, and retirement circumstance. }\end{array}$ & & $\begin{array}{l}\text { Three predictors of husbands' retirement adjustment were found } \\
\text { including a forced retirement, a fully retired work status and income. } \\
\text { In addition, education and number of health problems were found to } \\
\text { have a direct effect on well-being. The relationship between a } \\
\text { husband's income and his well-being was partially mediated by his } \\
\text { retirement adjustment. Two predictors of a wife's retirement } \\
\text { adjustment were found including a positive relationship with education } \\
\text { and income. In addition for wives, education, income, a forced } \\
\text { retirement and number of health problems were found to have a direct } \\
\text { effect on well-being. A wife's income and her well-being, and between } \\
\text { a wife's education and her well-being, was partially mediated by her } \\
\text { adjustment. }\end{array}$ & \\
\hline
\end{tabular}


findings support the results of earlier studies that examined gender differences in levels of adjustment to retirement (Hansen and Wapner, 1994; Slevin and Wingrove, 1995) and found that husbands and wives adjust to retirement at similar levels. A difference in patterns of stress handling ability was found, however, with wives experiencing significantly lower levels of stress handling ability than husbands. This finding supports the results of earlier studies in which women were found to have lower levels of well-being (Baruch \& Barnett, 1986; Beach, Katz, Kim \& Brody, 2003).

This second hypothesis stated that a forced retirement and health problems would predict lower levels of retirement adjustment and well-being for both husbands and wives. This hypothesis was partially supported for husbands.

A significant direct path between number of health problems and retirement adjustment, and a significant direct path from number of health problems to wellbeing, was consistent with partial mediation. Thus, for husbands, the effect of number of health problems on well-being is consistent with partial mediation by retirement adjustment. The hypothesis that the effect of a husband's number of health problems on his well-being is consistent with partial mediation by his retirement adjustment is supported for husbands in this analysis.

There was a significant direct path between forced retirement circumstance and retirement adjustment for husbands in this model and a non-significant direct path from forced retirement circumstance to well-being. Thus, a husband's forced 
retirement was a significant predictor of his retirement adjustment, but was not a significant predictor of his well-being.

Interestingly, retirement adjustment does not appear to be an important mediator of well-being for wives in this study. The hypothesis that retirement circumstance and number of health problems predict retirement adjustment, which in turn predicts well-being was not supported. The only significant path in this model was a direct negative relationship between number of health problems and well-being. Wives' well-being was not mediated by their retirement adjustment. Similarly, the relationship between wives' well-being and number of health problems was not mediated by their own retirement adjustment. These findings suggest that health problems are a significant predictor of well-being for wives and that a forced retirement does not predict retirement adjustment or well-being for wives.

The non-significant relationship between forced retirement and wives' wellbeing may be due to men's and women's differing role expectations and work history. Women in the current retirement cohort began their adult lives with fewer labor market opportunities. The booming economic conditions of post World War II America allowed more families to subsist on a single income (Znaniecki \& Steinhart, 1971). This economic shift led to an emphasis in gendered roles, specifically male breadwinner/female caregiver roles: more women stayed home to care for children and other family members, and more men provided a family income without assistance from their wives. 
Subsequent generations of women, compelled by economic necessity, the feminist movement, and expanding labor market opportunities, entered the workforce in larger numbers and with a greater probability of lifelong workforce employment (Han \& Moen, 1999). Many of these women currently participate in careers with minimal or no work role interruption due to caregiving duties. This does not mean that caregiving duties are reduced among working women, but that these duties are often performed in addition to work (Ruhm, 1996). A forced retirement from a lifelong, uninterrupted career is potentially more distressing for subsequent cohorts of women than for the cohort of women in this data set, who may have fewer attachments to the work role due to the aforementioned social, economic and cultural factors peculiar to them. Due to the higher levels of education of women now in the workforce, today's career-oriented women may face problems similar to those faced by men in transition to retirement. They will have needs for prestige, achievement, and recognition that must be met (Erdner \& Guy, 1990).

In the fifth hypothesis and final actor-effect hypothesis, predictors of positive retirement adjustment and well-being were hypothesized to be higher household income, fewer health problems, higher education, and a forced retirement circumstance. Higher levels of income resulted in higher levels of retirement adjustment. Higher levels of income are a well-documented indicator of enhanced well-being in adulthood (Murrel \& Meeks, 2002, Szinovacz, 1984). In the preliminary model which tested only for direct effects of five observed variables on retirement adjustment, without direct paths from the observed variables to 
well-being, education was a significant a predictor of husbands' retirement adjustment. This relationship lost significance, however, when a direct path from education to well-being was added to the model. The significant direct effect between education and well-being suggests that the relationship between education and wellbeing is not mediated by husbands' retirement adjustment and that for husbands, education is a more important predictor of well-being than retirement adjustment.

Education was also a significant predictor for wives of retirement adjustment in the preliminary model; however, a direct effect test of wives' education on wellbeing in the second model (as shown in Figure 9) was also significant. This suggests the relationship between education and wives' well-being was partially mediated by wives' retirement adjustment. This suggests education is an important predictor retirement adjustment and well-being for wives.

Similarly, the direct path from income to well-being in the second model remained significant, but income also remained a significant predictor of retirement adjustment for husbands and wives which suggests the relationship between income and well-being was partially mediated by retirement adjustment for both husbands and wives.

A forced retirement had a significant direct negative effect on well-being for husbands in this model but not for wives. A significant path was found for husbands between forced retirement and husbands' retirement adjustment, however. This suggests that a forced retirement negatively affects husbands' retirement adjustment, but does not have a direct effect on their well-being. The opposite was 
found for wives; a forced retirement did not have a significant effect on their retirement adjustment, but a forced retirement did not have a significant direct effect on their well-being. This effect may be attributed to the fact that most wives who were forced to retire, retired for health reasons, (see table 2) and therefore, retirement adjustment is secondary to overall well-being for wives. In other words, the relationship between a forced retirement and retirement adjustment is less important than the relationship between a forced retirement and well-being in wives whose wellbeing is compromised by illness.

Number of health problems had a significant negative direct effect on wellbeing for wives and husbands but was not a significant predictor of retirement adjustment for either husbands or wives. Overall, husbands and wives shared two predictors of retirement adjustment (i.e., higher levels of education and income), and three predictors of well-being (i.e., higher levels of education and income, and lower levels health problems).

The full model of predictors of retirement adjustment for husbands and wives found four additional common predictors for husbands and wives, including high levels of social support, maintaining standard one's standard of living, high levels of variety in leisure activities and low levels of boredom. For husbands, a fully retired work status, higher household income in the last year, and lack of setbacks in the past year had a significant positive relationship with retirement adjustment, in addition to the four predictors they shared in common with wives. 


\section{Partner-Effects Hypotheses}

It is important to think about retirement adjustment and well-being as an shared process among those living with a spouse and to consider the following question: does poor adjustment to retirement result from factors assessed at the individual level, such as a forced retirement or poor health status, or is poor adjustment the result of a crossover effect, in which an individual's adjustment is negatively influenced by a spouse's difficult adjustment? Similarly, is a positive adjustment to retirement the result of a crossover effect in which the individual's adjustment is positively influenced by a spouse's positive adjustment?

The third hypothesis explored the possibility of a crossover effect in spouses' retirement adjustment and well-being. Hypothesis 3 stated that the adjustment of one spouse would be influenced by that of the other and that a crossover effect regarding retirement adjustment would be found in this population. The regression analyses were conducted to evaluate the amount of variance shared between spouse's adjustment variables, i.e., the proportion of the variance in a partner's adjustment item (e.g., satisfaction with financial planning) that is explained by his or her spouse's same adjustment item. This hypothesis was partially supported by the findings, with highly significant intercorrelations between husbands' and wives' adjustment items, an indicator that a partner effect is present in levels of adjustment between spouses (Kenny, 1996). The results of the multiple regression analyses revealed an individual's adjustment is a significant predictor of his or her partner's adjustment to retirement. Therefore, it appears that the rate of one spouse's retirement adjustment is heavily 
influenced by the rate of the partner. In other words, evidence of a contagion effect is supported by these findings, further emphasizing the need to consider both partners when the retirement transition is studied.

The results of the structural equation model which tested for the relationship between one own adjustment and a partner's well-being was non-significant. As mentioned previously, high intercorrelations between these items could reduce the ability to determine a crossover effect between a husband's retirement adjustment and a wives' well-being, and vice versa. Conversely, low intercorrelations between items could improve the ability to determine a crossover effect between a partner's retirement adjustment and a spouse's well-being. In other words, crossover effects may be difficult to detect because of this method factor.

In the structural equation model, in which both latent variables retirement adjustment and well-being were included, the relationship between one's own adjustment and a partner's well-being was non-significant. There was, however, a negative direction which approached significance. This trend indicates potential synergy in spousal adjustment patterns. A larger sample with greater analytical power may have yielded a significant relationship between spouses' retirement adjustment and partners' well-being.

The fourth hypothesis proposed that an individual's own retirement adjustment would be influenced by his or her partner's retirement circumstance. That is, it was hypothesized that the spouse of an individual who was forced to retire would have lower levels of adjustment due to the hypothesized partner effect. Again, the findings 
were divided along gender lines. A significant negative relationship was found between wives' forced retirement and husbands' retirement adjustment, but wives' retirement adjustment was not negatively impacted by husbands' forced retirement.

These results were somewhat surprising given evidence of stronger crossover effects for wives than husbands in other studies. For example, the study conducted by Haug, Belgrave and Jones (1992) found that a husband's chronic condition impacted a wife's adjustment, but a wife's chronic condition did not impact a husband's retirement adjustment. The negative crossover effect present in husbands whose wives were forced to retire, then, was an unexpected finding. It appears that the distress of a forced retirement experienced by a wife is transferred to her husband through a crossover or contagion effect that is in some way more potent for wives than for husbands. One possible explanation for this may be attributed to the fact that both men and women most commonly cited illness as a reason for forced retirement. A wife's illness may be more distressing to a husband than a husband's illness is to a wife. This may be because husbands may feel unprepared to take on the caregiver role. Moreover, women, who are typically healthier than men in older adulthood (Gold, Malmberg, McClearn, Pedersen, \& Berg, 2002), may view a forced retirement for health reasons as a more non-normative event, whereas men may view retirement for health reasons as a more normative.

The magnitude of the crossover effects by gender were not tested in this study. Although a study examining the magnitude of crossover effects and retirement adjustment has not been published at this time, research on job stress indicates that the 
direction of crossover effects is influenced by gender. Westman (2002) reviewed 25 studies that have examined crossover of stress or strain; eight of these studies examined, and five found, bidirectional crossover effects between spouses. For instance, Hammer, Allen and Grigsby (1997) found a bidirectional crossover of workfamily conflict. After controlling for schedule flexibility, work salience, and family involvement, husbands' work-family-conflict accounted for additional variance explained in wives' work-family-conflict, and vice versa. Three of the studies with bidirectional designs investigated by Westman (2002) found only unidirectional crossover from husbands to wives (e.g., Jones \& Fletcher, 1993) or vice versa (e.g., Galambos \& Walters, 1992). Westman (2002) argues that these gender differences in the crossover process can be attributed to gender differences in coping strategies, and social support.

Another possible explanation for the significant negative relationship between wives' forced retirement circumstance and husbands' adjustment may be that wives may more effectively transmit the distress of their forced retirement to a spouse. Finally, it is also possible that wives' forced retirement results from perceived gender or age discrimination in the workforce, although more men than women in this sample cited age discrimination as reason for a forced retirement. The distress among wives may also relate to loss of income and loss of perceived independence relative to marital finances.

The absence of the work role and the influence of traditional gender roles appear to be important components of retirement adjustment and well-being. Role 
theory may offer some explanations for some of the differences between husbands and wives in this research, particularly related to the difference in effects of a forced retirement (significant for husbands, non-significant for wives; see results for tests of hypotheses). Role theory, as defined by the Social Work Dictionary (Barker, 1999), is "A group of concepts, based on sociocultural and anthropological investigations, which pertain to the way people are influenced in their behaviors by the variety of social positions they hold and the expectations that accompany those positions." Early role theorist Leonard Cottrell argued in 1942 that social roles diminish with age, leaving the individual with few resources for identity. In 1960, Burgess identified retirement as "roleless" due to the lack of defined role characteristics. Fry (1992) argued that negative images of aging can contribute to dissatisfaction with life in older adulthood. Retirees who are able to cultivate new roles to replace work roles may adjust with greater ease to retirement. This objective may be less necessary for the wives in this study because of the potential for the previously mentioned cohort effect in which wives may not have participated in the workforce consistently throughout their adult lives. The work role may have been secondary to family roles for these women, and because family roles tend to continue throughout older adulthood, the loss of the work role may require less adjustment for wives than husbands. For the retirees who were attached to their work roles, the ability to expand into new roles in retirement may predict their retirement adjustment and well-being. Some participants may have chosen to reclaim their work role by returning to work. Role theory may explain why 23 percent of the participants chose to re-enter the workforce after 
retirement. These individuals may have had a particularly strong attachment to their work roles.

For retired couples in previous studies, role theory appears to be particularly salient related to gender roles and the expectations associated with traditional gender roles. As discussed in the literature review, the results from Szinovacz's study (1996) of couples' employment and retirement patterns and perceptions of marital quality suggest that employment/retirement patterns that contradict spouses' role expectations undermine marital quality. The traditional gender-role employed husbands with retired wives in Szinovac's study reported somewhat higher marital quality than husbands in dual-earner couples. Although information about wives' work history was not available in the present data set, if a cohort effect does exist relative to wives' lower participation in the workforce, it is possible that many of the couples in this study embraced traditional gender roles and may therefore had fewer gender-role conflicts as they adjusted to retirement. Fewer gender-role conflicts may mean higher levels of adjustment for this sample than subsequent generations of retired couples who may embrace more egalitarian gender-role ideologies.

Taken together, these findings support the assumptions of family systems theory, in particular the idea that internal and external events that take place within a family have circular causality. Specifically, a single action by a family member will have an effect on the other family members, and their response will be reciprocal to that initial actor and the family's overall response (Nichols and Everett, 1986). In the case of husbands' and wives' retirement adjustment and well-being, the actions of one 
spouse can affect the other. The evidence of a crossover effect relative to a wife's forced retirement on a husband's retirement adjustment and well-being in retirement found in this present study is consistent with the family systems theoretical framework.

\section{Future Research}

The retirement transition is stressful for some retirees and for others it is not stressful. For whom is retirement adjustment stressful? The results from this study indicate that retirement is stressful for individuals who are forced to retire, have higher levels of boredom, and a higher number of health problems. A closer examination of the number and severity of health problems and the effects of these health problems on retirement adjustment and well-being may yield information about the relationship between functional limitations and well-being in retirement. The relationship between functional limitations and well-being in retirement may be moderated by other factors such as an individual's ability to recover from negative life events. Individuals who suffer from health problems, a forced retirement or other setbacks may adjust better to negative changes if they have high levels of resilience. Resilience is the ability to recover from or adjust easily to change. Some existing research indicates that resilient individuals "bounce back" from stressful experiences quickly and effectively (Tugade $\&$ Frederickson, 2004). Resilient people use positive emotions to rebound from stressful episodes, and existing research has found a number of key characteristics of resilient people, including psychological/dispositional attributes, family support, and 
external support systems (Friborg et al., 1999). Future research should shed light on the role of resilience as predictor of retirement adjustment.

The unexpected finding of the significant negative influence of wives' forced retirement and its significant negative influence on husbands' adjustment genelevels a number of questions for future research relative to gender and crossover effects. Specifically, are the contagion effects of one gender more highly transmittable than those of the other? Is one gender more prone to engage partners in marital conflict? If so, is gendered socialization responsible for these differences? What role does gendered communication play in the transmission of contagion effects among spouses? Future research into women's forced retirement should investigate women's work history and personal investment in work roles and should pay special attention to factors concerning women's caregiving roles and work interruption throughout the life course. Specifically, level of job involvement and attachment to the work role should be considered a possible predictor of women's retirement adjustment.

Low levels of boredom and greater variety of leisure activity appear to be an important link to successful retirement adjustment for both husbands and wives. Thus, this finding invites further research regarding leisure activity levels and wellbeing in retirement. Is it important for all retirees to maintain moderate levels of leisure activity, or are sedentary retirees equally satisfied with retirement? Mishra (1992), as cited in Brown and Lo (1999), studied the association between retirees' engagement in certain activities and their life satisfaction. The results from a sample of 720 retired men revealed a significant positive relationship between life satisfaction 
and involvement in activities connected with occupation, hobbies, and interaction with friends and members of voluntary organizations. However, engagement in religious and household activities had no impact on the participants interviewed and their happiness. Future research focused on the importance of these factors for women is necessary. The results from the present study indicate that variety in leisure activity was a significant predictor of retirement adjustment for both husbands and wives in adjustment to retirement. Future research into this topic would benefit from an analysis of activity type and its effect on retirement adjustment and well-being. Ideally, a survey developed to collect data on activity for the specific purpose of studying this question should include several sub-categories of types of activity.

A distinguishing characteristic of this data set is that in addition to responding to items inquiring about their own retirement experience, participants were given the opportunity to rate their partners on the same items. An interesting study may be to compare spousal differences in self-reported ratings. The research would involve examining differences between one's self-reported responses and a partner's responses to the same items. Are there significant differences between spouses in their selfreported ratings of the retirement experience? If so, does gender predict differences in how one perceives the retirement experience? Another layer of complexity may be added to the study by examining spousal differences in one spouse's perception of a partner's retirement experience versus the experience reported by that partner, and vice versa. 
Another distinguishing characteristic of this data set is the disproportionably large number of physicians surveyed: 58 of the respondents listed their primary occupation as physician. Further research concerning physicians and retirement, specifically, retirement adjustment among physicians, may be warranted due to higher levels of work salience that they may experience, and because little empirical information is available concerning physicians and retirement (Austrom, Perkins, Damush, \& Hendrie, 2003; Graitz, 1977; Weisberg, 1996). According to the study by Graitz, the typical physician places high values on work and values other activities less. Busy practitioners who have spent little time with their families and in recreational pursuits find themselves unprepared for their altered status when they stop working. The study by Austrom et al., (2003) found several factors which contributed to life satisfaction in retirement for physicians and their spouses, including better health, optimism, feelings of financial security, participation in activities and hobbies, and a good sexual relationship. For the spouses of physicians, good health, having a husband willing to help with chores, quality of relationships (including sexual relationship), and attending theater or sporting events were associated with higher levels of life satisfaction. Therefore, retirement adjustment issues may be especially significant for this population and for other populations whose professions require a high level of commitment to work demands.

\section{Implications}

Retirement represents a major transition for many older adults. Work and careers are associated with status, money, identity and power. Early retirement 
theorists viewed retirement adjustment from two theoretical frameworks: the degree of disengagement from pre-retirement activities, as proposed in the Disengagement Theory developed by Cumming and Henry (1961), or the level of activity in common roles, as proposed in Activity theory developed by Friedman and Havinghurst (1954). Since that time, retirement research has evolved toward a more complex and comprehensive interdisciplinary approach and conceptualizations. Findings from the present study indicate that studying couples and their retirement adjustment may more clearly define relationships between individuals and retirement than studies which analyze individuals without consideration of spouses or domestic partners.

It is important to consider partners in retirement research because among midlife and older adults, the support provided by a partner can assume even greater importance for psychological well-being, particularly as social ties weaken and other stressors accumulate (Cutrona, 1996). Alternatively, a partner can negatively influence a spouse's psychological well-being if they are depressed or otherwise distressed (Bookwala \& Schultz, 1996; Tower \& Kasl, 1995; Whiffen \& Aube, 1999).

To date, this study is unique in its use of dyadic data to examine retirement adjustment and well-being in couples. Therefore, the findings cannot be specifically related to those of any other study. The findings of this research are similar, however, to those of Whiffen \& Aube (1999), Bookwala \& Schultz (1996), and Tower \& Kasl (1995); specifically, this study and those all uncovered a strong correlation between spouses' levels of depression and in the present study; spouses levels of retirement adjustment and well-being. In sum, these findings suggest one's own retirement 
adjustment is correlated with a partner's retirement adjustment, one's own retirement adjustment is related to a partner's well-being, and individual retirement adjustment is correlated with individual well-being.

Disseminating this information throughout the field of social psychology and gerontology is important for practice. Specifically, the results can inform the mental health and counseling practices of professionals serving older adults by providing a framework for understanding the relationship between retirement adjustment and wellbeing and how spouses may influence each other's well-being as they transition to retirement. This information is useful for other practitioners, as well, including clinicians. Physicians and nurse practitioners who treat mental health issues in older adults can benefit from the insights found in this study and others which link individual well-being to their partner's well-being. Treatment which includes consideration of the spouse or domestic partner is potentially more efficacious and comprehensive. The findings in previous crossover research and in the contagion effects research indicate a spouse who is depressed is likely to have a partner who is depressed. If both partners are examined for depressive symptoms, and if necessary, treated, then the potential for a continued contagion effect will be reduced. Similarly, this research may benefit retirees themselves and give adults preparing for retirement more information about what a couple should consider in planning for, and managing their own approach to retirement. Specifically, the findings from this study suggest that individuals should strive to maintain optimal physical and mental health, cultivate activities and relationships outside of work, and engage in good financial planning for 
retirement, with the goal of maintaining one's standard of living throughout one's retirement years.

\section{Limitations}

Analyses of couples can be complicated by the intricacies of the marital relationship. As Atchley (1992) explained in his work on marital satisfaction and retirement, “...marriages are usually complex relationships that are not easily summarized because they vary over a large number of specific dimensions, and have a history that may span decades" (p. 157). One of the complex dimensions of the marital relationship is the idea that husbands and wives can significantly influence each other's state of being and thus are interdependent. Therefore, it is necessary to look beyond the individual when assessing adjustment and well-being in retirement in couples.

Ideally, the interdependent relationship between husbands' and wives' retirement adjustment and well-being should be examined over time. The crosssectional design of this study meant that data were captured at only one time point. A longitudinal study would provide several time intervals and follow-up information about how couples adjust over time. Furthermore, for those who have returned to work either part, or full-time, the information they report regarding retirement may be less accurate than those who are currently fully retired. This is a methodological limitation, because relying on respondents' memories may attenuate the validity of the results. In addition, the ability to capture the nature of husbands' and wives' retirement adjustment was limited by the fact that the survey instrument used to collect the data 
for this research did not include an item which inquired about length of time since retirement. Furthermore, information about the length of time participants had spent in full retirement before returning to work either full or part-time was not available. Consequently, it was not possible to tell whether the length of time spent in retirement was an important predictor of retirement adjustment. This item would be a particularly important question for further research on retirement adjustment because, as mentioned previously in the literature review, findings regarding length of time since retirement and level of adjustment are mixed.

For example, one study found retirees experienced a "honeymoon" period the first year of retirement followed by a more difficult period of adjustment (Szinovacz, 2004). Another found couples experience an initial disruption in their lives upon retirement but that disruption is resolved after two years (Moen, Kim \& Hofmeister, 2001). It is possible that some couples have difficulty adjusting to retirement initially but are satisfied long-term, as indicated by Moen, Kim and Hofmeister (2001). Hypotheses and other questions regarding the long-term effects of retirement adjustment cannot be answered with a cross-sectional study, such as the present one. There is a need for longitudinal research to address these questions.

As previously mentioned, the median household income for this sample was above average, at $\$ 100,000$ a year; therefore, results are potentially ungeneralizable to individuals and couples with lower incomes. Most of the participants had professional work histories as well, another factor which distinguished this sample from a sample that is representative of the general population. 
It is important to note a major limitation of this study concerning wives' employment history, however. Many women from this sample were engaged in parttime careers, an option which many couples with lower incomes cannot afford to exercise. Therefore, a sample with a lower median income may yield more information regarding wives' retirement adjustment and crossover effects due to the greater probability of wives' full participation in the work force. The present study did not find evidence of a crossover effect between husbands' and wives' retirement adjustment and well-being. A more diverse sample may yield results that support the findings from other studies, which found adjustment to retirement equally difficult for women and men (Erdner \& Guy, 1990; Szinovacz, Ekerdt, and Vinick, 1992).

Furthermore, because the participants in this study reported higher than average annual incomes, the relationship between income and retirement adjustment may be attenuated as compared to studies in which participants report a broader range of income levels. Having few differences among the participants regarding income means that income is a less sensitive predictor of retirement adjustment. This is a methodological reliability issue otherwise known as restriction of range. Restriction of range occurs when "the range on one or both variables is restricted by the sampling procedure" (Cohen \& Cohen, pg. 70, 1983).

Similarly, problems with range restriction occur in the relationship between education and its effect on retirement adjustment. Overall, this sample was highly educated; the majority of participants had obtained a college or graduate degree. Thus, 
the ability to predict the effect of education on retirement adjustment is lessened, as is the ability to predict the effect of income on retirement adjustment.

The primary conceptualization for the latent variable well-being and the rationale for selecting the items which composed it were the three components of the subjective well-being index (SWB): life satisfaction, the presence of positive mood, and the absence of negative mood (Ryan \& Deci, 2001). The results found here are consistent with what would be expected in the literature; future research would learn more by examining other aspects of well-being. The SWB conceptualization of wellbeing has been used widely in well-being research in the past 20 years; however, a more recent development in the measurement of well-being, the Psychological WellBeing (PSW) model defined by Ryff and Singer (1998) and its six components (selfacceptance; positive relations with others; autonomy; environmental mastery; purpose in life; and personal growth; may have been a more sensitive instrument for the study of retirement adjustment and well-being). The SWB conceptualization of well-being used for the latent variable well-being in the present study may not have completely captured the construct of well-being in this study. Had this study used the more complex PSW model of well-being to conceptualize well-being, it is possible the power of prediction would have been increased.

Similarly, the conceptualization for the latent variable retirement adjustment did not rely on a standardized measurement of adjustment. As mentioned previously, the conceptualization of the latent variable well-being was based on a component of the Dyadic Adjustment Scale (DAS) which utilizes measures of satisfaction to 
determine levels of adjustment in couples. Had the present study utilized a standardized measure, it is possible the power of prediction would have increased.

The ability to fully consider the effects of physical well-being on retirement adjustment and well-being was limited in this study because the item measuring physical health inquired only about number and type of health problems, therefore, the severity of health problems could not be examined. This is an important limitation because an individual may have only one health problem yet that health problem may have severe implications for well-being, e.g., cancer. Therefore, using the item "number of health problems" as the primary predictor of physical well-being, may not have adequately captured the dynamic between health, retirement adjustment and well-being in this study.

Another limitation in this study was the lack of data pertaining to respondents' sense of personal control. Research had found personal control to be a major component of psychological well-being across the life span. Personal control appears in the literature in several related forms, including internal locus of control (Rotter, 1966), personal efficacy, (Bandura, 1977), personal autonomy (Seeman \& Anderson, 1983), and mastery (Pearlin et al., 1981). This is another important limitation because a respondent's level of personal control may have been an important factor in the relationship between the predictors of retirement adjustment and well-being in the present study, however, data pertaining to personal control was not collected. Another design limitation was the mailed survey format. In general, the questionnaire format yields a higher response error than personal interviews 
(Weisberg, Krosnick \& Bowen, 1989). Furthermore, responses may have been clouded by a desire for social acceptability among respondents, which may have resulted in less candid responses, particularly regarding negative scenarios. Personal interviews conducted over the course of three or more time intervals would be the ideal format for a study such as this.

\section{Contributions}

There is consensus in the literature that older adults generally function better with a partner; however, if one member of a couple is not functioning well due to mental health or physiological health problems, then the likelihood that both members the couple will experience lower levels of well-being is increased (Mitchell et al., 1983). Knowledge of couples' conjoint circumstances furthers our understanding of the factors that enhance or detract from adjustment and well-being in retirement. The present study increases our understanding of the issues facing retired couples as a dyad and the ways in which members of couples influence their partners' well-being. This research provided insight into the issues facing couples as synchronous units, and may help researchers and practitioners better serve older adults in the future by contributing to our understanding of well-being as it is influenced by retirement adjustment in late midlife and beyond. To accurately predict well-being, researchers must recognize that people do not operate independently of one another, and the social context in which well-being occurs or does not occur must be taken into account. Similarly, health care practitioners should consider the spousal relationship in connection with well-being, particularly relative to mental health. 
Our understanding of and interest in how retirement impacts the lives of individuals has grown over the past 20 years. Studies have developed from small, convenience samples composed primarily of men to large, national longitudinal samples of men and women from different professional and socioeconomic backgrounds. Gaps in the literature remain; until the present study, we knew little about the impact of retirement beyond the individual. Other research on couples has produced evidence of crossover and contagion effects relative to depression and other outcomes including absenteeism, job stress and positive spillover effects. One objective of this research was to determine if there was similar crossover within couples relative to their retirement adjustment and well-being. Some such evidence was found. It is hoped that this research serves as a basis from which future research may generate ideas and identify other instances of partner and actor effects in retirement adjustment and well-being in older couples. 


\section{REFERENCES}

Abel, B. J., \& Hayslip, B. (2001). Locus of control and retirement preparation. Journal of Gerontology, 42, 165-167.

Abu-Bader, S. H., Rogers, A., \& Barusch, A. S. (2002). Predictors of life satisfaction in frail elderly. Journal of Gerontological Social Work, 38, 3-17.

Acitelli, L., \& Antonucci, T. (1994). Reciprocity of social support in older married couples. Journal of Personality and Social Psychology, 67, $688-698$.

Akiyama, H., Antonucci, T., Takahashi, K., \& Langfahl, E. S. (2003). Negative interactions in close relationships across the life span. Journals of Gerontology Series B: Psychological Sciences \& Social Sciences, 58, 70-88

Aquino, J. A., Russell, D. W., Cutrona, C. E., \& Altmaier, E. M. (1996). Employment status, social support, and life satisfaction among the elderly. Journal of Counseling Psychology, 43, 480-489.

Anderson, K., \& Berkhauser, R. (1985). The retirement-health nexus: A new measure of an old puzzle. Journal of Human Resources, 20, 315-330.

Anderson, T. B., \& McCulloch, B. J. (1983). Conjugal support: Factor structure for older husbands and wives. Journals of Gerontology, 48, 37-52.

Antonucci, T., \& Akiyama, H. (1991). Social relationships and aging well. Generations, 15, 43-59. 
Aronson, D. (1998). Introduction to Systems Thinking. Retrieved February 5, 2005, from Intro to Systems Thinking Website: Http ://www.thinking.net /Systemsthinking/Intro_to_ST/intro_to_st.html

Administration on Aging (AoA). (2002). A profile of older Americans: 2002. Washington, D.C.: U.S. Department of Health and Human Services. Atchley, R. C. (1975). The meaning of retirement. Journal of Communication, $24,97-100$.

Atchley, R. (1976). The sociology of retirement. New York: Schenkman.

Atchley, R. C. (1979). Issues in retirement research. Gerontologist, 8, 44-54.

Atchley, R. C. (1982). Retirement as a social institution. Annual Review of Sociology, 8, 263-287.

Atchley, R. C., Miller, S. J., \& Brubaker, T. H. (1983). Types of elderly couples: Family relationships in later life. In T. Brubaker (Ed.), Family relationships in later life (pp. 77-90). Beverly Hills: Sage.

Atchley, R. C. (1989). A continuity theory of normal aging. The Gerontologist, $29,183-190$.

Atchley, R. (1992). Retirement and marital satisfaction. In M. Szinovacz, D. Ekerdt \& B. Vinick (Eds.), Families and retirement (pp. 145-158). Newbury Park, CA: Sage.

Atchley, R. C. (1998). Selected social and psychological differences between men and women in later life. Journals of Gerontology, 31, 204-211.

Austrom, M. G., Perkins, A. J., Damush, T. M., \& Hendrie, H. C. (2003). Predictors of 
life satisfaction in retired physicians and spouses. Social Psychiatry and Psychiatric Epidemiology, 38, 134-141.

Ballweg, J.A. (1967). Resolution of conjugal role adjustment after retirement. Journal of Marriage and the Family, 29, 277-280.

Bandura, A., Adams, N., \& Beyer, J. (1977). Cognitive processes mediating behavioral change. Journal of Personality and Social Psychology, 35, 125-139. Barker, Robert L. (Ed.). (1999). The social work dictionary (4th Ed.). Washington, DC: NASW Press.

Baron, R. M., \& Kenny, D. A. (1986). The moderator-mediator variable distinction in social psychological research: Conceptual, strategic and statistical considerations. Journal of Personality and Social Psychology, 51, $1173-1182$.

Barnett, R. C., Raudenbush, S. W., Brennan, R. T., \& Pleck, J. H. (1995). Change in job and marital experiences and change in psychological distress: A longitudinal study of dual-earner couples. Journal of Personality \& Social Psychology, 69, 839-850.

Baruch, G. K., \& Barnett, R. C. (1986). Role quality, multiple role involvement, and psychological well-being in midlife women. Journal of Personality and Social Psychology, 51, 578-585.

Beach, S. R. H., Katz, J., Kim, S., \& Brody, G. H. (2003). Prospective effects of marital satisfaction on depressive symptoms in established marriages: A dyadic model. Journal of Social and Personal 
Relationships, 20,355-371.

Beck, S. H. (1982). Adjustment to and satisfaction with retirement. Journal of Gerontology, 37, 616-624.

Berkman, L. F., \& Breslow, L. (1983). Health and the ways of living: The Alameda County Study. New York, NY: Oxford University Press.

Berkman, L. F., \& S. Syme, L. (1979). Social networks, host resistance, and mortality: A nine-year follow-up study of alameda county residents. American Journal of Epidemiology, 109, 186-204.

Blaikie, A. (1999). Ageing and popular culture: New York, NY: Cambridge University Press.

Bolger, N., DeLonghis A., Kessler, R.C. \& Wethington, E. (1989). The contagion of stress across multiple roles. Journal of Marriage and The Family, 51, 175-183.

Bookwala, J., \& Schulz, R. (2000). A comparison of primary stressors, secondary stressors, and depressive symptoms between elderly caregiving husbands and wives: The caregiver health effects study. Psychology \& Aging, 15, 607-616.

Bosse, R., Levenson, M. R., Spiro, A., III, Aldwin, C. M., Mroczek, \& D. K., Vellas, B. J., et al. (1992). For whom is retirement stressful? Findings from the normative aging study: In B. Vellas \& J.L. Albarede (Eds.), Facts and research in gerontology (pp. 223-240). New York, NY: Springer.

Braithwaite, V.A., \& Gibson, D. M. (1987). Adjustment to retirement: What we know and what we need to know. Ageing and Society, 7, 1-18. 
Bureau of Labor Statistics web-site, (2004). Employed and unemployed full-and parttime workers by age, sex, race and Hispanic or Latino ethnicity. Retrieved on May, 2, 2005 from http://www.bls.gov/cps/home.htm

Butler, R. N. (1975). Why survive? Being old in America. New York, NY: Harper and Row.

Calasanti, T. M. (1996). Gender and life satisfaction in retirement: An assessment of the male model. Journals of Gerontology: Social Sciences, 51B, S18-S29.

Carstensen, L. L. (1992). Social and emotional patterns in adulthood: Support for socioemotional selectivity theory. Psychology and Aging, 7, 118-136.

Carter, M. A. T., \& Cook, K. (1995). Adaptation to retirement: Role changes and psychological resources. Career Development Quarterly, 44, 67-82.

Chirikos, T. N., \& Nestel, G. (1989). Occupation, impaired health, and the functional capacity of men to continue working. Research on Aging, 11, 8-24.

Choi, N. G. (2001). Relationship between life satisfaction and postretirement employment among older women. International Journal of Aging \& Human Development, 52, 45-70.

Choi, N. G. (2002). Self-defined retirement status and engagement in paid work among older working-age women: Comparison between childless women and mothers. Sociological Inquiry, 72, 43-71.

Cliff, D. R. (1993). 'Under the wife's feet': Renegotiating gender divisions in 
early retirement. Sociological Review, 41, 1993.

Cohen, J., \& Cohen, P. (1983). Applied multiple regression/correlation analysis for the behavioral sciences. Mahwah: Lawrence Erlbaum Associates.

Cottrell, L. S. (1942). The adjustment of the individual to his age and sex roles. American Sociological Review, 7, 617-620.

Crystal, S., Shea, D., \& Krishnaswami, S. (1992). Educational attainment, occupational history, and stratification: Determinants of later-life economic outcomes. Journals of Gerontology, 47, S213-S222.

Cummings, E., \& Henry, WE. (1961). Growing old: The process of disengagement. New York, NY: Basic Books.

Cutrona, C., Russell, D., \& Rose, J. (1986). Social support and adaptation to stress by the elderly. Psychology \& Aging, 1, 47-54.

Dahl, S. A., Nilsen, O. A., \& Vaage, K. (2003). Gender differences in early retirement behaviour. European Sociological Review, 19, 179-198.

Dean, A., Matt, G. E., \& Wood, P. (1992). The effects of widowhood on social support from significant others. Journal of Community Psychology, 20, 309-325.

Dewitt, L. (March 2003). Brief History of Social Security. Retrieved March 17, 2004, from Http://www.ssa.gov/history/briefhistory3.html

Diener, E., \& Biswas-Diener, R. (2002). Will money increase subjective wellbeing? Social Indicators Research, 57, 119-169.

Donahue, W. T., Orbach, H., \& Pollak, O. (1960). Retirement, the emerging 
social pattern. In T. Clark (Ed.), Handbook of Social Gerontology, (pp. 330406). Chicago: University of Chicago Press.

Dorfman, L. T. (1995). Health conditions and perceived quality-of-life in retirement. Health \& Social Work, 20, 192-199.

Dressler, D. M. (1973). Life adjustment of retired couples. International Journal of Aging \& Human Development, 4, 335-349.

Duhl, B.S. 1983. From the inside out, and other metaphors: creative and integrative approaches to training in systems thinking. New York, NY: Brunner/Mazel.

Eckenrode, J., \& Gore, S. (1981). Stressful events and social supports: The significance of context. In B. Gottlieb (Ed.), Social networks and social support (pp. 165-188). Beverly Hills, CA: Sage Publications.

Ekerdt, D.J., Bosse', R., \& LoCastro, J.S. (1983). Claims that retirement improves health. Journal of Gerontology, 38, 231-236.

Ekerdt, D. J., \& DeViney, S. (1990). On defining persons as retired. Journal of Aging Studies, 4, 234-243.

Ekerdt, D. J., \& Vinick, B. H. (1991). Marital complaints in husband-working and husband-retired couples. Research on Aging, 13, 364-382.

Eisdorfer, C., \& Wilkie, F. (1977) Stress, disease, aging and behavior. In J.E. Birren and K.W. Schaie (Eds.), Handbook of the Psychology of Aging, (pp. 215-44). New York, NY: Academic Press.

Erdner, R. A., \& Guy, R. F. (1990). Career identification and women's attitudes toward retirement. International Journal of Aging and Human 
Development, 30, 119-133.

Feinstein, J. S. (1993). Relationship between socioeconomic status and health: A review of the literature. Milbank Quarterly, 71, 279-322.

Field, D., \& Minkler, M. (1998). Continuity and change in social support between young-old and old-old or very-old age. Journals of Gerontology, 43, 244-256.

Fingerman, K. L., \& Bermann, E. (2000). Applications of family systems theory to the study of adulthood. International Journal of Aging and Human Development, 51, 210-246.

Floyd, F. J., Haynes, S. N., Doll, E. R., Winemiller, D., \& Lemsky, C. (1992). Assessing retirement satisfaction and perceptions of retirement experiences. Psychology and Aging, 7, 96-110.

Forster, L. E., \& Stoller, E. P. (1992). Impact of social support on mortality: A seven-year follow-up of older men and women. Journal of Applied Gerontology, 11, 86-101.

Frazier, L. D. (2002). Perceptions of control over health: Implications for sense of self in healthy and ill older adults. In S. P. Shohov (Ed.), Advances in psychology research (pp. 237-258). New York, NY: Nova Science.

Free, M. M. (1995). Private world of the Hermitage: Lifestyles of the rich and old in an elite retirement home. Bergin \& Garvey, Westport, CT.

Friedmann, E. H.,\& Havinghurst, R. J. (Eds.). (1954). The meaning of work and retirement. Chicago: University of Chicago Press. 
Fry, C., Ikels, C., Keith, J., Dickerson-Putman, J., \& Draper, P.(1992). Perceptions of the adult life course: a cross-cultural analysis. Ageing and Society, 12, 49-84.

Gall, T., Evans, D., \& Howard, J. (1997). The retirement adjustment process:

Changes in the well-being of male retirees across time. Journals of Gerontology, 52, S110-S117.

Galambos, N. L., \& Walters, B. J., (1992). Work hours, schedule inflexibility and stress in dual earner spouses. Canadian Journal of Behavioral Sciences, 24, 290-302.

George, L.K., Okun, M.A., \& Landerman, R. (1985). Age as moderator of the determinants of life satisfaction. Research on Aging, 7, 209-233.

Gigy, L. L. (1980). Self-Concept of single women. Psychology of Women Quarterly, 5, 321-336.

Gilford, R. (1984). Contrasts in marital satisfaction throughout old age: an exchange theory analysis. Journal of Gerontology, 39, 325-333.

Glamser, F. D. (1976). Determinants of a positive attitude towards retirement. Journal of Gerontology, 31, 104-107.

Gold, C. H., Malmberg, B., McClearn, G. E., Pedersen, N. L., \& Berg, S. (2002).Gender and health: A study of older unlike-sex twins. Journals of Gerontology, 3, S168-S176.

Graebner, W. (1980). A history of retirement: The meaning and function of an American institution, 1885-1978. New Haven, CT: Yale University Press.

Gratton, B., \& Haug, M. R. (1983). Decision and adaptation: Research on 
female retirement. Research on Aging, 5, 87-101.

Group, T. W. B. (2004). Retrieved March 19, 2004, from http://www.worldbank.org/data/countrydata/countrydata.html

Haber, C. (1982). Beyond sixty-five: The dilemma of old age in America's past. New York, NY: Cambridge University Press.

Haber, C. (1988). Old Age in Colonial America. American People, American Lives. New York, NY: Harcourt Brace Jovanovich, Inc.

Haber, C., \& Gratton, B. (1993). Old age and the search for security: An American social history. Bloomington, Indiana: Indiana University Press.

Hale, W. D., Hedgepeth, B. E., \& Taylor, E. B. (1985-1986). Locus of control and psychological distress among the aged. International Journal of Aging and Human Development, 21, 214-229.

Hammer, L. B., Allen, E., \& Grigsby, T. (1997). Work-family conflict in dualearner couples: Within-individual and crossover effects of work and family. Journal of Vocational Behavior, 50, 185-203.

Hammonds-Smith, M., Courtless, J. C., \& Schwenk, F. N. (1992). Comparison of income, income sources, and expenditures of older adults by educational attainment. Family Economics Review, 5, 2-8.

Han, S. K., \& Moen, P. (1999). Clocking out: Temporal patterning of retirement. American Journal of Sociology, 105, 54-67.

Hardy, M. A. (1984). Effects of education on retirement among white male 
Wage-and-salary-workers. Sociology of Education, 57, 84-98.

Haug, M. R., Belgrave, L. L., \& Jones, S. (1992). Partners' health and retirement adaptation of women and their husbands. Journal of Women and Aging, 4, 5-29.

Hatfield, E., Cacioppo, J. T., \& Rapson, R. L. (1993). Emotional contagion. Current Directions in Psychological Science, 2, 96-99.

Havighurst, R. J., Neugarten, B., \& Thomae, H. (1968). Adjustment to retirement: A cross-national study. American Journal of Sociology, 76, 1176-1178.

Herzog, A. R., House, J. S., \& Morgan, J. N. (1991). Relation of work and retirement to health and well-being in older age. Psychology and Aging, $6,142-158$

Higginbottom, S. F., Barling, J., \& Kelloway, E. K. (1993). Linking retirement experiences and marital satisfaction: A mediational model. Psychology and Aging, 8, 476-494.

Hoffman, L. (1981). Foundations of family therapy. New York, NY: Basic Books.

Hofmeister, H., \& Moen, P. (1999). Late midlife employment, gender roles and marital quality: His and her perspectives. Sociological Focus, 32, 112125.

Hornstein, G. A., \& Wapner, S. (1985). Modes of experiencing and adapting to retirement. International Journal of Aging and Human Development, 21, 146-169.

Isaksson, K., \& Johansson, G. (2000). Adaptation to continued work and early 
retirement following downsizing: Long-term effects and gender differences. Journal of Occupational and Organizational Psychology, 73, 241-256.

Jackson, J.S. \& Antonucci, T.C. (1992): Social support processes in health and effective functioning of the elderly. In M.L. Wykle, E. Kahana, \& J. Kowal, (Eds.), Stress and health among the elderly (pp. 75-95). New York, NY: Springer

Jewson, R. H., \& Szinovacz, M. (1982). After retirement: An exploratory study of the professional woman. S. Maximiliane (Ed.), In Women's Retirement: Policy Implications of Recent Research (pp. 129-144). London: Sage.

Johnston, T. (1990). Retirement: What happens to the marriage? Issues in Mental Health Nursing, 11, 347-359.

Jones, F., \& Fletcher, B. (1993). An empirical study of occupational stress transmission in working couples. Human Relations, 46, 881-902.

Judd, C. M., Kenny, D. A., \& McClelland, G. H. (2001). Estimating and testing mediation and moderation in within-subject designs. Psychological Methods, 6, 115-134.

Kahn, R. L., \& Juster, F. T. (2002). Well-being: Concepts and measures. Journal of Social Issues, 58, 627-644.

Kahneman, D., Deiner, E., \& Schwarz, N. (1999). Well-Being: The Foundations of Hedonic Psychology. New York, NY: Russell Sage Foundation.

Keating, N. C., \& Cole, P. (1980). What do I do with him 24 hours a day? 
Changes in the housewife role after retirement. Gerontologist, 20, 89-103. Kenny, D. (2003). Structural Equation Modeling. Retrieved April 10, 2004, from $\mathrm{http}: / /$ davidakenny.net/dyad.htm.

Kenny, D. A. (1996). The design and analysis of social-interaction research. Annual Review of Psychology, 47, 59-74.

Kenny, D. A. (1996). Models of non-independence in dyadic research. Journal of Social \& Personal Relationships, 13, 279-294.

Kenny, D. A., \& Cook, W. (1999). Partner effects in relationship research: Conceptual issues, analytic difficulties, and illustrations. Personal Relationships, 6, 433-448.

Kenny, D. A, \& Kashy, D. A. (1991). Analyzing interdependence in dyads. In B. M. Montgomery \& S. Duck (Eds.), Studying interpersonal interaction (pp. 275-285). New York, NY: Guilford.

Kertzer, D. I., \& Laslett, P. (1995). Aging in the past: demography, society, and old age. Berkeley, CA: University of California Press.

Kilpatrick, S. D., Bissonnette, V. L., \& Rusbult, C. E. (2002). Empathic accuracy and accommodative behavior among newly married couples. Personal Relationships, 9, 369-393.

Kim, J. E., \& Moen, P. (2002). Retirement transitions, gender and psychological well-being: a life-course ecological model. Journal of Gerontology: Psychological Science, 57, S212-S222.

Kim, J. E., \& Moen, P. (1999). Work-retirement transitions and psychological 
well-being in late midlife. Ithaca, NY: Cornell Employment and Family Careers Institute.

Kim, S., \& Feldman, D. (2000). Working in retirement: The antecedents of bridge employment and its consequences for the quality of life in retirement. Academic of Management Journal, December, 88-102.

Kimmel, D. C., Price, K. F., \& Walker, J. W. (1978). Retirement choice and retirement satisfaction. Journal of Gerontology, 33, 119-134.

Knesek, G. E. (1992). Early versus regular retirement: Differences in measures of life satisfaction. Journal of Gerontological Social Work, 19, 3-34.

Kraemer, H. C., \& Jacklin, C. N. (1979). Statistical analysis of dyadic social behavior. Psychological Bulletin, 86, 217-224.

Krause, N. (1987). Chronic strain, locus of control, and distress in older adults. Psychology \& Aging, 2, 375-382.

Kreppner, K., \& Lerner, R. M. (1989). Family systems and life-span development: Issues and perspectives. In K. Kreppner, \& R. M. Lerner (Eds.), Family systems and life-span development (pp. 1-13). Hillsdale, England: Lawrence Erlbaum Associates.

Kulik, L. (1999). Continuity and discontinuity in marital life after retirement: life orientations, gender role ideology, intimacy, and satisfaction. Families in Society: the Journal of Contemporary Human Services, 17, 286-294.

Kulik, L. (2001). The impact of men's and women's retirement on marital 
relations: A comparative analysis. Journal of Women \& Aging, 13, 21-37.

Kulik, L. (2001). Marital relations in late adulthood, throughout the retirement process. Ageing and Society, 21, 447-469.

Kupperbusch, C., Levenson, R.W., \& Ebling, R. (2003). Predicting husbands' and wives' retirement satisfaction from the emotional qualities of marital interaction. Journal of Social and Personal Relationships, 20, 335-354.

Lachman, M. E. (1985). Personal efficacy in middle and old age: Differential and normative patterns of change. In G. H. Elder (Ed.), Life count dynamics: Trajectories and transitions (pp. 188-213). London, England: Cornell University Press.

Larson, R., Mannell, R., \& Zuzanek, J. (1986). Daily well-being of older adults with friends and family. Psychology and Aging, 1, 117-126.

Lee, G. R., \& Shehan, C.L., (1989). Retirement and marital satisifaction. Journal of Gerontology, 44, 226-230.

Levy, J. (1980). Retirement: A time to aspire for new experiences. Canadian Health Journal, 46, 12-24.

Levenson, R. W. (1997). Long-term marriages: Effective adjustment to age and retirement. Berkeley, CA: University of California-Berkeley.

Lowenthal, M. F., \& Haven, C. (1968). Interaction and adaptation: Intimacy as a critical variable. American Sociological Review, 33, 20-30.

Luborsky, M. R. L., \& Ian, M. (2003). Cross-cultural perspectives on the concept of retirement: An analytic redefinition. Journal of Cross-Cultural 
Gerontology, 18, 251-271.

Mancini, J. A., \& Quinn, W. H. (1981). Dimensions of health and their importance for morale in old age: A multivariate examination. Journal of Community Health, 7, 222-248.

Marshall, V. W., Clarke, P. J., \& Ballantyne, P. J. (2001). Instability in the retirement transition: Effects on health and well-being in a Canadian study. Research on Aging, 23, 334-352.

Matthews, A. M., \& Brown, K. H. (1987). Retirement as a critical life event: The differential experiences of women and men. Research on Aging, 9, 10-29.

Minkler, M., \& Langhauser, C. (1988). Assessing health differences in an elderly population. A five-year follow-up. Journal of the American Geriatrics Society $36,113-118$.

Minois, G. (1989). History of old age: From antiquity to the Renaissance. Chicago, IL: University of Chicago Press.

Mitchell, O. S., \& Moore, J.F. (1998). Can americans afford to retire? New evidence on retirement saving adequacy, Journal of Risk \& Insurance 65 , $371-400$.

Moen, P., Robison, J. \& Fields, V. (1994). Women's work and caregiving roles: A life course approach. Journal of Gerontology: Social Sciences, 49, S176-S186.

Moen, P. (1996). A life course perspective on retirement, gender, and wellbeing. Journal of Occupational Health Psychology, 1, 131-144. 
Moen, P., Erickson, W. A., Agarwal, M., Fields, V., \& Todd, L. (2000). Cornell retirement and well-being study: Final report. Ithaca, NY: Bronfenbrenner Life Course Center, Cornell University.

Moen, P., Kim, J. E., \& Hofmeister, H. (2001). Couple's work/retirement transitions, gender, and marital quality. Social Psychology Quarterly, 64, 5576.

Morgaine, C. (2001). Family Systems Theory, retrieved on March 25, 2004, from http://web.pdx.edu/ cbcm/CFS410U/FamilySystemsTheory.pdf

Morrison, M. H., Pifer, A., \& Bronte, L. (1986). Work and retirement in an older society: New York, NY: W.W. Norton and Company.

Murrell, S. A., \& Meeks, S. (2002). Psychological, economic, and social mediators of the education-health relationship in older adults. Journal of Aging and Health, 14, 527-550.

Mutran, J.E., Donald, R., \& Fernandez, M. (1997). Factors that influence attitudes toward retirement. Research on Aging, 19, 251-273.

Myers, S. M. (1996). Men's retirement and marital quality. Journal of Family Issues, 17, 336-357.

Myles, J., Minkler, M., \& Estes, C. L. (1991). Postwar capitalism and the extension of Social Security into a retirement wage. Amityville, NY: Baywood Publishing.

Myles, J., \& Quadagno, J. S. (1991). States, labor markets, and the future of old age policy. Philadelphia, PA: Temple University Press. 
Newsom, J. T. (2002). A multilevel structural equation model for dyadic data. Structural Equation Modeling, 9, 431-44.

Neugarten, B., Havighurst, R., \& Tobin, S. (1961). The measurement of life satisfaction. Journal of Gerontology; 16, 134-143

Nichols, W. C., \& Everett, C. A. (1986). Systemic family therapy: An integrative approach. New York, NY: Guilford.

Olson, R. (1999). U.S. Bureau Census Bureau website. Current Population Surveys. Retrieved April, 4, 2004, from http://www.bls.gov/cps/home.htm.

O'Connor, D.L. (1995) Caring for a memory-impaired spouse: A gendersensitive perspective. Journal of Women and Aging 7, 25-42.

Orcutt, J.D. (1983). Analyzing deviance, Homewood: Dorsey Press.

Ozawa, M. N., \& Law, S. W. (1991). Health status of recently retired workers. Social Work Research and Abstracts, 27, 24-33.

Palmore, E. B., Burchett, B. M., Filenbaum, G. G., George, L. K., \& Wallman, L. M. (1985). Retirement: Causes and consequences. New York, NY: Springer.

Palmore, E. B., George, L. K., \& Fillenbaum, G. G. (1982). Predictors of retirement. Journal of Gerontology, 37, 212-235.

Pearlin, L., Lieberman, M., Menaghan, E., \& Mullan, J. (1981). The stress process. Journal of Health and Behavior, 22, 337-356.

Perkins, K. (1992). Psychosocial implications of women and retirement. Social Work, 37, 526-532.

Phillipson, C. (1994). The Modernisation of the life course: Implications for 
social security and older people. In Baldwin, S. and Falkingham, J. (Eds.), Social Security and Social Change - New Challenges to the Beveridge Model (pp. 103-147). London: Harvester Wheatsheaf.

Pienta, A. M. (2003). Partners in marriage: An analysis of husbands' and wives' retirement behavior. Journal of Applied Gerontology, 22, 340358.

Prentis, R. S. (1980). White collar working women's perception of retirement. Gerontologist, 20, 90-93.

Price-Bonham, S. \& Johnson, C. (1982). Attitudes toward retirement: A comparison of professional and nonprofessional married women. In M. Szinovacz (Ed.), Women's retirement: Policy implications of recent research (pp. 32-56). Beverly Hills: Sage.

Price, C. A. (2000). Women and retirement: Relinquishing professional identity. Journal of Aging Studies, 14, 625-650.

Price, C. A. (2002). Professional women's retirement adjustment: The experience of re-establishing order. Journal of Aging Studies, 17, 443-467.

Price, C. A., \& Bruchey, S. (1998). Women and retirement: the unexplored transition. New York, NY: Garland Publishers.

Quick, H. E., \& Moen, P. E. (1997). Gender, employment, and retirement quality: A life course approach to the differential experiences of men and women. Ithaca, NY: Bronfenbrenner Life Course Center, Cornell University. 
Reeves, J. B., \& Darville, R. L. (1992). Aging couples in dual-career/earner families: Patterns of role-sharing. Journal of Women and Aging, 4, 49-67.

Reid, D.W., Haas, G., \& Hawkins, D. (1977). Locus of desired control and positive self-concept of the elderly. Journal of Gerontology, 32, 441-450.

Reitzes, D. C., Mutran, E. J., \& Fernandez, M. E. (1996). Does retirement hurt well-being? Factors influencing self-esteem and depression among retirees and workers. Gerontologist, 36, 649-656.

Reitzes, D. C., Mutran, E. J., \& Fernandez, M. E. (1998). The decision to retire: A career perspective. Social Science Quarterly, 79, 607-619.

Richardson, V. E., \& Kilty, K. M. (1995). Gender differences in mental-health before and after retirement: A longitudinal analysis. Journal of Women \& Aging, 7, 19-35.

Riddick, C. C. (1985). Life satisfaction for older female homemakers, retirees, and workers. Research on Aging, 7, 88-109.

Riley, D., \& Eckenrode, J. (1986). Social ties: Subgroup differences in costs and benefits. Journal of Personality and Social Psychology, 51, 770-778.

Rodin, J., \& Langer, E. J. (1977). Long-term effects of control-relevant intervention among the institutionalized aged. Journal of Personality and Social Psychology, 35, 897-908.

Rowe, J. W., \& Kahn, R. L. (1987). Human aging: Usual and successful. Science, 237, 313-335.

Ross, C. E., \& Drentea, P. (1998). Consequences of retirement activities for 
distress and the sense of personal control. Journal of Health \& Social Behavior, 39, 317.

Rotter, J. B. (1966). Generalized expectancies for internal versus external control of reinforcement. Journal of Consulting and Clinical Psychology, $80,1-32$

Ruhm, C. J. (1996). Gender differences in employment behavior during late middle age. Journals of Gerontology, 11, S11-S17.

Ryan, R. M., \& Deci, E. L. (2001). On happiness and human potentials: A review of research on hedonic and eudaimonic well-being. Annual Review of Psychology, 52, 141-166.

Ryff, C. D. (1995). Psychological well-being in adult life. Current Directions in Psychological Science, 4, 99-104.

Ryff, C. D., \& Marshall, V. W. (1999). Self and society in aging processes. New York, NY: Springer Publishing.

Ryff, C. D., \& Singer, B. (1998). The contours of positive human health. Psychological Inquiry, 9, 1-52.

Satir, V. (1972). Peoplemaking. Palo Alto, CA: Science and Behavior Books.

Seccombe, K., \& Lee, G. R. (1986). Gender differences in retirement satisfaction and its antecedents. Research on Aging, 8, 112-132.

Seeman, M., \& Anderson, C. S. (1983). Alienation and alcohol: The role of work, mastery, and community in drinking behavior. American Sociological Review, 48, 60-77. 
Siebert, D. C., Mutran, E. J., \& Reitzes, D. C. (1999). Friendship and social support: The importance of role identity to aging adults. Social Work, $44,522-533$

Siegel, J. M., Bradley, E.H., Gallo, W.T., \& Kasl, S.V. (2004). The effect of spousal mental and physical health on husbands' and wives' depressive symptoms, among older adults: Longitudinal evidence from the health and retirement survey. Journal of Aging Health, 16, 398-425.

Serow, W. J., Sly, D. F., \& Wrigley, J. M. (1990). Population aging in the United States. New York, NY: Greenwood Press.

Sherman, E. (1994). Structure of well-being in the life narratives of the elderly. Journal of Aging Studies, 8, 105-116.

Slevin, K. F., \& Wingrove, C. R. (1995). Women in retirement: A review and critique of empirical research since 1976. Sociological Inquiry, 65, 1-23.

Smith, D. B., \& Moen, P. (1998). Spousal influence on retirement: His, her, and their perceptions. Journal of Marriage and the Family, 60, 455-469.

Smith, G. C., Kohn, S. J., Savage-Stevens, S. E., Finch, J. J., Ingate, R., \& Lim, Y.O. (2000). Effects of interpersonal and personal agency on perceived control and psychological well-being in adulthood. Gerontologist, 40, 85-103.

Smith, K. R., \& Moen, P. (1988). Passage through midlife: Women's changing family roles and economic well-being. Sociological Quarterly, 29, 212-228.

Spanier, G. (1976). Measuring dyadic adjustment: New scales for assessing the quality of marriage and similar dyads. Journal of 
Marriage and the Family, 38, 15-28.

Stanford, E. \& Usita, P. (2002). Retirement: Who is at risk? Generations, 16, $45-48$.

Stearns, P. N. (1982). Old age in preindustrial society. New York, NY: Holmes \& Meier.

Stone, R. (1984). Effects of retirement on the health status of older unmarried women. San Francisco, CA:

Stone, R., Cafferata, G., \& Sangl, J. (1987). Caregivers for the frail elderly: A national profile. The Gerontologist, 27, 616-626.

Stull, D. E. (1988). Dyadic approach to predicting well-being in later life. Research on Aging, 10, 60-79.

Sullins, E.S. (1991). Emotional contagion revisited: Effects of social comparison and expressive style on mood congruence. Personality and Social Psychology Bulletin, 17, 166-174.

Szinovacz, M. (1982). Women's retirement: Policy implications of recent research. Beverly Hills, CA: Sage Publications.

Szinovacz, M. (1984). Life events, retirement preparation and womens' adjustment to retirement: A comparative study final report. Tallahassee, FL: Florida State University, Department of Sociology Gerontology Center.

Szinovacz, M. E. (1986-87). Preferred retirement timing and retirement satisfaction in women. International Journal of Aging \& Human Development, 24, 301-317. 
Szinovacz, M., Ekerdt, David J., \& Vinick, B. H. (1992). Families and retirement. Newbury Park, CA: Sage Publications.

Szinovacz, M., \& Washo, C. (1992). Gender differences in exposure to life events and adaptation to retirement. Journals of Gerontology, 47, 43-67.

Szinovacz, M. E., \& Schaffer, A. M. (2000). Effects of retirement on marital conflict tactics. Journal of Family Issues, 21, 367-389.

Szinovacz, M. E., \& Davey, A. (2004). Honeymoons and joint lunches: Effects of retirement and spouse's employment on depressive symptoms. Journal of Gerontology: Psychological Sciences, 59B, P233P245.

Tabachnik, B. G., \& Fidell, L. S. (1996). Using multivariate statistics. New York, NY: Harper Collins.

Taylor, M. A., \& Shore, L. M. (1995). Predicting retirement age: Personal, psychological, and organizational factors. Psychology and Aging, 10, 76-83.

Thoits, P. A. (1983). Multiple identities and psychological well-being: A test of the social isolation hypothesis. American Psychological Review, 48, 174-187.

Thompson, K. (1985). The division of labour in society. Thousand Oaks, CA: Sage.

Tower, R. B., \& Kasl, S.V. (1995). Depressive symptoms and the moderating effect of marital closeness. Psychology and Aging, 10, 625-638.

Townsend, A. J., Miller, B., \& Guo, S. (2001). Depressive symptomatology in 
middle-aged and older married couples: A dyadic analysis. Journals of Gerontology, 56B, 352-365.

Tucker, R. C. E. (1978). The Marx-Engels Reader. New York, NY: Norton.

Vaughn, M. J., \& Matyastik Baier, M. E. (1999). Reliability and validity of the Relationship Assessment Scale. American Journal of Family Therapy, $27,137-147$.

Vinick, B. H., \& Ekerdt, D. J. (1991). Retirement: What happens to husbandwife relationships? Journal of Geriatric Psychiatry, 24, 457-471.

Warr, P. B., Butcher, V., Robertson, I., \& Callinan, M. (2004). Older people's well-being as a function of employment, retirement, environmental characterisitcs and role preference. British Journal of Psychology, 95, 297-324.

Walker, J. W., Kimmel,K.C., \& Price, K.J. (1980-1981). Retirement style and retirement satisfaction: Retirees aren't all alike. International Journal of Aging and Human Development, 12, 267-281.

Waterman, A. S. (1993). Two conceptions of happiness: contrasts of personal expressiveness (eudaimonia) and hedonic enjoyment. Journal of Personality \& Social Psychology, 64, 678-691.

Weisberg, H. F., Krosnick, J. A., \& Bowen, B. D. (1996). An introduction to survey research, polling, and data analysis (3rd ed.). Columbus, $\mathrm{OH}$ : Ohio State University Press.

Wendorf, C. A. (2002). Comparisons of structural equation modeling and 
hierarchical linear modeling approaches to couples' data. Structural Equation Modeling: A Multidisciplinary Journal, 9, 126-140.

Westman,M., Vinokur, A. (1998) Unraveling the relationship of distress levels within couples: Common stressors, empathic reactions, or crossover via social interaction? Human Relations, 51, 137-56.

Whiffen, V. E., \& Aube, J. A. (1999). Personality, interpersonal context and depression in couples. Journal of Social \& Personal Relationships, 16, 369-383.

Williamson, R., Rinehart, A., \& Blank, T. (1992). Early retirement: promises and pitfalls. New York, NY: Plenum Press.

Wilson, S. E. (2001). Socioeconomic status and the prevalence of health problems among married couples in late midlife. American Journal of Public Health, 91, 543-569.

Zhan, M., \& Pandey, S. (2002). Postsecondary education and the well-being of women in retirement. Social Work Research, 26, 171-184.

Zipp, J. F., \& Toth, J. (2002). She said, he said, they said: The impact of spousal presence in survey research. Public Opinion Quarterly, 66, 177-208.

Znaniecki, H., \& Steinhart, F. (1971). Work histories of American urban women. Gerontologist, 11, 55-72. 